\title{
A FUNÇÃO DE PRODUÇÃO DA AGROPECUÁRIA BRASILEIRA: DIFERENÇAS REGIONAIS E EVOLUÇÃO NO PERÍODO 1975-1985
}

\section{LUIZ ARTUR CLEMENTE DA SILVA}

Engenheiro Agrônomo

Orientador: Prof. RODOLFO HOFFMANN

Tese Apresentada à Escola Superior de Agricultura "Luiz de Queiroz", da Universidade de São Paulo, para obtenção do título de Doutor em Ciências, Área de concentração: Economia Aplicada.

P I R A C I C A B A

Estado de São Paulo - Brasil

Novembro - 1996 
Dados Internacionais de Catalogação na Publicação (CIP) DIVISÃo de BIBLIOTECA E DOCUMENTAÇÃo - Campus "Luiz de Queiroz"/USP

Silva, Luiz Artur Clemente da

A função de produção da agropecuária brasileira: diferanças regionais e evolução no periodo 1975-1985 / Luiz Artur Clemente da Silva. - Piracicaba, 1996.

$157 p$.

Tese (doutorado) - Escola Superior de Agricultura Luiz de Queiroz, 1996. Bibliografia

1. Desenvolvimento regional - Brasil 2. Produção agropecuária(1975-85) Brasil I. Titulo

CDD 338.1 


\section{A FUNÇÃO DE PRODUÇÃO DA AGROPECUÁRIA BRASILEIRA: DIFERENÇAS REGIONAIS E EVOLUÇÃO \\ NO PERÍODO 1975-1985}

LUIZ ARTUR CLEMENTE DA SILVA

Aprovada em: 18.02 .1997

Comissão Julgadora:

Prof. Dr. Rodolfo Hoffmann

Prof. Dr. José Vicente Caixeta Filho

Prof. Dr. Pedro Valentim Marques

Prof. Dr. Flávio Abranches Pinheiro

Prof. Dr. Flávio Condé de Carvalho
ESALQ/USP

ESALQ/USP

ESALQ/USP

FCA - Botucatu/UNESP

IEA

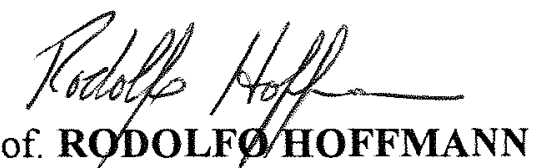

Orientador 


\section{AGRADECIMENTOS}

Ao Prof. Rodolfo Hoffmann, pela valiosa e dedicada orientação, apoio e incentivos durante toda a realização deste trabalho;

Aos docentes do Departamento de Economia e Sociologia Rural - DESR/ESALQ, pelos ensinamentos, e, em especial aos Profs. José Vicente Caixeta Filho e Pedro Valentim Marques, pelas críticas e sugestões apresentadas;

Aos funcionários do Departamento de Economia e Sociologia Rural DESR/ESALQ, pela colaboração e amizade, e, em especial, a Maria Aparecida Maielli Travalini, Valdeci Altarugio e Helena Aparecida Cardoso de Oliveira, pela inestimável gentileza, cordialidade e presteza no atendimento às várias dificuldades durante a realização deste trabalho;

Aos colegas do curso de Pós-graduação, Ariel, Clóvis, Regina, Cristina, Paschoal, João Carlos e Francisco Crócomo, pela amizade e agradável convivência durante o curso;

Aos colegas do Departamento de Economia Agrícola da Universidade Federal do Ceará e, em especial, aos Profs. José Valdeci Biserra, Teobaldo Campos Mesquita, Roberto de Azevedo e José Aluísio Pereira, pela amizade, incentivo e colaboração;

À bibliotecária do Departamento de Economia Agrícola da Universidade Federal do Ceará, Margareth de Figueiredo Nogueira, pela amizade, cooperação e permanente incentivo, o que em muito contribuiu para amenizar as dificulfdades encontradas;

À CAPES, pela concessão da bolsa de doutorado, através do programa PICDT. 


\section{SUMÁRIO}

Página

LISTA DE TABELAS ....................................................................

RESUMO

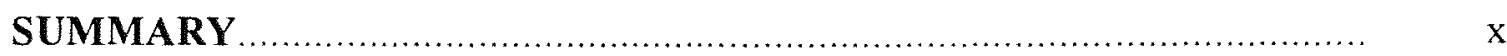

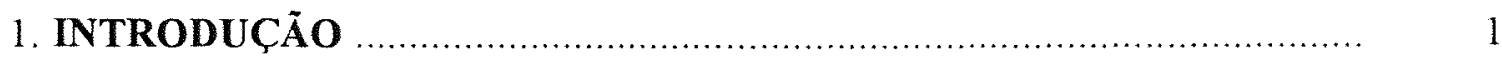

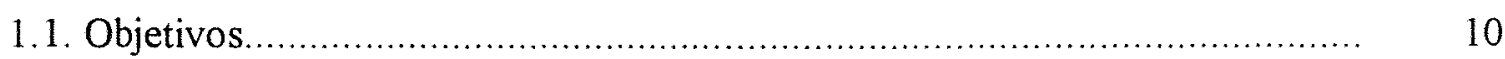

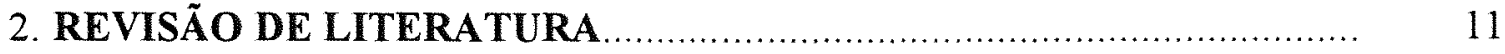

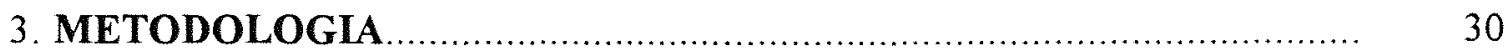

3.1. Considerações Teóricas........................................................................ 30

3.2. A Função de Produção Agregada tipo "Cobb-Douglas".............................. 32

3.2.1. Principais Características da Função de Produção

tipo "Cobb-Douglas".......................................................................... 33

3.3. A Função de Produção Agregada tipo "Ulveling-Fletcher".......................... 39

3.3.1. Principais Características da Função de Produção tipo "Ulveling-Fletcher" ................................................................. 41

3.4. Modelos Analíticos Utilizados............................................................ 43

3.4.1. Estimativa da Função de Produção Agregada.......................................... 44

3.4.2. Análise das Diferenças Regionais..................................................... 45

3.4.3. Análise Comparativa das Funções de Produção em 1975, 1980 e 1985..... 47

3.5. Definição das Variáveis............................................................................. 48

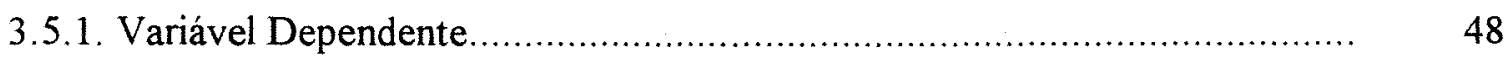

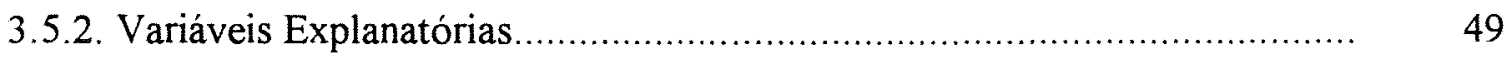

4. ANÁLISE DOS RESULTADOS .......................................................... 55

4.1. A Função de Produção Cobb-Douglas em 1985 ............................................. 65

4.1.1 A Função de Produção para as 300 MRH.............................................. 65

4.1.2. As Funções de Produção Regionais...................................................... 75

4.2. A Função de Produção Cobb-Douglas em 1980.......................................... 83

4.2.1 A Função de Produção para as 300 MRH................................................. 83 
Página

4.2.2. As Funções de Produção Regionais......................................................... $\quad 90$

4.3. A Função de Produção Cobb-Douglas em 1975 ........................................ 97

4.3.1. A Função de Produção para as 300 MRH............................................... 97

4.3.2. As Funções de Produção Regionais...................................................... 105

4.4. Produtividades Marginais dos Principais Fatores de Produção..................... 110

4.5. Comparação Intertemporal das Funções de Produção.................................... 119

4.6. A Função de Produção Ulveling-Fletcher para as $300 \mathrm{MRH}$,

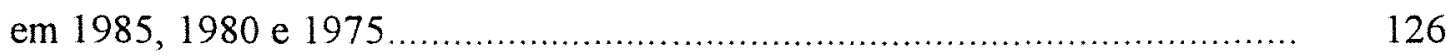

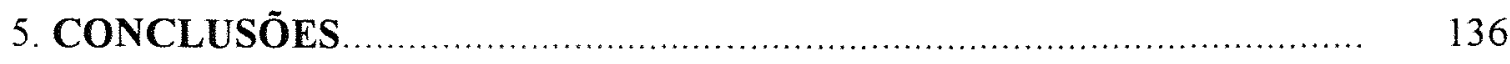

REFERÊNCIAS BIBLIOGRÁFICAS ............................................. 141

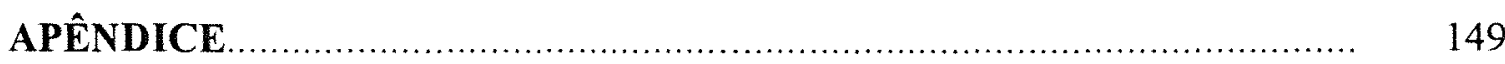




\section{LISTA DE TABELAS}

Página

1 Variação real da produção agropecuária na década de 70 , no Brasil e seis regiões (\%)

2 Variação real da produção por hectare explorado (em Cr\$ de 1970) nos anos de 1970, 1975 e 1980, variação porcentual.

3 Valor agregado por equivalente-homem na agricultura (em Cr\$ de 1970) e taxas anuais de variação em 1970, 1975 e 1980, para o Brasil e seis regiões.

4 Distribuição das familias conforme o seu rendimento mensal familiar, o seu rendimento familiar médio ( $\mu$, em salários mínimos por familia), e considerando uma linha de pobreza (z) igual a 1 salário mínimo por família e a $1 / 4$ de salário mínimo per capita, de acordo com o Censo Demográfico de 1980 .

5 Distribuição das pessoas conforme o rendimento familiar per capita para familias residentes em domicilios, cujo chefe tem atividade principal na agropecuária, extração vegetal e pesca, e distribuição dos pobres por regiões, em 1980 .

6 Média aritmética, variação porcentual da média aritmética, e média geométrica, nas $300 \mathrm{MRH}$, das variáveis utilizadas para estimar as funções de produção.

7 Matriz das correlações simples entre as variáveis em 1985

8 Matriz das correlações simples entre as variáveis em 1980 ......................... 61

9 Matriz das correlações simples entre as variáveis em 1975

10 Equações de regressão para as $300 \mathrm{MRH}$, com 12 ou 13 variáveis explanatórias, em 1985

11 Equações de regressão para as $300 \mathrm{MRH}$, com 11 ou 12 variáveis explanatórias, em 1975 
12 Equações de regressão para as $300 \mathrm{MRH}$, com 10 ou 11 variáveis explanatórias, em 1985

13 Equações de regressão para as quatro regiões, adotando-se a equação 5, em 1985

14 Equações de regressão para as quatro regiões, adotando-se a equação 6, em 1985.

15 Testes das diferenças interregionais na função de produção, adotando-se o modelo da equação 6, em 1985

16 Equações de regressão para as $300 \mathrm{MRH}$, com 12 ou 13 variáveis explanatórias, em 1980.

17 Equações de regressão para as $300 \mathrm{MRH}$, com 11 ou 12 variáveis explanatórias, em 1980.

18 Equações de regressão para as $300 \mathrm{MRH}$, com 10 ou 11 variáveis explanatórias, em 1980

19 Equações de regressão para as $300 \mathrm{MRH}$, com 11 ou 12 variáveis explanatórias, em 1980 .

20 Equações de regressão para as quatro regiões, adotando-se a equação 5 , em 1980

21 Equações de regressão para as quatro regiões, adotando-se a equação 6, em 1980

22 Testes das diferenças interregionais na função de produção, adotando-se o modelo da equação 6 , em 1980.

23 Equações de regressão para as $300 \mathrm{MRH}$, com 12 ou 13 variáveis explanatórias, em 1975

24 Equações de regressão para as $300 \mathrm{MRH}$, com 11 ou 12 variáveis explanatórias, em 1975

25 Equações de regressão para as $300 \mathrm{MRH}$, com 10 ou 11 variáveis explanatórias, em 1975 
26 Equações de regressão para as $300 \mathrm{MRH}$, com 11 ou 12 variáveis explanatórias, em 1975

27 Equações de regressão para as quatro regiões, adotando-se a equação 5 , em 1975.

28 Equações de regressão para as quatro regiões, adotando-se a equação 6 , em 1975 .

29 Testes das diferenças interregionais na função de produção, adotando-se o modelo da equação 6 , em 1975

30 Produtividades marginais, em 1975, 1980 e 1985, por cruzeiro gasto ou investido nos fatores de produção, no ponto das médias geométricas das variáveis, adotando-se os coeficientes de elasticidade das equações 5 e 6 dos respectivos anos.

31 Produtividades marginais, em 1975, 1980 e 1985, por cruzeiro gasto ou investido nos fatores de produção, para as regiões Nordeste, Sudeste (exclusive SP), São Paulo e Sul, no ponto das médias geométricas das variáveis, das respectivas regiões, adotando-se a equação 5 .

32 Produtividades marginais, em 1975, 1980 e 1985, por cruzeiro gasto ou investido nos fatores de produção, para as regiões Nordeste, Sudeste (exclusive SP), São Paulo e Sul, no ponto das médias geométricas das variáveis, das respectivas regiões, adotando-se a equação 6 .

33 Testes das diferenças na função de produção entre 1975, 1980 e 1985, para as $300 \mathrm{MRH}$ e as quatro regiões, adotando-se o modelo da equação 6.

34 Decomposição da produtividade bruta do trabalho e de sua variação nos anos de 1975, 1980 e 1985, nas 300 MRH, alterando inicialmente os insumos

35 Equações de regressão tipo Ulveling-Fletcher para as $300 \mathrm{MRH}$, com 12 ou 13 variáveis explanatórias, em 1985

36 Equações de regressão tipo Ulveling-Fletcher para as $300 \mathrm{MRH}$, com 12 ou 13 variáveis explanatórias, em 1980. 
Página

37 Equações de regressão tipo Ulveling-Fletcher para as $300 \mathrm{MRH}$, com 13 variáveis explanatórias, em 1980.

38 Equações de regressão tipo Ulveling-Fletcher para as $300 \mathrm{MRH}$, com 12 ou 13 variáveis explanatórias, em 1975.

39 Equações de regressão tipo Ulveling-Fletcher para as $300 \mathrm{MRH}$, com 13 variáveis explanatórias, 1975 


\title{
A FUNÇÃO DE PRODUÇÃO DA AGROPECUÁRIA BRASILEIRA: DIFERENÇAS REGIONAIS E EVOLUÇÃO \\ NO PERÍODO 1975-1985
}

\author{
Autor: LUIZ ARTUR CLEMENTE DA SILVA \\ Orientador: Prof. RODOLFO HOFFMANN
}

\section{RESUMO}

Esta pesquisa teve como principal objetivo verificar a contribuição dos fatores de produção na agropecuária brasileira, em 1975, 1980 e 1985, através de funções de produção tipos Cobb-Douglas e Ulveling-Fletcher. Especificamente, estimaram-se funções de produção para a agropecuária brasileira, como um todo, e para quatro regiões. Os dados básicos constam dos Censos Agropecuários de 1975, 1980 e 1985, dos Censos Demográficos de 1970 e 1980, e de tabulações especiais do Censo Agropecuário de 1985 .

As funções de produção foram ajustadas a dados de 300 microrregiões homogêneas (MRH) que compõem as regiões Nordeste, Sudeste (exclusive São Paulo), São Paulo e a região Sul.

A variável dependente usada nos ajustamentos foi o valor bruto da produção (VP) em cada MRH, e como variáveis explanatórias, mão-de-obra (EH), área com lavouras $(\mathrm{AL})$, área com pastagens (AP), área com matas (AM), capital em culturas (CC), capital em animais (CA), valor das instalações e outras benfeitorias, máquinas e instrumentos 
agrários (VI), despesas com adubos e corretivos (DA), despesas com animais (DM), outras despesas (OD), grau de escolaridade (ESC1), grau de urbanização (URB), e preço da terra (PRT).

Com base nos resultados obtidos, pode-se observar que os fatores de produção que contribuíram mais intensivamente na determinação do valor da produção agropecuária das $300 \mathrm{MRH}$ foram, em 1985, mão-de-obra, outras despesas, preço da terra e área de lavouras; em 1980, mão-de-obra, capital em animais, outras despesas e preço da terra; e, em 1975, outras despesas, mão-de-obra, capital em animais e área de lavouras.

Entre os fatores de produção incluídos nos modelos, a mão-de-obra agregada (EH) e suas formas decompostas EHF (mão-de-obra familiar) e EHA (mão-de-obra assalariada) se constituíram nos fatores mais importantes na formação do valor da produção. Seus coeficientes de elasticidade foram sempre positivos e altamente significativos em todos os modelos ajustados para os três anos, vindo em seguida capital em animais, preço da terra e área de lavouras.

Ao se analisar as produtividades marginais dos fatores, observou-se que aqueles que correspondem a capital fixo $(\mathrm{CC}, \mathrm{CA}$ e VI) apresentaram baixa produtividade marginal por cruzeiro investido, não correspondendo, portanto, ao valor da amortização e aos juros sobre o capital empatado. Os fatores de produção que correspondem a capital circulante (DA, DM e OD) apresentaram, em sua grande maioria, produtividade marginal maior que 1, que pode ser considerada boa. 
Os ajustamentos das funções de produção regionais foram altamente significativos ao nível de $5 \%$ de significância, porém, apresentaram sérios problemas de multicolinearidade. Constatou-se, também, que a produtividade marginal da mão-de-obra assalariada no estado de São Paulo é aproximadamente 2,2 vezes a do Nordeste, 3,9 vezes a do Sudeste, e 1,2 vez a da região Sul. Isto, se deve, certamente, ao elevado grau de mecanização e uso de insumos modernos da agricultura paulista.

Verificou-se, também, que a agricultura brasileira, como um todo, apresentou mudança tecnológica entre 1975 e 1985, e retornos constantes à escala em 1975, 1980 e 1985.

Finalmente, constatou-se que os ajustamentos através do modelo UlvelingFletcher foram muito bons, porém, não diferem dos obtidos através do modelo CobbDouglas no que se refere à qualidade dos ajustamentos e à significância e sinais dos parâmetros estimados. Porém, o modelo Ulveling-Fletcher permitiu verificar que o coeficiente de elasticidade da área de lavouras é afetado positivamente pelo preço da terra e pela urbanização, e que a elasticidade da mão-de-obra é influenciada pelo grau de escolaridade média nas microrregiões. 


\title{
THE PRODUCTION FUNCTION OF THE BRAZILIAN AGRICULTURE: REGIONAL DIFERENCES AND EVOLUTION FROM 1975 TO 1985
}

\author{
Author: LUIZ ARTUR CLEMENTE DA SILVA \\ Adviser: Prof. RODOLFO HOFFMANN
}

\section{SUMMARY}

The main objective of this study was to verify the contribution of the factors of production in the Brazilian agriculture in 1975, 1980 and 1985, using Cobb-Douglas and Ulveling-Fletcher type production functions. Specificaly, the aggregated production functions for the Brazilian agriculture and four from its regions were estimated. The data used came from the 1975, 1980 and 1985 agricultural censuses; the 1970 and 1980 demographic censuses; and, special tables of the 1985 agricultural census.

The observations are 300 homogeneus microregions integrating the Northeast, Southeast (without the state of São Paulo), the state of São Paulo and Southern regions of the country.

The value of agricultural gross product (VP) was the dependent variable of the functions. The explanatory variables were: labor $(\mathrm{EH})$, cropping land $(\mathrm{AL})$, pasture land (AP), land under forests (AM), capital in culture (CC), capital in livestock (CA), value of 
installations and other constructions, machinery and agricultural equipments (VI), expenditure with fertilizers and correctives (DA), expenditure with livestocks (DM), other expenditures (OD), literacy rate (ESC1), urbanization (URB) and land price (PRT).

The results obtained indicate that the production factors which contributed the most for the determination of the gross product value in 1985 were: labor, other expenditures, land price and cropping land. In 1980, the main production factors were: labor, capital in livestock and other expenditures. Finally, in 1975, other expenditures, labor, capital in livestock and cropping land were the most important production factors.

Among the production factors included in the models, aggregated labor (EH) as well as its desagregated forms, EHF (family labor) and EHA (hired labor), became the most important ones in the formation of gross product value. Their coefficients of elasticity were allways positive and highly significant for all the models adjusted over the three years. They were followed by capital in livestock, land price and cropping land, in decreasing order of importance.

A low marginal productivity per invested cruzeiro was found for fixed capital (CC, $\mathrm{CA}$ and $\mathrm{VI})$. Those values were not high enough to compensate for depreciation and services on invested capital.

On the contrary, the production factors corresponding to operating capital (DA, $\mathrm{DM}$ and $\mathrm{OD}$ ) presented marginal productivities greater than one in most cases.

The production functions estimated for the regions were highly significant at the 5 percent level. However, they presented serious multicolinearity problems. It was also found that the marginal productivity of hired labor in the State of São Paulo is 
approximately 2,2 times larger than the one for the Northeast region, 3,9 times that of Southeast region and close to 1,2 that the of Southern region. This fact is due to the high degree of mechanization and the use of modern inputs in São Paulo's agriculture.

It was also determined that the aggregated Brazilian agriculture showed technical change bettween 1975 and 1985, as well as constant returns to scale in 1975, 1980 and 1985.

Finally, it was observed that Ulveling-Fletcher fitted models very well, but their goodness of fit was not different from that of the Cobb-Douglas models. However, the Ulveling-Fletcher model permited to verify that the elasticity of cropping land is positively affected by land price and by urbanization. In addition, the elasticity of labor is affected by the average literacy rate in the microregions. 


\section{INTRODUÇÃO}

O desenvolvimento econômico de uma região ou país requer, entre outros fatores, o desenvolvimento intensivo da agricultura, de modo a prover alimentos para o consumo interno e para a exportação, gerando divisas para a obtenção de produtos e serviços de outros setores, e também fornecendo capital e mão-de-obra para os outros setores da economia.

Para que o setor agrícola atenda a estas demandas, faz-se necessário que, na medida em que se reduza o seu tamanho relativo, em comparação com outros setores, aumente sua produtividade. Essa alteração na produtividade é quase sempre uma conseqüência das forças dinâmicas que operam na economia, como o progresso técnico, a organização das empresas e instituições e o uso intensivo de capital fisico e humano (Nadiri, 1970, p.1137-77).

Porém, para que se possa buscar este aumento de produtividade torna-se imprescindível, "a priori", sob o ponto de vista técnico, o conhecimento de como os "fatores produtivos" estão sendo alocados no processo de produção, para a partir daí se tentar definir uma estratégia de produção que proporcione os ganhos de produtividade desejados. 
Engler, em pesquisa realizada em 1979 sobre a importância do capital humano na agricultura de São Paulo, afirmou que "o acelerado crescimento econômico do Brasil em geral e de São Paulo em particular, que vem ocorrendo nos últimos anos, requer uma análise da alocação dos recursos nos diversos setores da economia, de modo a detectar possiveis distorções no emprego atual dos fatores produtivos para conseguir uma eficiência econômica maior e, quando possivel, orientar os investimentos públicos e privados" (Engler, 1979, p.849). Deste modo, dada a escassez de recursos das economias, e particularmente no setor agrícola, a busca pela eficiência econômica requer, além de continuas pesquisas sobre a quantidade e a combinação desses recursos produtivos, o conhecimento dos custos relativos do uso dessas técnicas. Para isso, a análise do desempenho do setor agrícola e da combinação de fatores produtivos, com o objetivo de oferecer subsídios para sua realocação e para políticas governamentais que visem ao aumento da produtividade do setor, pode ser realizada através da análise de uma função de produção agregada.

Porém, antes de se tentar determinar como se deve empregar de forma eficiente os recursos produtivos de uma economia, deve-se observar como a modernização, através do progresso técnico, se relaciona com o desenvolvimento econômico.

O desenvolvimento econômico, na maioria das vezes, é precedido por uma modernização nos setores produtivos através, basicamente, da alteração na base técnica de produção. Esta modernização e sua difusão, porém, não têm ocorrido uniformemente entre setores nem intra-setores. No setor agricola, especificamente, sua difusão e generalização é dificultada por barreiras de ordem natural - "os condicionantes naturais 
da produção", quais sejam: fatores climáticos gerais, fatores ligados à dotação de recursos naturais e processos biológicos relacionados com o crescimento das plantas e animais - e principalmente dificuldades impostas pela escassez de capital, ocasionando quase sempre processos parciais de modernização tanto em termos de produtos, regiões, como também até mesmo de fases dentro de um determinado ciclo produtivo.

No Brasil, o modelo de modernização adotado transformou não só a base técnica, mas "deu-se integradamente com o avanço do processo de proletarização - e, portanto, com o aumento da utilização do trabalho assalariado nos estabelecimentos rurais -; com a generalização das trocas monetárias a todos os níveis do processo de produção e às mais distantes regiões; com a substituição de sistemas tradicionais de comercialização e crédito por sistemas cooperativos ou de venda direta a agroindústrias (e supermercados), além da importância crucial do sistema oficial de crédito rural" (Hoffmann et al., 1985, p.596-7).

Esta modernização, porém, não atingiu a todos os produtos e regiões do país de maneira uniforme quanto ao modo de produzir, financiar e comercializar a produção, mantendo-se, portanto, as profundas desigualdades regionais, embora se reconheça que este processo de modernização agrícola reduziu as desigualdades regionais no sentido da forma de produzir. Esta desigualdade é confirmada através dos dados das tabelas a seguir, onde se observa que a variação do valor da produção agropecuária se deu em ritmo diferenciado nas regiões brasileiras na década de 70 .

Nesta década, as regiões que apresentaram maior desempenho da agropecuária no que se refere à variação real da produção foram a Centro-Oeste e a Norte, com variações reais de 151 e 130 por cento, respectivamente. 
Tabela 1 - Variação real da produção agropecuária na década de 70 , no Brasil e seis regiōes $(\%)$.

\begin{tabular}{lccc}
\hline Região & $1970 / 75$ & $1975 / 80$ & $1970 / 80$ \\
\hline Norte & 29,8 & 77,1 & 130,0 \\
Nordeste & 43,8 & 8,2 & 55,5 \\
Sudeste (-SP) & 28,5 & 25,1 & 60,7 \\
São Paulo & 36,8 & 30,7 & 78,8 \\
Sul & 47,4 & 23,8 & 82,4 \\
Centro-Oeste & 47,6 & 70,3 & 151,3 \\
Brasil & 37,8 & 30,4 & 79,7 \\
\hline
\end{tabular}

Fonte: Hoffmann et al. (1985, p.521).

O menor desempenho deu-se na região Nordeste, com apenas 55,5\%.

Este comportamento desigual do desempenho da agropecuária das regiões brasileiras se confirma ao se analisar outras relações, tais como: o valor da produção por hectare ("produtividade" da terra), e o valor agregado por equivalante-homem (produtividade do trabalho). Assim, pode-se observar, conforme a Tabela 2, que a "produtividade" da terra cresceu em todas as regiões durante a década de 70 , porém este crescimento deu-se de forma desigual, de modo que em 1980 a "produtividade" da terra na região Sudeste, exclusive o estado de São Paulo, foi 1,4 vez superior à da região Nordeste, e 2,9 vezes a da região Norte. Quando se compara o estado de São Paulo com 
Tabela 2 - Valor real da produção por hectare explorado (em Cr\$ de 1970) nos anos de 1970, 1975 e 1980, variação porcentual.

\begin{tabular}{l|rrr|rrr}
\hline \multirow{2}{*}{ Região } & \multicolumn{3}{|c|}{ Valor da Produção/ha } & \multicolumn{3}{c}{ Variação (\%) } \\
\cline { 2 - 7 } & 1970 & 1975 & 1980 & $70 / 75$ & $75 / 80$ & $70 / 80$ \\
\hline Norte & 43 & 38 & 53 & $-12,3$ & 39,2 & 22,2 \\
Nordeste & 90 & 120 & 113 & 33,0 & $-6,0$ & 25,0 \\
Sudeste(-SP) & 107 & 127 & 156 & 18,6 & 22,8 & 45,6 \\
São Paulo & 287 & 388 & 514 & 35,1 & 32,3 & 78,7 \\
Sul & 227 & 325 & 381 & 43,1 & 17,2 & 67,7 \\
Centro-Oeste & 32 & 40 & 58 & 26,5 & 43,1 & 81,1 \\
Brasil & 109 & 134 & 155 & 22,7 & 15,6 & 41,8 \\
\hline
\end{tabular}

Fonte: Hoffmann et al. (1985, p.523).

aquelas duas regiões, esta relação passa para 4,5 e 9,7, respectivamente, confirmando a grande disparidade entre estas regiões.

A desigualdade entre as regiões brasileiras também é evidente quando se analisa a produtividade do trabalho. Observa-se na Tabela 3 que as maiores taxas anuais de crescimento da produtividade do trabalho ocorreram nas regiões Sul, Centro-Oeste, e no estado de São Paulo, contribuindo portanto para aumentar as discrepâncias regionais já existentes em 1970. 
Tabela 3 - Valor agregado por equivalente-homem na agricultura (em $\mathrm{Cr} \$$ de 1970) e taxas anuais de variação em 1970, 1975 e 1980, para o Brasil e seis regiões.

\begin{tabular}{l|ccc|ccc}
\hline \multirow{2}{*}{ Região } & \multicolumn{3}{|c|}{ Valor Agregado/EH } & \multicolumn{3}{c}{ Taxas (\% ao ano ) } \\
\cline { 2 - 7 } & 1970 & 1975 & 1980 & $70 / 75$ & $75 / 80$ & $70 / 80$ \\
\hline Norte & 902 & 733 & 1015 & $-4,1$ & 6,7 & 1,2 \\
Nordeste & 607 & 718 & 666 & 3,4 & $-1,5$ & 0,9 \\
Sudeste (-SP) & 1481 & 1567 & 1624 & 1,1 & 0,7 & 0,9 \\
São Paulo & 2486 & 3052 & 3372 & 4,2 & 2,0 & 3,1 \\
Sul & 1911 & 2303 & 2810 & 3,8 & 4,1 & 3,9 \\
Centro-Oeste & 1791 & 1753 & 2322 & $-0,4$ & 5,8 & 2,6 \\
Brasil & 1299 & 1413 & 1586 & 1,7 & 2,3 & 2,0 \\
\hline
\end{tabular}

Fonte: Hoffmann et al. (1985, p.528).

Este comportamento do desempenho regional se reflete diretamente no poder de compra das familias. Deste modo, pode-se observar na Tabela 4 que a maior concentração de pobres no Brasil, no ano de 1980, encontra-se na região Nordeste, onde estavam $53,6 \%$ das famílias do país que recebiam até 1(um) salário mínimo (SM).

Considerando uma linha de pobreza (z) de 1/4 de salário mínimo per capita, esta porcentagem se eleva para aproximadamente $55 \%$. Por outro lado, nas regiões Sul e Sudeste, a concentração de familias pobres é consideravelmente menor do que a do Nordeste, principalmente quando se considera uma linha de pobreza de $1 / 4$ de salário mínimo. O Nordeste apresenta também o menor rendimento médio familiar: 2,61 SM contra 4,76 SM das regiões Sul e Centro-Oeste. 
Tabela 4 - Distribuição das famílias conforme o seu rendimento mensal familiar, o seu rendimento familiar médio ( $\mu$, em salários mínimos por família), e considerando uma linha de pobreza (z) igual a 1 salário minimo por familia e a 1/4 de salário mínimo per capita, de acordo com o Censo Demográfico de 1980.

\begin{tabular}{|c|c|c|c|c|c|}
\hline \multirow[t]{2}{*}{ Região } & \multirow{2}{*}{$\begin{array}{c}\text { Renda } \\
\text { total } \\
(\%)\end{array}$} & \multirow{2}{*}{$\begin{array}{c}A \\
(\%)\end{array}$} & \multirow{2}{*}{$\stackrel{\mu}{(\mathrm{SM})}$} & \multicolumn{2}{|c|}{ Famílias Pobres ( $\%$ ) } \\
\hline & & & & $\begin{array}{c}z=1 S M \\
\text { por família }\end{array}$ & $\begin{array}{c}z=1 / 4 S M \\
\text { per capita }\end{array}$ \\
\hline Norte & 3,3 & 4,3 & 3,71 & 4,3 & 5,5 \\
\hline Nordeste & 14,5 & 26,8 & 2,61 & 53,6 & 54,9 \\
\hline Sudeste & 59,9 & 46,2 & 6,25 & 24,3 & 21,9 \\
\hline Sul & 16,3 & 16,6 & 4,76 & 12,2 & 11,8 \\
\hline Centro-Oeste & 6,0 & 6,1 & 4,76 & 5,6 & 6,0 \\
\hline Brasil & 100,0 & 100,0 & 4,83 & 100,0 & 100,0 \\
\hline
\end{tabular}

Fonte : Extraído de Hoffmann ( 1984, p.190, 192 e 196 ).

A- famílias com declaração de rendimentos.

$\mu$ - rendimento médio familiar.

$z$ - linha de pobreza.

SM- salário mínimo

Essa desigualdade é conseqüência de um processo geral da economia que se reflete também no setor agropecuário de forma diferenciada entre as regiões.

A Tabela 5 apresenta algumas características da distribuição das pessoas conforme o rendimento familiar per capita, considerando todas as pessoas de famílias cujo chefe tem atividade principal na agropecuária, extração vegetal e pesca, para o Brasil e 6 regiões. Pode-se observar que o maior rendimento médio $(\mathrm{m})$ é o de São Paulo, atingindo quase um salário mínimo (SM) per capita, e o menor é o da região 
Tabela 5 - Distribuição das pessoas conforme o rendimento familiar per capita para familias residentes em domicilios particulares, cujo chefe tem atividade principal na agropecuária, extração vegetal e pesca, e distribuição dos pobres por regiões, em 1980.

\begin{tabular}{|c|c|c|c|c|c|c|c|c|}
\hline \multirow[b]{2}{*}{ Região } & \multirow[b]{2}{*}{$\mathrm{m}$} & \multirow[b]{2}{*}{ G } & \multirow[b]{2}{*}{$50^{-}$} & \multirow[b]{2}{*}{$10^{+}$} & \multicolumn{4}{|c|}{$\begin{array}{c}\text { considerando uma linha de pobreza } \\
\text { de } 1 / 4 \text { de SM per capita } 1\end{array}$} \\
\hline & & & & & $\begin{array}{l}\% \text { de } \\
\text { pobres }\end{array}$ & $\mathrm{H}$ & FGT* $^{*}$ & $\mathrm{CTR}^{*}$ \\
\hline Norte & 0,429 & 0,481 & 19,5 & 38,6 & 6,2 & 45,6 & 0,076 & 4,45 \\
\hline Nordeste & 0,273 & 0,512 & 17,8 & 40,8 & 59,0 & 68,9 & 0,184 & 68,69 \\
\hline Sudeste (-SP) & 0,579 & 0,590 & 14,5 & 50,5 & 13,9 & 44,5 & 0,085 & 11,58 \\
\hline São Paulo & 0,978 & 0,596 & 14,7 & 52,2 & 3,1 & 20,2 & 0,022 & 1,45 \\
\hline Sul & 0,701 & 0,584 & 14,5 & 49,1 & 11,8 & 34,7 & 0,062 & 9,28 \\
\hline Centro-Oeste & 0,656 & 0,606 & 13,8 & 52,4 & 6,0 & 40,8 & 0,072 & 4,55 \\
\hline Brasil & 0,493 & 0,596 & 14,0 & 50,2 & 100,0 & 51,4 & 0,118 & 100,0 \\
\hline
\end{tabular}

Fonte: Extraído de Hoffmann (1990, p. 15 e 24).

Notas: $\mathrm{SM}=$ salário mínimo;

$\mathrm{m}=$ rendimento familiar per capita médio, em SM;

$\mathrm{G}=$ indice de Gini;

$50^{-}=$porcentagem da renda recebida pelos $50 \%$ mais pobres;

$10^{+}=$porcentagem da renda recebida pelos $10 \%$ mais ricos;

$\mathrm{H}=$ proporção de pobres na população;

FGT = índice de pobreza de Foster, Greer e Thorbecke;

CTR = contribuição de cada região para o índice FGT do Brasil.

(*) - estes índices foram calculados a partir dos dados de tabulações especiais do Censo Demográfico de 1980.

Nordeste, com rendimento médio inferior a $0,3 \mathrm{SM}$. Por outro lado, excluindo-se a região Norte, e com base nas medidas de desigualdade $G, 50^{-}$e $10^{+}$, nota-se que o rendimento per capita na agropecuária do Nordeste é menos concentrado do que nas

\footnotetext{
1 Para uma descrição detalhada sobre esses índices, ver Hoffmann (1995, p.623-32).
} 
demais regiões. Isto ocorre porque a amplitude entre os menores e os maiores rendimentos das pessoas é menor do que a das outras regiões.

Considerando-se uma linha de pobreza de $1 / 4$ de SM per capita, observa-se que $59 \%$ das pessoas pobres ligadas à agropecuária brasileira concentra-se no Nordeste; $14 \%$ no Sudeste (exclusive São Paulo), e apenas 3,1\% em São Paulo. Na região Nordeste, quase $69 \%$ das pessoas de famílias cujo chefe tem atividade principal na agropecuária tem rendimento per capita inferior a $1 / 4$ de SM. Essa proporção de pobres é muito maior do que a média nacional $(51,4 \%)$.

A desigualdade interregional do rendimento das pessoas ligadas à agropecuária é confirmada, também, através do índice de pobreza de Foster, Greer e Thorbecke (FGT) e a contribuição de cada região (CTR). Pode-se observar, mais uma vez, que o Nordeste se destaca por apresentar maior índice FGT $(0,184)$ e, de longe, a maior contribuição $(68,69 \%)$ para o índice FGT do Brasil. O índice de pobreza FGT para São Paulo é 0,022 , e corresponde a uma contribuição (CTR) de apenas 1,45\%.

Resumidamente, pode-se concluir que o Brasil apresenta grande diversidade regional tanto na intensidade do uso de fatores de produção, com altas "produtividades" da terra e do trabalho nas regiões Sudeste, Sul, e no estado de São Paulo, e baixas nas demais regiões, com destaque para a região Nordeste, como no que se refere à distribuição da renda familiar entre as regiões. A desigualdade na distribuição do rendimento e, consequentemente, da pobreza entre pessoas e regiões encontra-se presente, também, no setor agropecuário. Isto foi constatado ao se considerar a distribuição das pessoas conforme o rendimento familiar per capita cujo chefe tem 
atividade principal na agropecuária. Deste modo, torna-se de suma importância determinar como os fatores de produção agrícolas têm sido empregados em cada região, e como este emprego tem evoluído no tempo. Adicionalmente, uma análise das diferenças da produção e produtividade dos fatores entre regiões pode contribuir, ao fornecer subsídios a técnicos e tomadores de decisão, na formulação de políticas que venham a combater essas desigualdades.

\subsection{Objetivos}

Geral - Medir a contribuição dos diferentes fatores de produção na agropecuária brasileira, em 1975, 1980 e 1985, por meio do ajustamento de funções de produção.

Específicos - Considerando, sempre, os anos de 1975, 1980 e 1985:

a) Estimar funções de produção para a agropecuária brasileira nos 3 anos.

b) Comparar as funções de produção da agropecuária brasileira estimadas no item (a).

c) Estimar as funções de produção regionais²

d) Comparar as funções de produção em cada região.

e) Analisar as diferenças entre as regiões para cada ano em estudo.

2 Serão analisadas as regiões Nordeste, Sudeste (exclusive São Paulo), São Paulo e Sul. 


\section{REVISÃO DE LITERATURA}

A Economia da Produção Agrícola se baseia na teoria microeconômica, mais especificamente, na teoria da firma, e busca, principalmente, contribuir na tomada de decisões do empresário agrícola no que se refere ao uso eficiente dos recursos produtivos (terra, capital e trabalho) disponiveis. É baseada nos princípios da otimização: uso mais eficiente dos recursos com o objetivo de maximizar a produção, dadas as quantidades de recursos disponíveis, ou maximizar as receitas, dada a estrutura de custos, ou ainda, minimizar os custos para dada produção. Neste contexto, a Economia da Produção Agrícola tem como principal objetivo contribuir com o empresário rural na determinação de uma estrutura produtiva que lhe permita a maximização do lucro no negócio agrícola.

O esforço para entender os processos produtivos, ou seja, a relação entre os fatores produtivos e seus efeitos sobre a produção, remonta a épocas distantes.

No início do século XIX, Von Thünen, um dos precursores da Escola Neoclássica, já analisava claramente a relação entre os fatores de produção e a produção na agricultura, ao afirmar que ${ }^{3}$

\footnotetext{
3 Ver Schneider (1963, p.148), citado em Hoffmann et al. (1990, p.79).
} 
"Na agricultura possuímos uma série de meios para aumentar não só o rendimento imediato, como o rendimento permanente do solo: cuidados normais no amanho da terra, na colheita de frutos, etc.; compra de adubo, gesso, farinha de ossos, guano, etc.; eliminação ... do mofo; introdução de um tipo de terra que esteja faltando, etc."

"O aumento da renda assim alcançado decorre sempre de uma aplicação de capital e de trabalho, e deve existir um ponto em que o valor do acréscimo de renda se torne igual ao acréscimo da despesa - e este é, ao mesmo tempo, o ponto em que há o máximo de renda líquida".

Pode-se observar que estava claro para Von Thünen, já naquela época, que a maximização da receita líquida é alcançada quando a produtividade-receita marginal se iguala ao custo de empregar uma unidade adicional do fator.

Apesar desta visão bastante clara de Von Thünen, cuja idéia geral já havia sido expressa de certa forma por Cournot em 1838 ao indicar que "os incrementos de grandezas econômicas são mais importantes para as reflexões econômicas do que as grandezas totais"(Schneider, 1968, p.146), foi Liebig, em 1855, quem pela primeira vez fez efetivamente uma tentativa de trabalhar com funções de produção, descrevendo a produção de lavouras em resposta a fertilizantes em termos de fatores limitativos (Thompson, 1973, p.149). Em sua relação de produção, os nutrientes são considerados como complementos perfeitos e a produção responde de forma linear quando um fator 
limitante é adicionado, até o momento em que outro fator limitante seja acrescentado ${ }^{4}$. Esta idéia, porém, considera as relações físicas de produção fixas e pré-determinadas, sem considerar a possibilidade de substituição entre fatores - a lei das proporções variáveis - e portanto a influência dos preços relativos. Nesta visão, o problema se resumia em se buscar a maximização da produção sem considerar o problema econômico da maximização da receita líquida observada por Von Thünen.

Esta idéia foi retomada posteriormente por Leontief ao descrever a função de produção com proporções fixas (Ferguson, 1991, p.193-7). Esta função relaciona essencialmente o caso em que a produção é obtida a partir de uma proporção fixa entre os fatores de produção, de modo que ao se tentar aumentar o uso de um fator, mantidas constantes as quantidades dos demais fatores, a produção permanecerá constante e, conseqüentemente, o processo de produção afasta-se do ótimo, sob o ponto de vista econômico. Nestas condições a única forma de se conseguir aumentos no produto é através do acréscimo das quantidades de todos os insumos, mantidas constantes as proporções entre eles.

Mitscherlich, porém, tinha uma visão mais realista da relação fator-produto. Em trabalho publicado em 1909 postulou uma função de produção ${ }^{5}$ na qual permitia retornos decrescentes a um fator variável; ela se aproxima assintoticamente de um nível máximo ( $\alpha$ ) de produção e, portanto, não apresenta o $3^{\underline{Q}}$ estágio de produção. É de amplo

\footnotetext{
${ }^{4}$ Considerações sobre características e propriedades da função de Liebig encontram-se em Beatte e Taylor (1985, p. 70) e Heady \& Dillon (1961, p. 10).
}

${ }^{5} Y=\alpha\left[1-10^{-\gamma(X+\theta)}\right]$; onde. $Y$ é a produção; $X$ é o fator de produção; e $\alpha, \gamma$ e $\theta$ são os parâmetros a serem estimados. 
emprego na experimentação agrícola, principalmente na determinação da dose ótima de adubo a ser usada.

Porém, segundo Girão $(1965$, p.4) 'Knut Wicksell é geralmente apontado como tendo sido o primeiro autor a sugerir uma forma algébrica para a função de produção agrícola". Este autor sugeriu também que o produto agrícola era função das quantidades empregadas dos fatores de produção terra, trabalho e capital, e admitiu, a nível da empresa agrícola, acréscimos constantes nos rendimentos quando as quantidades utilizadas de todos os fatores de produção aumentavam em uma dada proporção, e crescimento decrescente quando apenas alguns desses fatores eram incrementados. Por outro lado, admitiu também que, a nível nacional, a função de produção possa apresentar retornos crescentes, decrescentes ou constantes.

A tentativa mais importante na determinação de formas matemáticas que representassem a resposta de produção aos insumos foi realizada por C. W. Cobb e P. H. Douglas nos anos de 1920, ao definir que a relação entre a produção e os insumos pode ser representada segundo a seguinte função: $Y=A L^{\alpha} K^{\beta} \cdot \varepsilon$; onde, $Y$ é a produção, $L$ é o trabalho, $K$ é o capital e $\varepsilon$ é um erro aleatório multiplicativo ${ }^{6}$.

Dada a facilidade de ajustamento e interpretação dos resultados, esta função passou a ser amplamente utilizada em trabalhos econométricos. São inúmeros os trabalhos em economia agrícola que utilizaram essa função de produção, ajustando-a a dados de uma amostra dos estabelecimentos agropecuários de uma região.

\footnotetext{
${ }^{6}$ Considerações sobre as características desta função encontram-se a partir da página 33
} 
Griliches (1963) empregou funções de produção agregadas tendo como unidades de observação várias regiões de produção dos Estados Unidos. As hipóteses testadas foram: i) diferenças em educação da mão-de-obra são importantes na explicação das diferenças de produtividade; ii) preços de mercado talvez não sejam os corretos a serem usados na construção de índices totais de insumos na presença de desequilíbrio, economias de escala, e erros sistemáticos de medida; e iii) economias de escala explicam, em grande parte, o elevado crescimento na produção por unidade de insumos, na agricultura americana.

Os resultados obtidos indicaram que a influência da variável educação na produção foi bastante significativa, e que seu coeficiente não foi muito diferente do coeficiente da variável mão-de-obra, o que levou o autor a sugerir que a variável mão-deobra pode ser substituída pela variável educação, ao invés de se usar ambas no mesmo modelo, uma vez que a igualdade dos coeficientes sugere tratar-se de um mesmo insumo ${ }^{7}$. E, finalmente, concluiu que há indicação de substancial economia de escala.

Griliches (1964) estimou uma função de produção agregada, do tipo CobbDouglas, para a agricultura dos Estados Unidos. Os dados utilizados foram expressos como média das propriedades rurais de 39 Estados, nos anos de 1949, 1954 e 1959, deflacionados em relação ao ano de 1949. As variáveis incluídas no modelo foram: terra e construções, maquinaria, fertilizantes, trabalho, despesas (em ração e gado, juro sobre o estoque de gado, e despesas em sementes e outros insumos), educação (em anos de

\footnotetext{
7 Vale assinalar, porém, que se os coeficientes de duas variáveis, em uma regressão múltipla, forem iguais, não há prejuizo em agregar as variáveis, e que a eliminação de uma dessas variáveis da regressão, provavelmente, ocasionaria uma subestimação do parâmetro.
} 
escolaridade ponderados por homem), e despesas com pesquisa e extensão. Os principais objetivos eram testar a hipótese de elasticidade unitária de substituição entre trabalho e os demais insumos, e analisar os retornos à educação, pesquisa e assistência técnica.

As principais conclusões foram: i) o nível de educação do agricultor não apresenta na função um coeficiente significativamente diferente daquele do fator trabalho; ii) excluídos os coeficientes de elasticidades parciais de produção referentes às variáveis educação, pesquisa, extensão e às variáveis binárias, o somatório dos coeficientes das demais variáveis foi maior que a unidade, indicando, portanto, a existência de economias de escala; e iii) as diferenças de produtividade entre os Estados podem ser atribuídas às diferenças da qualidade dos insumos, sobretudo educação, economias de escala e aos investimentos em pesquisa e extensão.

Um trabalho de grande repercussão utilizando funções de produção agregadas, do tipo Cobb-Douglas, para estudar as diferenças de produtividade entre 38 países desenvolvidos e em desenvolvimento, foi o realizado em 1970 por Hayami e Ruttan (1988, p.139-46) onde utilizaram como variável dependente o valor da produção, descontadas as parcelas destinadas a sementes e a alimentação do gado, e como variáveis explanatórias foram incluídas terra, trabalho, maquinaria, fertilizante, educação formal em geral, e educação superior em ciências agrárias. Estes pesquisadores verificaram que $95 \%$ das diferenças da produtividade da mão-de-obra entre as regiões estudadas devem-se à quantidade e à qualidade de recursos disponiveis; à tecnologia incorporada ao capital fixo e de trabalho, e ao capital humano, incluindo educação geral e educação superior em ciências agrárias. 
Em pesquisa realizada em 1971, Hayami \& Ruttan (1988, p.191-234), a nível mais agregado, ajustaram uma metafunção de produção para analisar de forma ampla o crescimento da agricultura dos Estados Unidos e do Japão. Constataram que, nos Estados Unidos, a maior elasticidade da oferta de terra para a agricultura em relação à oferta de trabalho e as reduções dos preços da terra e da maquinaria em relação aos salários formam os principais fatores que estimularam a substituição do trabalho por terra e por maquinaria. Por outro lado, constataram que no Japão, onde a oferta de terra era menos elástica e seu preço aumentava em relação aos salários, a substituição do trabalho por terra e maquinaria não foi favorecida, tendo sido induzidas, por outro lado, inovações biológicas, permitindo a seleção de variedades que respondessem de forma mais efetiva à aplicação de fertilizantes e a conseqüente substituição de terra por esse insumo, cujo preço tornou-se mais vantajoso.

Com base nesses resultados os autores propuseram um novo modelo de desenvolvimento agricola onde as mudanças técnicas e institucionais são consideradas como endógenas ao sistema, e concluíram que a principal fonte de crescimento da produtividade agricola é a capacidade de desenvolver tecnologia agrícola adaptada às condições específicas de cada região ou país, e que para isso é primordial investir em educação dos agricultores, transformar as instituições de pesquisa e desenvolver programas de extensão rural.

No Brasil, vários estudos econométricos com o emprego de funções de produção têm sido realizados tanto a nível regional, a partir de dados de uma amostra dos 
estabelecimentos agropecuários de uma região, como a nível mais agregado, onde as unidades de observação são as microrregiões homogêneas.

A nivel regional, pode-se citar o trabalho de Engler (1968), que utilizou o modelo sugerido por C. W. Cobb e P. H. Douglas com o objetivo de determinar a natureza dos rendimentos à escala; os valores dos produtos marginais dos fatores empregados; as taxas marginais de substituição entre esses fatores e a quantidade ótima a ser usada dos recursos de modo a maximizar a renda líquida dos produtores. Os dados analisados foram obtidos através de entrevistas com os agricultores dos municípios de Itapetininga e Guaíra, estado de São Paulo. A variável dependente usada no modelo foi o valor da produção total, e como variáveis explanatórias, terra com culturas, terra com pastagem, trabalho, capital na forma de benfeitorias, capital na forma de equipamento, capital na forma de animais produtivos, capital na forma de animais de trabalho, e despesas de custeio.

Suas principais conclusões foram: i) nos dois Municípios, todos os fatores produtivos, com exceção de terra em pastagem, estavam sendo usados no estágio racional de produção; ii) os fatores produtivos mais fortemente associados ao valor total da produção no município de Itapetininga foram capital na forma de animais produtivos e de trabalho, e despesas de custeio; e para o município de Guaira foram trabalho e capital na forma de animais produtivos e despesas de custeio. O autor constatou também a existência de rendimentos constantes à escala nos dois Municípios.

Engler (1978) utilizou novamente a função de produção agregada tipo CobbDouglas para analisar a agricultura do estado de São Paulo. Especificamente, o objetivo 
principal da pesquisa foi avaliar a eficiência econômica na agricultura assim como suas diferenças regionais de produção e produtividade. Os dados básicos foram obtidos junto ao Instituto de Economia Agrícola (IEA) do estado de São Paulo e constam de entrevistas realizadas com 6.996 agricultores com área explorada acima de 5 hectares. A variável dependente foi o valor da produção e as variáveis explanatórias foram: terra, trabalho, experiência na agricultura, educação, capital de operação, capital fixo, capital total e assistência técnica.

Como principais conclusões pode-se citar: i) a agricultura no estado de São Paulo é bastante diversificada, com grande variação inter-regional que reflete as características fisicas e as vantagens comparativas de cada região; ii) a área utilizada para a produção agropecuária ocupa cerca de $70 \%$ da área total das propriedades do Estado; iii) existe entre as regiões do Estado grande diferença quanto ao uso do capital fixo, sendo que os investimentos em terra e em benfeitorias continuam sendo os principais, correspondendo a mais de $90 \%$ do total; e iv) investimento em capital humano, através de um aumento porcentual no nível de educação, teria o mesmo impacto sobre a produção agrícola que um aumento em igual porcentagem no fator trabalho. Deste modo, segundo o Autor (p.99), "É possível aumentar a produção e a produtividade agrícola da agricultura paulista, principalmente nas regiões menos desenvolvidas, mantendo-se constante, ou mesmo reduzindo em alguns casos, a área cultivada, desde que se aumentem os investimentos em capital humano, na pesquisa que favorece o desenvolvimento de novas tecnologias adaptadas à área em estudo, bem como na difusão dessa tecnologia e na assistência técnica". 
Um trabalho de grande relevância para a agricultura brasileira foi o realizado por Thompson (1974), utilizando dados do Censo Demográfico de 1970 e dos Censos Agrícolas de 1960 e 1970, publicados pela Fundação Instituto Brasileiro de Geografia e Estatística (FIBGE), tendo os Estados como unidades de observação. O modelo analítico empregado foi uma função de produção agregada do tipo Cobb-Douglas ajustada a dados de 18 Estados brasileiros. As variáveis definidas foram agrupadas em três tipos: i) insumos tradicionais, constituidos por terra cultivada, trabalho e animais; ii) insumos modernos representados por fertilizantes e tratores; e (iii) insumos não convencionais como educação rural, força de trabalho em pesquisa agrícola e extensão. Três variáveis importantes não constam do modelo final ajustado, quais sejam: $1^{\underline{a}}$ ) o consumo de fertilizantes, que foi excluído por problemas de multicolinearidade; $2^{\underline{a}}$ ) a área de pastagem, que não foi incluída por falta de dados; e, $3^{\underline{a}}$ ) as variáveis relativas ao capital em construções e benfeitorias.

O Autor concluiu que diferenças em investimentos em educação rural e em pesquisa e extensão agrícola são responsáveis por diferenças na produção agrícola entre os Estados, e que estas são tão importantes quanto as diferenças em terra e trabalho; e que, dadas as diferenças na produtividade do trabalho entre as regiões Nordeste e Sul, em favor desta última, o deslocamento de força de trabalho do Nordeste para o Sul tende a aumentar o valor da produção agrícola nacional, e que elevadas taxas de crescimento na agricultura somente poderão ser alcançadas e mantidas, através de investimentos nos insumos não convencionais. 
O mais recente trabalho sobre a agricultura brasileira utilizando-se de funções de produção agregadas foi o realizado por Hoffmann et al. (1990). Os dados básicos constam dos Censos Demográficos de 1970 e 1980, e dos Censos Agropecuários de 1975 e 1980 publicados pela FIBGE. A variável dependente foi o valor bruto da produção, e as variáveis explanatórias foram terra, trabalho e capital em suas várias formas de desagregação, além de escolaridade, urbanização, preço da terra e valor da terra. Foram ajustadas as funções Linear, Transcendental e a Cobb-Douglas. Destas, a que apresentou melhor ajustamento, sob o ponto de vista estritamente estatístico, foi a função Transcendental. No entanto os Autores optaram pela forma Cobb-Douglas, dada sua facilidade e simplicidade de estimação, e por reconhecerem que a forma Transcendental, apesar de apresentar mais flexibilidade, dado o maior número de parâmetros que ela permite estimar, proporcionou resultados "estranhos" em relação aos esperados.

Pode-se observar nas páginas 113 e 114 do referido trabalho que, com 0 ajustamento da função Transcendental, as variáveis capital em culturas (CC), que corresponde ao valor das culturas permanentes e das matas plantadas, e despesas com medicamentos para animais, sal e ração (RC), apresentam coeficientes negativos. Consequentemente seus produtos marginais são também negativos, sugerindo que uma redução no uso destes fatores provocaria um aumento no valor da produção. Isto mostra, de certa forma, que a função ajustada não conseguiu explicar as verdadeiras relações entre as variáveis.

Os Autores constataram, ainda, que os agricultores estão utilizando capital na forma do valor das instalações e outras benfeitorias, e na forma de despesas gerais, em 
proporções inadequadas; e justificam que "isso pode ser interpretado como uma consequêencia do crédito agricola subsidiado, que teve grande influência na compra de equipamentos (particularmente tratores) pelos agricultores na década de 70" (p.111).

Em relação às diferenças regionais, observaram que existem diferenças significativas entre a região Nordeste e as regiões Sul, Centro-Sul e o estado de São Paulo; e que entre as regiões Sudeste (exclusive São Paulo), São Paulo, Sul e CentroOeste, a única diferença significativa a 5\% ocorre entre São Paulo e Sudeste (exclusive São Paulo). Ao agrupar as regiões Sul, Centro-Oeste e Sudeste em uma grande região, a qual denominaram Centro-Sul, verificaram que o valor da produção, o valor do capital fixo e o valor do capital circulante, todos por equivalente-homem, eram 4, 3,9 e 6 vezes superiores aos da região Nordeste, respectivamente; a produtividade marginal por equivalente-homem no Centro-Sul é 2,5 vezes maior do que no Nordeste; e que a produtividade média - valor da produção por equivalente-homem - da região Centro-Sul é $300 \%$ superior à da região Nordeste.

Finalmente, os Autores observaram que há uma diferença significativa entre as metafunções de produção de 1975 e 1980 para o Brasil como um todo, assim como para as regiões Nordeste, Sudeste (exclusive São Paulo), e São Paulo; e que a produtividade bruta do trabalho no Brasil cresceu $24 \%$ nesse periodo. A produtividade por equivalentehomem, na região Nordeste, cresceu $21,2 \%$ no período $1975-1980$. No entanto, em 1980 esta produtividade correspondeu a apenas $1 / 4$ da produtividade no Centro-Sul.

A função de produção Cobb-Douglas tem sido ajustada tanto a dados nãoexperimentais quanto a dados experimentais. Heady e Dillon dedicam grande parte de sua 
obra clássica "Agricultural Production Functions" ao estudo de funções de produção ajustadas a dados experimentais.

No entanto, segundo Heathfield \& Wile (1987, p.89), muito do sucesso com funções Cobb-Douglas deve-se a resultados relacionados a interesses distributivos, pois quando ajustadas a dados de renda nacional, foi geralmente encontrado que os valores obtidos para os parâmetros $\beta$ e $\alpha$ se constituíam numa verdadeira divisão entre capital e trabalho $(0,7$ para o capital e 0,3 para o trabalho). Isto, segundo estes autores, indicou que a "macro-tecnologia" foi do tipo Cobb-Douglas, e que a função de Cobb-Douglas foi, consequentemente, a representação correta da "macro-tecnologia".

Porém, a "macro-função Cobb-Douglas" foi seriamente questionada por Fisher (1971, p.305-7) após realizar uma série de simulações com esta função. Suas principais conclusões foram: i) uma função Cobb-Douglas agregada somente funciona bem enquanto a participação da mão-de-obra for relativamente constante; ii) quando a participação da mão-de-obra varia, previsões feitas com uma Cobb-Douglas agregada deixam de ser confiáveis, uma vez que uma Cobb-Douglas agregada pressupõe uma participação constante para o trabalho; iii) o ponto essencial dos resultados obtidos não é que uma Cobb-Douglas agregada deixa de funcionar bem quando a participação do trabalho deixa de ser aproximadamente constante, é que uma função Cobb-Douglas agregada continua funcionando bem enquanto a participação do trabalho for aproximadamente constante; e iv) apesar deste fato da constância não ser uma conseqüência de a economia possuir uma tecnologia que é realmente representada por 
uma Cobb-Douglas, este tratamento da Cobb-Douglas é importante sob o ponto de vista empirico e descritivo.

Para Heathfield \& Wile (1987, p.89), os resultados obtidos por Fisher não foram inesperados uma vez que, como a função de produção é um "micro conceito", não se pode esperar que um "micro conceito" possa ser usado em "macro estudos", a não ser que os fatores de produção dos setores da economia estejam relacionados segundo proporções fixas 8 .

Shaikh (1974, p.115-7), por outro lado, questionou os resultados obtidos por Fisher, ao afirmar que, como os dados empíricos foram obtidos através de simulações, associado ao pressuposto da existência de $\boldsymbol{n}$ indústrias com produtos e trabalho homogêneos, - dado um estoque de capital - e ao considerar uma função de produção microeconômica Cobb-Douglas, as condições teóricas para agregação foram violadas; e que as relações obtidas por Fisher são puramente matemáticas e, consequentemente, seus resultados não apresentam nenhuma dependência com alguma lei da produção9 .

Para Shaikh, em tal economia o salário agregado é freqüentemente variável no tempo e, portanto, não se esperaria que uma Cobb-Douglas agregada desse um bom ajustamento. No entanto concorda que, ao se considerar salário agregado aproximadamente constante, o critério econômico da teoria da distribuição e produção agregada requer uma função Cobb-Douglas.

Jatileksono \& Otsuka (1993), ao estudarem os efeitos de variedades melhoradas de arroz e das condições ambientais de produção, caracterizadas pela presença ou não de

\footnotetext{
8 Uma demonstração algébrica deste fato encontra-se em Heathfield e Wile (1987, p.90).

9 Uma critica ao artigo de Shaikh encontra-se em Solow (1974, p.121).
} 
irrigação, áreas de planícies e áreas montanhosas, sobre o preço da terra e a produção de arroz, empregou funções de produção tipo Cobb-Douglas a dados obtidos em 20 localidades circunvizinhas, na província de Lampung na Sumatra, Indonésia. Foram selecionadas aleatoriamente, em cada localidade, 40 propriedades familiares para a realização das entrevistas.

Para estimar a função de produção, os Autores utilizaram como variável dependente a produção de arroz de cada propriedade, e como variáveis explicativas, trabalho, insumos correntes (fertilizantes), terra e tecnologia (representada por 4 variedades melhoradas de arroz e pelas condições ambientais de produção).

$\mathrm{Na}$ estimativa da função de determinação do preço da terra foi considerada como variável dependente a relação entre o preço da terra e o preço da terra própria para o cultivo do arroz, e como variáveis explicativas, o preço da área cultivada deflacionado por um índice de custo de vida; a relação entre os preços da área cultivada e dos insumos correntes; distância a mercados urbanos; interações entre variedades e irrigação; e variáveis binárias para distinguir os subdistritos, e as áreas de planícies das áreas montanhosas.

As principais conclusões do trabalho foram: a) o uso de variedades melhoradas em condições ambientais favoráveis aumentou significativamente a produtividade da terra; b) o emprego de variedades melhoradas afetou o preço da terra por aumentar a produtividade do arroz, e que este aumento não ocorreu apenas nas localidades onde as variedades foram introduzidas, mas em toda a região (porém, os autores observaram que o preço da terra aumentou mais em áreas irrigadas do que em áreas de sequeiro); c) o 
preço da terra é positivamente afetado pela proximidade a mercados urbanos; e, d) concluiram, finalmente, que embora a adoção de variedades melhoradas tenha aumentado a demanda por trabalho e, portanto, salários em áreas com condições de produção favoráveis ao cultivo de arroz no curto prazo, migração interregional de áreas nãofavoráveis para áreas favoráveis reduziu, significativamente, a diferença regional de salários no longo prazo.

Fulginiti \& Perrin (1993), com o objetivo de verificar o efeito de políticas de preços passados sobre a tecnologia incorporada e, consequentemente, sobre a produtividade agrícola de 18 países em desenvolvimento, empregou função de produção agregada tipo Cobb-Douglas. O pressuposto básico é que os coeficientes da função de produção são variáveis no tempo e estão relacionados com mudanças antecipadas nos preços, com a tecnologia corrente, com o ambiente institucional e com a qualidade dos recursos humanos.

Para verificar o efeito das distorções de preços na produtividade, ajustaram uma função de produção, usando dados agrupados dos paises, cujos coeficientes, juntamente com as distorções de preços estimados, foram empregados para calcular os efeitos de políticas de preços passados sobre a produtividade agrícola estimada. A produtividade foi considerada como a diferença residual entre o crescimento da produção observada e a estimada, por quantidade de insumo adicionado.

$\mathrm{Na}$ estimativa da função de produção foi usada como variável dependente o valor da produção, em milhões de dólares, e como variáveis explanatórias, terra arável para culturas e pastos permanentes, em mil hectares; estoque animal, em equivalentes-vaca; 
máquinas, em cavalos-vapor; fertilizantes, em mil toneladas; e, trabalho, medido pelo número total de trabalhadores empregados na agricultura. Incluíram, também, na função de produção, três tipos de variáveis de mudança tecnológica: a) aquelas relacionadas com as expectativas, com base nos preços passados; b) aquelas relacionadas com a introdução de novas técnicas; e, c) aquelas relacionadas com as tecnologias já existentes em cada país. Como "proxy" para estas variáveis os autores usaram: i) preço do produto, definido como a média móvel de 5 anos do índice de preços dos principais produtos agrícolas; ii) salário, definido como a média móvel de 5 anos de salários mensais pagos, nos Estados Unidos, a trabalhadores agrícolas; e, iii) preço dos fertilizantes, definido como a média móvel de 5 anos de um índice de preços pagos por fertilizantes.

Os Autores concluíram que existe uma relação positiva entre preços passados do produto e produtividade corrente dos recursos nos países menos desenvolvidos, enquanto que salários passados têm um efeito negativo sobre a produtividadade. Observaram, também, que as estimativas dos efeitos de preços na produtividade são bastante fortes em comparação com as "proxy" alternativas para outras variáveis de mudança tecnológica, tais como pesquisa, qualidade da terra e capital humano, indicando, portanto, que estas variáveis se constituem, também, em fatores de mudança tecnológica e, consequentemente, de mudança da produtividade dos recursos. E, finalmente, verificaram que a função de produção reflete, aproximadamente, retornos constantes à escala, o que permite pressupor que as estimativas do produto adicional devido aos preços passados se refletem, sem dúvida, em mudanças na produtividade dos recursos. 
Ahmad \& Bravo-Ureta (1995) empregaram a função de produção tipo CobbDouglas para decompor a variação da produção entre mudança tecnológica, crescimento de insumos e eficiência técnica. Para isso utilizaram dados de 96 fazendas leiteiras de Vermont (USA). Foram realizadas 1072 observações, no período de 1971 a 1984 . O número de observações variou de menos de 6 a mais de 40 , por fazenda.

Todos os modelos empregados foram baseados na especificação Cobb-Douglas, e a eficiência técnica foi determinada através da fronteira estocástica, assumindo que a eficiência técnica é: a) constante no tempo e obedece uma distribuição semi-normal; b) constante no tempo e obedece uma distribuição normal truncada; c) variável no tempo e obedece uma distribuição semi-normal; e, d) variável no tempo e obedece uma distribuição normal truncada. Como variável dependente usaram a produção anual de leite, em centenas de libras, e como variáveis explanatórias, o número de vacas leiteiras; total de trabalho empregado, inclusive trabalho familiar, em equivalentes-homem; ração, em toneladas; despesa animal (medicamentos, manejo, reposição do estoque animal); despesas com pasto (fertilizantes, sementes, pulverização, máquinas e equipamentos); e, outras despesa (energia, depreciação de prédios e equipamentos).

Os Autores concluíram que o efeito escala representou um papel maior do que o crescimento da produtividade sobre o aumento da produção de leite, durante o período em estudo, e que o crescimento da produtividade foi influenciado, principalmente, pelo progresso tecnológico, enquanto que mudança na eficiência técnica apresentou menor importância. Concluíram, também, que, em média, a eficiência técnica foi em torno de $77 \%$, e que apresentou pequena variação, para a amostra, durante o período em estudo. 
Ulveling \& Fletcher (1970), ao incorporar uma variável indexada ao modelo Cobb-Douglas tradicional, obtiveram uma forma modificada deste modelo em que as elasticidades parciais e os retornos à escala tornaram-se variáveis. Assim, com o objetivo de avaliar a influência da intensidade de capital na produção, expressa pela relação entre serviço de capital e terra, sobre as elasticidades parciais de produção e retornos à escala, utilizaram informações de 100 propriedades do México. Por hipótese, admitiram que a variável intensidade de capital influenciava indiretamente o valor da produção através das variáveis trabalho e fluxo de capital; e que variações positivas naquela variável aumentariam a elasticidade do fator trabalho e reduziriam a elasticidade do fator fluxo de capital. As variáveis incluídas no modelo foram o valor da produção das culturas da fazenda, em pesos; terra, em hectares; trabalho, em horas; e fluxo de capital, em pesos. Os resultados obtidos permitiram aos autores concluir que as elasticidades e os retornos à escala eram, geralmente, influenciados pela intensidade de capital de produção; e que os retornos à escala eram mais elevados quando se empregavam tecnologias mais intensivas em capital.

Finalmente, embora nesta revisão não tenham sido considerados trabalhos onde a função de produção é estimada a partir de dados experimentais, cabe ressaltar que tanto o modelo Cobb-Douglas como o modelo Ulveling-Fletcher tem sido usados nestes casos, obtendo-se bons ajustamentos [exemplos poderão ser encontrados em Lima (1971) e Rocha (1972)]. 


\section{METODOLOGIA}

\subsection{Considerações teóricas}

O modelo de análise a ser usado nessa pesquisa consiste, essencialmente, na estimativa de uma função de produção que, segundo Barbosa (1985, p.219), pode ser definida como 'uma relação técnica que associa cada dotação de $n$ fatores de produção à máxima quantidade de produto obtida a partir da utilização desses fatores. Assim, se denominarmos por $X_{1}, X_{2}, \ldots, X_{n}$ as quantidades (de serviços) dos fatores usados na produção da quantidade $Q$ de produto, a função de produção pode ser representada por:

$$
Q=Q\left(X_{1}, X_{2}, \ldots, X_{n}\right) \cdots
$$

Esse conceito, porém, contém em si limitações, por supor que se esteja considerando um produto homogêneo, pois a variável dependente é a quantidade de produto $(Q)$. Segundo Hoffmann et al. $(1990$, p.80) "tal conceito é diretamente aplicável quando se dispõe de dados experimentais que permitam relacionar a variação na quantidade de alguns fatores com a variação na quantidade produzida. Esse é o caso, tipicamente, dos experimentos de adubação, onde se observa como a produção de determinada cultura por unidade de área varia em função das quantidades de nitrogênio, fósforo e potássio adicionadas ao solo". 
O conceito de função de produção, porém, tem sido utilizado em modelos teóricos e análises empíricas a nível muito mais agregado.

Existem, obviamente, diferenças entre as condições impostas pela teoria da produção e as condições do mundo real. Assim, na estimativa e uso da função de produção, como um instrumento de análise na alocação de recursos, se faz necessário a imposição de vários pressupostos, entre os quais menciona-se: i) existência de perfeito conhecimento dos mercados de fatores e de produtos; ii) divisibilidade dos insumos e do produto em qualquer proporção, a fim de proporcionar um nível ótimo de uso dos insumos; iii) os preços dos fatores e do produto são pré-determinados e independentes; iv) o nivel tecnológico é dado; v) as isoquantas são convexas em relação à origem dos eixos das coordenadas, permitindo infinitas combinações entre os fatores de produção; vi) as funções de produção individuais (firmas, propriedades, microrregiões, etc.) são aditivamente separáveis. Isto permite que a função de produção agregada do setor seja obtida através da soma das funções de produção individuais; e, vii) os insumos e o produto são homogêneos ${ }^{10}$.

\footnotetext{
${ }^{10}$ Chambers (1988, p.6-18 e 36-48).
} 


\subsection{A Função de Produção Agregada tipo "Cobb-Douglas"}

C.W. Cobb e P.H. Douglas ${ }^{11}$, citados em Hoffmann et al. (1990, p.80) e Klein $(1978$, p.116), foram os pioneiros em estimação de funções de produção agregada. Eles propuseram, em artigo intitulado "A Theory of Production", publicado em 1928 na American Economic Review, o uso da função

$$
Y=A L^{\alpha} K^{\beta} \cdot \varepsilon,
$$

onde,

$Y$ é a produção, $L$ é o trabalho empregado, $K$ é o capital utilizado e $\varepsilon$ é o erro aleatório multiplicativo.

Genericamente, o modelo econométrico da função de produção agregada tipo Cobb-Douglas utilizado nesta pesquisa pode ser expresso em sua forma mais geral como $^{12}$

$$
Y=A X_{1}^{\beta_{1}} X_{2}^{\beta_{2}} \ldots X_{n}^{\beta_{n}} \cdot \varepsilon=A \prod_{i=1}^{n} X_{i}^{\beta_{i}} \cdot \varepsilon
$$

onde,

$Y$ é a variável dependente e representa o valor bruto da produção;

$X_{1}$ a $X_{n}$ são as variáveis explanatórias, e representam os fatores de produção;

$A$ é uma constante positiva, pois não é possivel produção negativa;

${ }^{11}$ Cobb, C. W. \& P. H. Douglas. A theory of Production. The American Economic Review. v. 18, n. 1 p.139-65, 1928.

12 Uma exposição detalhada desse modelo é encontrada em Heady \& Dillon (1969, p. 16-30 e 228-32) 
$\beta_{1}$ a $\beta_{n}$ são os coeficientes de regressão, e representam os coeficientes de elasticidade parciais da produção em relação aos fatores;

$\varepsilon$ é um erro aleatório multiplicativo cujo logaritmo tem distribuição normal com média zero e variância $\sigma^{2}$.

\subsubsection{Principais Características da Função de Produção tipo "Cobb-Douglas"13}

a) O produto fisico médio de um fator $X_{i}\left(P F M e_{X_{i}}\right)$ qualquer é positivo e decresce à medida que se intensifica o uso do fator $X_{i}$. É definido como a relação entre o volume produzido (ou valor total da produção) e a quantidade do fator utilizado.

$$
\text { PFMe }_{x_{i}}=\frac{Y}{X_{i}}=\frac{A X_{1}^{\beta_{1}} X_{2}^{\beta_{2}} \ldots X_{n}^{\beta_{n}}}{X_{i}}=A X_{1}^{\beta_{1}} X_{2}^{\beta_{2}} \ldots X_{i}^{\beta_{1}-1} \ldots X_{n}^{\beta_{n}}>0
$$

b) O produto fisico marginal de $X_{i}\left(P F M a_{x_{i}}\right)$, definido como a variação na produção decorrente da variação de uma unidade do fator de produção, é positivo se $\beta_{i}>0$, e decresce à medida que se intensifica o uso do fator $X_{1}$.

$$
\text { PFMa }_{x_{i}}=\frac{\partial Y}{\partial X_{i}}=\beta_{i} A X_{1}^{\beta_{1}} X_{2}^{\beta_{2}} \ldots X_{i}^{\beta_{1}-1} \ldots X_{n}^{\beta_{n}}=\beta_{i}\left(\frac{Y}{X_{i}}\right)>0
$$

13 Baseado em Thompson (1973, p.152-7), Silberberg (1990. p.94-5 e 286-7), Simonsen (1993, p.230-6 e 240-57) e Barbosa (1985, p.226-9). 
Observa-se, portanto, através dessa função que o produto fisico marginal não pode ser negativo nem igual a zero, pois $\beta_{i}$ é, por definição, positivo, e $Y$ e $X_{i}$ não podem ser negativos por se tratar de função de produção. Assim, a função de produção não pode atingir um ponto máximo de produção.

c) A elasticidade parcial de produção de $X_{i}\left(\varepsilon_{x_{i}}\right)$, definida como a relação entre a variação relativa da produção e a variação relativa do fator de produção, é constante, isto é, independe da combinação $X_{1}, \ldots, X_{n}$ e $Y$.

Como, por definição

$$
\begin{aligned}
\varepsilon_{x_{i}} & =\frac{\partial Y}{\partial X_{i}} \cdot \frac{X_{i}}{Y} ; \quad \text { e, tendo em vista a equação (5), obtém-se: } \\
\varepsilon_{x_{i}} & =\left[\beta_{i}\left(\frac{Y}{X_{i}}\right)\right]\left[\frac{X_{i}}{Y}\right]=\beta_{i}
\end{aligned}
$$

d) O grau de retornos à escala, ou o grau de homogeneidade da função é dado por

$$
G=\sum_{i=1}^{n} \beta_{i}
$$

Assim, $G$ poderá assumir um valor maior, menor ou igual a 1 , o que implicará em retornos à escala crescentes, decrescentes ou constantes, respectivamente ${ }^{14}$. No cálculo de $G$ não serão consideradas as elasticidades parciais dos fatores de produção não-convencionais: escolaridade (ESC1), preço da terra (PRT) e urbanização (URB).

${ }^{14}$ Maiores detalhes sobre as implicações do grau de homogeneidade da função Cobb-Douglas sobre a produção poderão ser vistos em James e Throsby (1977, p.181-97 e 201-8) e Klein (1978, p. 108-14). 
Vale lembrar que as condições de $2^{\mathrm{a}}$ ordem para um ponto de lucro máximo só são obedecidas quando ocorrem retornos à escala decrescentes $(G<1)$, implicando em uma função de produção "Cobb-Douglas" côncava"s.

e) A existência de um ponto ótimo de produção implica em se considerar retornos decrescentes para cada fator, isto é,

$$
\frac{\partial\left(\text { PFMa }_{x_{i}}\right)}{\partial X_{i}}<0 \quad \text { com } \quad i=1,2, \ldots, n
$$

A partir da equação (5), pode-se obter:

$$
\frac{\partial\left(P F M a_{x_{i}}\right)}{\partial X_{i}}=\beta_{i}\left(\beta_{i}-1\right) A X_{1}^{\beta_{1}} X_{2}^{\beta_{2}} \ldots X_{i}^{\beta_{i}-2} \ldots X_{n}^{\beta_{n}}=\beta_{i}\left(\beta_{i}-1\right)\left(\frac{Y}{X_{i}^{2}}\right)<0
$$

para $0<\beta_{i}<1$.

f) A função Cobb-Douglas não apresenta ponto de máximo em razão da produtividade fisica marginal de $X_{i}\left(P F M a_{x_{i}}\right)$ ser sempre positiva.

g) As isoquantas ou curvas de isoproduto são convexas e se aproximam assintoticamente dos eixos das coordenadas. Considerando um nível de produção constante igual a $Y_{0}$, a forma geral para isoquantas é dada por:

$$
X_{i}=\left[\frac{Y_{0}}{A \prod_{h \neq i} X_{h}^{\beta_{h}}}\right]^{\frac{1}{\beta_{i}}}
$$

15 Allen (1947, p.185-6 e 303-5) e Chiang (1982, p.223 e p.307-9) apresentam as condições necessárias e suficientes para que uma função seja concava. 
h) A taxa marginal de substituição entre dois fatores $X_{i}$ e $X_{j} \quad\left(T M S_{x_{i} x_{j}}\right)$ é uma função linear da razão entre os insumos, com inclinação $\beta_{j} / \beta_{i}$ conforme demonstra-se a seguir:

$$
T M S_{x_{i} x_{j}}=\frac{\partial X_{i}}{\partial X_{j}}=\frac{f_{j}}{f_{i}}=\frac{\partial Y / \partial X_{j}}{\partial Y / \partial X_{i}}=\frac{\beta_{j}}{\beta_{i}} \cdot \frac{X_{i}}{X_{j}}
$$

Observa-se, portanto, que a taxa marginal de substituição depende apenas da razão entre as quantidades dos dois fatores considerados.

i) As isóclinas na função de produção tipo Cobb-Douglas são retas que passam pela origem dos eixos das coordenadas, coincidindo com a linha de escala, que é definida como o lugar geométrico formado por pontos em que os fatores produtivos se combinam segundo uma proporção fixa.

Por definição, ao longo de uma isóclina a taxa marginal de substituição entre dois fatores é constante $(K)$. Da expressão (10), tem-se

$$
\frac{\beta_{j}}{\beta_{i}} \cdot \frac{X_{i}}{X_{j}}=K
$$

Logo a expressão de uma isóclina será $X_{i}=K\left(\beta_{i} / \beta_{j}\right) X_{j}$. Portanto, nesse modelo a combinação ótima dos fatores produtivos apresenta uma proporção constante, independente do nível de produção. Isto significa que o "caminho de expansão" é linear e passa pela origem.

j) A elasticidade de substituição $\left(\varepsilon_{S}\right)$ é constante e igual a 1 .

Por definição, a elasticidade de substituição é dada pela relação entre as variações relativas das razões entre as quantidades utilizadas dos fatores, $\partial\left(X_{1} / X_{j}\right) /\left(X_{1} / X_{j}\right)$, e 
as variações relativas das razões entre as taxas marginais de substituição, $\partial\left(f_{j} / f_{i}\right) /\left(f_{j} / f_{i}\right)$, isto é:

$$
\begin{array}{r}
\varepsilon_{s}=\frac{\partial\left(X_{i} / X_{j}\right) /\left(X_{i} / X_{j}\right)}{\partial\left(f_{j} / f_{i}\right) /\left(f_{j} / f_{i}\right)}=\frac{\partial\left(X_{i} / X_{j}\right)}{\partial\left[\left(\beta_{j} / \beta_{i}\right)\left(X_{i} / X_{j}\right)\right]} \frac{\left(\beta_{j} / \beta_{i}\right)\left(X_{i} / X_{j}\right)}{\left(X_{i} / X_{j}\right)}= \\
=\frac{\partial\left(X_{i} / X_{j}\right)}{\left(\beta_{j} / \beta_{i}\right) \partial\left(X_{i} / X_{j}\right)}\left(\beta_{j} / \beta_{i}\right)=1
\end{array}
$$

k) A função Cobb-Douglas é linear nos logaritmos.

Aplicando-se logaritmo neperiano na equação (3), obtém-se a forma linear

$$
\ln Y=\ln A+\beta_{1} \ln X_{1}+\beta_{2} \ln X_{2}+\cdots+\beta_{n} \ln X_{n}+\ln \varepsilon=\phi+\sum_{i=1}^{n} \beta_{1} X_{i}+u
$$

o que torna fácil o ajustamento da função.

A função tipo 'Cobb-Douglas", porém, apresenta algumas limitações para pesquisas em economia da produção, tais como:

i) a função, vistas as características mencionadas nos itens (b) e (c), não permite analisar processos produtivos que contenham fases de produtividade marginal crescentes, decrescentes e/ou constantes. Por isso não se consegue explicar através dessa função os diferentes estágios da produção.

ii) a função não apresenta ponto de máximo, visto que o produto fisico marginal não atinge valor zero. 
iii) a função implica na pressuposição de que todos os fatores são disponíveis à produção, pois qualquer valor nulo para uma das variáveis explanatórias implicará em valor nulo para a produção (variável dependente).

iv) a característica "assintótica" das isoquantas aos eixos das coordenadas implica que os fatores de produção podem ser combinados de forma ilimitada para obter uma determinada produção, o que não é real, pois como é facilmente observável, principalmente em processos de produção na agricultura, a partir de certo ponto a produtividade marginal dos fatores é nula e poderá até mesmo ser negativa; e

v) a função de produção "Cobb-Douglas" determina que a proporção ótima em que dois fatores se combinam seja constante, o que não é necessariamente coerente com a realidade.

Essas limitações, porém, não impedem, ou invalidam, o uso da função de produção 'Cobb-Douglas", pois, essa função, por outro lado, apresenta as seguintes vantagens:

i) simplicidade na estimação dos parâmetros, pois na forma logarítmica a função Cobb-Douglas é uma equação de regressão linear múltipla, e, portanto, de fácil estimação.

ii) as elasticidades parciais de produção são os próprios coeficientes da regressão e podem ser diretamente comparadas entre si, pois são independentes das quantidades de produto e de fatores;

iii) por ser uma função homogênea, a natureza dos rendimentos à escala é determinada diretamente pela soma dos coeficientes da regressão; 
iv) comparativamente com outros modelos, apresenta um pequeno número de parâmetros a serem estimados, e portanto tem-se um maior número de graus de liberdade nos testes estatísticos;

v) simplicidade na determinação da produtividade marginal dos "fatores", pois basta efetuar a multiplicação do respectivo coeficiente de elasticidade (no caso, o coeficiente da regressão) pela produtividade média do fator, para obter a produtividade marginal no ponto médio.

\subsection{A Função de Produção Agregada tipo "Ulveling-Fletcher"}

O modelo desenvolvido por Ulveling \& Fletcher (1970, p.322-9), e posteriormente generalizado por De Janvry (1972, p.234-7), é na realidade uma modificação da função Cobb-Douglas tradicional, descrita anteriormente, em que as elasticidades parciais de produção tornam-se variáveis, possibilitando, consequentemente, retornos à escala variáveis. Assim, este modelo poderá ser utilizado em processos de produção em que, por hipótese, uma ou mais variáveis explanatórias influenciam a produção não de forma direta e sim indiretamente através das elasticidades parciais de produção de uma ou mais variáveis explanatórias incluídas no modelo.

Originalmente, este modelo foi expresso da seguinte forma (Ulveling \& Fletcher, 1970, p.323):

$$
Y=A X_{1}^{B_{1}} X_{2}^{B_{2}} X_{3}^{B_{3}}
$$

onde, 
$Y$ representa o valor da produção, em pesos;

$X_{1}$ é o fator de produção terra empregada, em hectares;

$X_{2}$ é o trabalho utilizado, em horas;

$X_{3}$ é o capital empregado, em pesos; e

$$
B_{1}=B_{1}(K), \quad B_{2}=B_{2}(K) \quad \text { e } \quad B_{3}=B_{3}(K) \text { são as elasticidades parciais de }
$$
produção, as quais são funções da variável $K$.

Genericamente, o modelo econométrico da função de produção tipo 'UlvelingFletcher" empregado nesta pesquisa pode ser apresentado como:

$$
Y=A \prod_{i=1}^{n} X_{i}^{B_{i}\left(K_{j}\right)} \cdot \varepsilon ; \quad \operatorname{com} j=1, \ldots, w .
$$

Desta forma as variáveis $K_{j}$ passam a influenciar as elasticidades parciais de produção e, consequentemente, os retornos à escala. Ademais, a introdução destas variáveis geralmente torna a função de produção não homogênea.

Como, por hipótese, admite-se que $K_{j}$ sejam variáveis observáveis e contínuas, pode-se escrever a equação (14) na forma logarítmica, como segue:

$$
\ln Y=\ln A+\sum_{i=1}^{n} B_{i}\left(K_{j}\right) \ln X_{i}+\ln \varepsilon
$$

As funções $B_{i}\left(K_{j}\right)$ podem assumir as mais variadas formas, "permitindo testar hipóteses de que diversas variáveis influenciam as elasticidades parciais, ou de que variáveis diferentes influenciam cada uma dessas elasticidades separadamente" (Camargo, 1974, p.33). Porém, a equação (15) é linear nos parâmetros, desde que cada uma das funções $B_{i}\left(K_{j}\right)$ seja também linear nos parâmetros; e apresenta diversos termos interativos 
em decorrência do produto de $K_{j}$ pelas variáveis $X_{i}$ transformadas, podendo ser estimada pela aplicação do método dos mínimos quadrados (Ulveling \& Fletcher, 1970, p.323).

\subsubsection{Principais Características da Função de Produção tipo "Ulveling-Fletcher"}

a) $\mathrm{O}$ produto físico médio de um fator de produção $X_{i}\left(P F M e_{x_{i}}\right)$ qualquer é positivo e decresce, se $B_{i}\left(K_{j}\right)<1$, à medida que se intensifica o uso desse fator, mantida constante a variável $K_{j}$.

$$
\begin{aligned}
\operatorname{PFMe}_{x_{i}}=\frac{Y}{X_{i}} & =\frac{A X_{1}^{B_{1}\left(K_{j}\right)} X_{2}^{B_{2}\left(K_{j}\right)} \ldots X_{i}^{B_{i}\left(K_{j}\right)} \ldots X_{n}^{B_{n}\left(K_{j}\right)}}{X_{i}}= \\
& =A X_{1}^{B_{1}\left(K_{j}\right)} X_{2}^{B_{2}\left(K_{j}\right)} \ldots X_{i}^{B_{i}\left(K_{j}\right)-1} \ldots X_{n}^{B_{n}\left(K_{j}\right)}>0
\end{aligned}
$$

b) O produto fisico marginal de um fator $X_{i}\left(P F M a_{x_{i}}\right)$ qualquer é sempre positivo se $B_{i}\left(K_{j}\right)>0$, e decresce, se $B_{l}\left(K_{j}\right)<1$, à medida que se intensifica o uso desse fator, mantida constante a variável $K_{j}$.

$$
\begin{aligned}
& P F M a_{x_{i}}=\frac{\partial Y}{\partial X_{i}}=B_{i}\left(K_{j}\right) A X_{1}^{B_{1}\left(K_{j}\right)} X_{2}^{B_{2}\left(K_{j}\right)} \ldots X_{i}^{B_{i}\left(K_{j}\right)-1} \ldots X_{n}^{B_{n}\left(K_{j}\right)}= \\
&=B_{i}\left(K_{j}\right)\left(\frac{Y}{X_{i}}\right)>0
\end{aligned}
$$

Observa-se, portanto, que a função de produção não apresenta ponto de máximo uma vez que o produto físico marginal não pode ser negativo ou nulo se $B_{i}>0$. 
c) A elasticidade parcial de produção do fator $X_{i}\left(\varepsilon_{x_{i}}\right)$ é variável e está relacionada à variável $K_{j}$.

$$
\varepsilon_{x_{i}}=\frac{\partial Y}{\partial X_{i}} \cdot \frac{X_{i}}{Y}=\left\{B_{i}\left(K_{j}\right)\left[\frac{Y}{X_{i}}\right]\right\}\left[\frac{X_{i}}{Y}\right]=B_{i}\left(K_{j}\right)
$$

d) Os retornos à escala são obtidos através do somatório das funções $B_{i}\left(K_{j}\right)$ sendo consequentemente variáveis.

Tendo em vista as características mencionadas acima, pode-se relacionar como principais vantagens deste modelo; i) o fato de as elasticidades parciais de produção serem dadas diretamente através das expressões $B_{i}\left(K_{j}\right)$; ii) a facilidade da obtenção dos rendimentos à escala, os quais são obtidos pela simples soma $\operatorname{dos} B_{i}\left(K_{j}\right)$; iii) simplicidade do cálculo das produtividades marginais no ponto médio, obtidas através da multiplicação da produtividade média pelo coeficiente de elasticidade do respectivo fator; e iv) as elasticidades parciais e total serem variáveis.

Entretanto, o referido modelo possui algumas desvantagens (Silva, 1973, p.50), tais como: i) não admite que qualquer insumo $\left(X_{i}\right)$ que entre no ajustamento assuma valor zero; ii) as isoquantas se aproximam assintoticamente dos eixos coordenados; e iii) as isóclinas são retas que passam pela origem dos eixos cartesianos, o que implica que a combinação ótima dos fatores seja constante, o que nem sempre se verifica. Apesar destas limitações, este modelo será utilizado nesta pesquisa, uma vez que se acredita que algumas variáveis, tais como: nivel de escolaridade (ESC1), grau de urbanização (URB) e preço da terra (PRT), definidas a seguir, não são propriamente insumos que entram 
diretamente na produção mas que interferem indiretamente através de outras variáveis, ao modificarem suas respectivas elasticidades.

\subsection{Modelos Analíticos Utilizados}

Antes de apresentar os modelos a serem utilizados nesta pesquisa, para atender aos objetivos preestabelecidos, cabe fazer algumas considerações sobre os principais problemas econométricos enfrentados por pesquisadores quando da estimação de funções de produção agregadas ${ }^{16}$. O primeiro é o fato de que em todo processo de produção, principalmente na produção agropecuária, são inúmeros os fatores que interferem direta e/ou indiretamente neste processo. Geralmente o pesquisador não tem condições de obter todas as informações sobre todos aqueles fatores, e por isso pode ser levado a excluir variáveis importantes na regressão, o que leva à obtenção de estimadores de mínimos quadrados ordinários viesados. Isto é bastante comum dada a dificuldade na obtenção de informações. Varian (1984) reconhece este fato ao afirmar que, como há limitações usuais nos dados disponiveis, não é provável que o ajustamento de funções de produção pelo método dos mínimos quadrados ordinários leve a boas estimativas dos parâmetros tecnológicos subjacentes.

Por outro lado, a inclusão de um grande número de variáveis na regressão ocasiona, quase sempre, altas correlações entre as variáveis explanatórias, aumentando o problema da multicolinearidade e levando à obtenção de estimadores imprecisos.

\footnotetext{
16 Varian (1984, p. 171-9) e Klein (1978. p.114-20).
} 
Hoffmann et al. (1990, p.85-6) reconhecem e sintetizam estes problemas ao afirmarem que "Se, por um lado, a exclusão de variáveis relevantes torna viesadas as estimativas dos coeficientes das variáveis incluídas no modelo, a inclusão de muitas variáveis, por outro lado, tende a aumentar o problema da multicolinearidade, fazendo com que as estimativas dos parâmetros sejam muito imprecisas. Ao ajustar uma função de produção com dados agregados o econometrista se defronta, geralmente, com esse dilema: obter estimativas dos parâmetros sabidamente viesadas ou estimativas altamente imprecisas".

Uma outra dificuldade no ajustamento de funções de produção diz respeito ao problema da "Identificação"; isto é, a escolha da forma da função de produção, pois o pesquisador corre o sério risco de ajustar uma função que não represente satisfatoriamente as relações reais entre as variáveis. Neste trabalho optou-se por utilizar os modelos de função de produção dos tipos 'Cobb-Douglas" e 'Ulveling-Fletcher", por razões já descritas anteriormente.

\subsubsection{Estimativa da Função de Produção Agregada}

Para atender aos objetivos (a) e (c), à página 10, a forma geral das funções a serem ajustadas é

$$
\ln V P=\alpha+\sum_{i} \beta_{i} \ln X_{i}+\sum_{j} \gamma_{j} Z_{j}+u
$$

onde, 
$V P$ é o valor da produção; $X_{i}(i=1, \ldots, k)$ representa as variáveis explanatórias AL, APP, APN, AM, CC, CA, VI, DA, DM, OD e EH (ver definições a partir da p.49) ou variáveis agregadas como $\mathrm{AP}=\mathrm{APP}+\mathrm{APN}$ correspondentes aos fatores de produção controlados pelo empresário agrícola; $\beta_{i}$ representa as elasticidades do valor da produção em relação a esses fatores; $Z_{j}$ representa as variáveis $\operatorname{lnPRT}$, ESC e URB, correspondentes aos fatores de produção não controlados pelo empresário agrícola, e $u$ é o erro aleatório (com as pressuposições usuais).

\subsubsection{Análise das Diferenças Regionais}

Para analisar as diferenças entre as 4 regiões, objetivo (e) à página 10 , será ajustado o seguinte modelo:

$$
Y=\alpha+\sum_{h=1}^{3} \delta_{h} S_{h}+\sum_{i=1}^{n} \beta_{i} Z_{i}+\sum_{h=1}^{3} \sum_{i=1}^{n} \gamma_{h i} S_{h} Z_{i}+u
$$

onde,

$Y$ é o logaritmo de $V P$ em cada MRH (microrregião homogênea); $Z_{i}$ (com $i=$ $1, \ldots, n)$ são as variáveis incluídas no modelo, controladas ou não pelo empresário; $\alpha, \delta_{h}$, $\beta_{i}$ e $\gamma_{h i}$ são parâmetros a serem estimados; $u$ é o erro aleatório, com as pressuposições usuais, e $n$ é o número de variáveis do modelo. $S_{h}$ são variáveis binárias ${ }^{17}$, com $h=1$, 2,3 , e tem como objetivo captar as diferenças entre as regiões.

${ }^{17}$ Sobre o uso de variáveis binárias ver Hoffmann e Vieira (1993, cap.5, p.203-28) e Johnston (1977, p. 239-46). 
Assim, para as microrregiões do Nordeste as variáveis $S_{h}$ são iguais a zero; para as da região Sudeste (exclusive SP) a variável $S_{1}$ assume valor 1 e as demais binárias são iguais a zero; para as microrregiões de SP apenas $S_{2}$ é igual a 1 ; e para as MRH do Sul apenas $S_{3}$ é igual a 1 . Os parâmetros para a região Nordeste são $\alpha$ e $\beta_{i}$ (com $i=$ $1, \ldots, n)$ e os parâmetros para as demais regiōes são $\alpha+\delta_{h}$ e $\beta_{i}+\gamma_{h i}(i=1, \ldots, n), \operatorname{com} h=$ 1 para a região Sudeste (exclusive SP), $h=2$ para São Paulo e $h=3$ para a região Sul.

O teste a ser utilizado para verificar se há diferença da função de produção entre as regiões será o teste "F". Assim, para verificar se a função de produção na $h$-ésima região é diferente da função de produção no Nordeste testa-se a hipótese

$$
\mathrm{H}_{0}: \delta_{h}=0 \text { e } \gamma_{h i}=0 ; \quad \text { com } \quad i=1, \ldots, n
$$

e para testar se a função de produção da $h$-ésima região é diferente da função de produção na $k$-ésima região, testa-se a hipótese

$$
\mathrm{H}_{0}: \delta_{h}=\delta_{k} \text { e } \gamma_{h i}=\gamma_{k i} ; \quad \text { com } \quad i=1, \ldots, n
$$




\subsubsection{Análise Comparativa das Funções de Produção em 1975, 1980 e 1985.}

Para comparar as funções de produção de 1975,1980 e 1985, será ajustado o seguinte modelo:

$$
Y=\alpha+\sum_{h=1}^{2} \delta_{h} T_{h}+\sum_{i=1}^{n} \beta_{i} Z_{i}+\sum_{h=1}^{2} \sum_{i=1}^{n} \gamma_{h i} T_{h} Z_{i}+u
$$

onde,

$T_{h}(h=1,2)$ é uma variável binária criada para captar se há diferença entre os anos na regressão. Assim, para 1975 as duas variáveis binárias são iguais a zero. Para as microrregiões homogêneas (MRH) do Brasil, no ano de 1980, a variável binária $T_{1}$ é igual a 1 e $T_{2}$ igual a zero; e para $1985 T_{2}$ assume valor 1 e $T_{1}$ será zero.

O teste a ser aplicado para verificar se há diferença significativa entre a função de produção de 1975 e as funções de produção em 1980 ou 1985 será o teste "F", considerando a hipótese de nulidade

$$
\mathrm{H}_{0}: \delta_{h}=0 \text { e } \gamma_{h i}=0 ; \quad \text { com } \quad i=1, \ldots, n
$$

e para verificar se a função de produção de 1980 é diferente da função de produção de 1985 será testada a hipótese

$$
\mathrm{H}_{0}: \delta_{1}=\delta_{2} \text { e } \gamma_{1 i}=\gamma_{2 i} ; \quad \quad \text { com } \quad i=1, \ldots, n
$$


Esta análise comparativa tem por objetivo principal verificar se houve mudança tecnológica na função de produção da agropecuária brasileira durante esses anos.

Entende-se como mudança técnológica uma mudança no conjunto das técnicas de produção que podem ser utilizadas. Não constituem mudanças tecnológicas as variações nas produtividades dos fatores de produção decorrentes de escolha entre técnicas conhecidas. Fixada a produção, este conjunto de técnicas conhecidas pode ser representado por uma isoquanta onde cada ponto corresponde uma técnica particular. Um aumento na produção decorrente do uso mais intensivo dos insumos é essencialmente uma mudança técnica. Por outro lado, a mudança tecnológica é decorrente do resultado da aplicação de novos conhecimentos científicos nas técnicas de produção, de modo que o aumento da produção seja consequência da melhoria da eficiência dos insumos, e não de seu uso mais intensivo (Binswanger, 1978, p. 18-22).

\subsection{Definição das Variáveis}

\subsubsection{Variável Dependente}

A variável dependente é o valor bruto da produção agropecuária em cada microrregião homogênea (MRH), em milhões de $\operatorname{cruzeiros}^{18}$. Essa variável é denominada de "Valor da Produção" e é indicada por VP

18 Todos os valores estão em cruzeiros de 1985 , e foram atualizados através do Índice Geral de Preços (IGP), coluna 2, disponibilidade interna. da Conjuntura Econômica da Fundação Getúlio Vargas. 


\subsubsection{Variáveis Explanatórias}

a) Mão-de-obra em equivalentes-homem (EH), isto é, a mão-de-obra medida em unidades equivalentes ao trabalho anual de um homem adulto, incluindo estimativa da mão-de-obra contratada por empreitada. Essa variável pode ser desagregada em duas: EHF, que é a mão-de-obra familiar (responsável pelo estabelecimento agropecuário e membros não-remunerados da família); e EHA, que inclui todas as demais categorias, com predominância de assalariados.

Dada a precariedade dos dados disponíveis nos Censos Agropecuários sobre emprego na agricultura brasileira, surgiram várias propostas de ajustamento por estudiosos do assunto ${ }^{19}$. No entanto, nenhuma é considerada ideal, dada a fragilidade da forma como são coletados os dados. Para esta pesquisa optou-se pela metodologia sugerida por Graziano da Silva e Kageyama (1983), utilizando-se o número médio de trabalhadores temporários ao longo do ano, e incluindo-se uma estimativa da mão-deobra contratada por empreitada.

O número de empregados temporários foi obtido através da média aritmética do pessoal ocupado nos doze meses do ano. O número de crianças foi estimado utilizando-se a proporção de crianças no total de empregados temporários (em 31 de Dezembro). Como os censos não apresentam a discriminação por idade para homens e mulheres da categoria "outra condição", estimou-se o número de crianças com base nas proporções de crianças entre parceiros-homens e parceiras-mulheres.

19 Ver Lopes (1978): Graziano da Silva (1982); Kageyama (1982); Graziano da Silva e Kageyama (1983). 
$\mathrm{Na}$ estimativa do número de equivalentes-homem correspondente à mão-de-obra contratada por empreitada, dividiu-se o total de despesas com "serviços de empreitada" pela remuneração anual de um trabalhador eventual publicada pelo Centro de Estudos Agrícolas-IBRE/FGV (Fundação Getúlio Vargas, 1985).

É usual que mulheres (e crianças) dediquem apenas parte do tempo às atividades agrícolas (produção) por empregarem parte substancial do tempo a atividades domésticas e/ou produção de subsistência. Por isto, no cálculo do número de equivalentes-homem, adotou-se os fatores de conversão da força de trabalho sugeridos por Graziano da Silva e Kageyama (1983), que são:

i) homem adulto, em qualquer situação $=1,0 \mathrm{EH}$;

ii) membros não remunerados da família do responsável pelo estabelecimento: mulher $=0,6 \mathrm{EH}$, criança, menos de 14 anos, ambos os sexos =0,4 EH;

iii) parceiros e outra condição: mulher $=0,66 \mathrm{EH}$, criança $=0,5 \mathrm{EH}$; e

iv) empregados permanentes ou temporários: mulher $=1,0 \mathrm{EH}$, criança $=0,5 \mathrm{EH}$.

b) Área com lavouras (AL), obtida através da soma das áreas com lavouras temporárias (ALT) e com lavouras permanentes (ALP), em hectares.

c) Área com pastagens (AP), que pode ser subdividida em área com pastagens plantadas (APP) e área com pastagens naturais (APN), em hectares.

d) Área com matas (AM), incluindo tanto as matas naturais como as plantadas, em hectares.

e) Capital em culturas (CC), abrangendo valor das culturas permanentes e das matas plantadas, em milhões de cruzeiros 
f) Capital em animais (CA), que corresponde ao valor dos animais de criação, de reprodução e de trabalho, em milhões de cruzeiros.

g) Valor das instalações e outras benfeitorias, máquinas, instrumentos agrícolas, veículos e outros meios de transporte, em milhões de cruzeiros. Essa variável será indicada por VI.

h) Despesa com adubos, corretivos, sementes, mudas e defensivos agrícolas, em milhões de cruzeiros. Essa variável será indicada por DA.

i) Despesas com medicamentos para animais, sal e rações, em milhões de cruzeiros (DM).

j) Despesas com aluguel de máquinas e equipamentos, transporte da produção, sacaria e outras embalagens, combustiveis, lubrificantes, energia elétrica e outras despesas, em milhões de cruzeiros (OD).

k) Escolaridade (ESC1), medida como a proporção de pessoas com pelo menos 1 ano de escolaridade no total de pessoas com 5 anos de idade ou mais na microrregião, excluidas as pessoas sem declaração ou com anos de estudo não determinados. Ressaltese que no cálculo dessa variável são consideradas tanto a população urbana como a rural, uma vez que os dados para a população rural não são publicados separadamente.

Uma vez que não foi realizado Censo Demográfico em 1975 e 1985, foi calculada a média aritmética dos valores de 1970 e 1980 como estimativa do valor da mesma variável para 1975. Para se estimar o valor dessa variável para o ano de 1985 , foi calculada a taxa aritmética anual de crescimento entre 1970 e 1980 , a qual foi utilizada para estimar, através de projeções. os valores para 1985. 
1) A proporção de pessoas com 9 ou mais anos de estudo no total de pessoas com 5 anos ou mais de idade e com anos de estudo determinados (ESC9). Essa seria uma medida da escolaridade "avançada", pois considera as pessoas que atingem o $2^{-}$grau. Para 1975 foi considerada a média aritmética dos valores de ESC9 obtidos a partir dos Censos Demográficos de 1970 e 1980. O valor dessa variável para o ano de 1985 foi obtida através de projeções utilizando-se a taxa aritmética anual de crescimento calculada a partir dos dados dos Censos Demográficos de 1970 e 1980.

m) Grau de urbanização das pessoas ocupadas (URB), definido como a porcentagem das pessoas de 10 anos ou mais de idade ocupadas que trabalharam, no ano de referência (1/9/79 a 3/8/80), em atividades que não fossem agropecuária, extração vegetal e pesca. Essa variável não foi calculada para o ano de 1985 pela inexistência de informações no Censo Demográfico de 1991 que permitam seu cálculo.

n) Preço da terra (PRT), obtido pela divisão do valor das terras pela área total dos estabelecimentos agropecuários, em milhões de cruzeiros por hectare.

o) Valor da terra (VT), em milhões de cruzeiros.

$\mathrm{Na}$ estimativa das funções de produção foram utilizados os logaritmos naturais das variáveis, exceto os casos de ESC1 e URB.

Os dados básicos para esta pesquisa constam dos Censos Agropecuários de 1975, 1980 e 1985, dos Censos Demográficos de 1970 e 1980, e de tabulações especiais do Censo Agropecuário de 1985. Em todos esses casos tratam-se de dados coletados pela Fundação Instituto Brasileiro de Geografia e Estatística (FIBGE). 
O uso de tabulações especiais do Censo Agropecuário de 1985 deve-se ao fato de o Censo Agropecuário de 1985 não apresentar de forma discriminada os valores dos bens imóveis, tais como benfeitorias e instalações, animais de trabalho, tratores e máquinas, etc.

Foram utilizados, também, dados da Fundação Getúlio Vargas (1985) sobre valor da diária paga a trabalhadores rurais e preço por hectare de terra para lavouras.

Neste estudo são consideradas 4 regiões: Nordeste, Sudeste (exclusive São Paulo), São Paulo e Sul. Isto decorre das mudanças na Divisão Político-Administrativa e Regional ocorrida durante a década de 70 e início da de $80^{20}$, e criação de um grande número de novas MRH no Norte e Centro-Oeste, que impossibilita realizar estudos comparativos com as outras regiões nesse período.

Do total das $302 \mathrm{MRH}$ que compõem as regiões Nordeste, Sudeste (exclusive SP), São Paulo e Sul, foram eliminadas $2 \mathrm{MRH}$ por apresentarem informações discrepantes.

Um dado discrepante no Censo agropecuário de 1980 diz respeito ao valor das despesas com adubos e corretivos no município de Ibiapina na MRH (62), Ibiapaba, no estado do Ceará. Conforme afirmam Hoffmann et al. (1990, p.13), essa despesa corresponde a $77,5 \%$ do total da despesa com adubos e corretivos em todo o estado do Ceará em 1980, enquanto que em 1975 essa despesa corresponde a 5,5\% do total do Estado.

${ }^{20}$ FIBGE (1994, p. 1-30). 
As tabulações especiais do Censo Agropecuário de 1985 também apresentam números discrepantes. Segundo Figueiredo (1996, p.34), em 1985 os valores de "veículos", e, "máquinas e instrumentos agrícolas" no município de Tuntum, da MRH (40), Médio Mearim, no estado do Maranhão, correspondem, respectivamente, a $91 \%$ e $88 \%$ do total do Estado. Segundo observa a Autora, 'Esses dados não condizem com o pequeno número de tais equipamentos no Município nem com os baixos níveis de produção e produtividade observados. Além disso, os valores desses itens são em Tuntum, pelo menos 20 vezes os encontrados nos municípios mais mecanizados em São Paulo". Por isso decidiu-se descartar as informações referentes às MRH Ibiapaba (62) e Médio Mearim (40). 


\section{ANÁLISE DOS RESULTADOS}

Antes de apresentar e discutir as funções de produção estimadas, objeto central deste estudo, faz-se uma análise comparativa entre as principais variáveis incluídas nas regressões, e suas respectivas evoluções durante os anos em estudo. Na Tabela 6 encontram-se os valores das médias aritméticas, e suas respectivas variações porcentuais, e das médias geométricas das variáveis nas 300 microrregiões homogêneas (MRH), para os anos de 1975, 1980 e 1985.

Com base nas médias aritméticas, pode-se observar que a área com lavouras temporárias (ALT) e a área com lavouras permanentes (ALP) cresceram 26,4 e 12,2\%, respectivamente, no período 1975/1985. Porém, no qüinqüênio 1980/1985 houve uma redução de $7,2 \%$ na área com lavouras permanentes. Assim, a área com lavouras temporárias, que em 1975 era 3,3 vezes a área com lavouras permanentes, passa a representar, em 1985, 3,7 vezes aquela área. Consequentemente, a área com lavouras temporárias passa a corresponder a $79 \%$ da área total de lavouras (AL). Observa-se, ainda, que o aumento de $23,1 \%$ na área total de lavouras deve-se, não somente, mas principalmente ao acréscimo da área das lavouras temporárias.

A área com pastagens (AP), que em 1975 correspondia a 2,9 vezes a área com lavouras, passa a representar 2,3 vezes em 1985. Isto se deve tão somente ao aumento da 


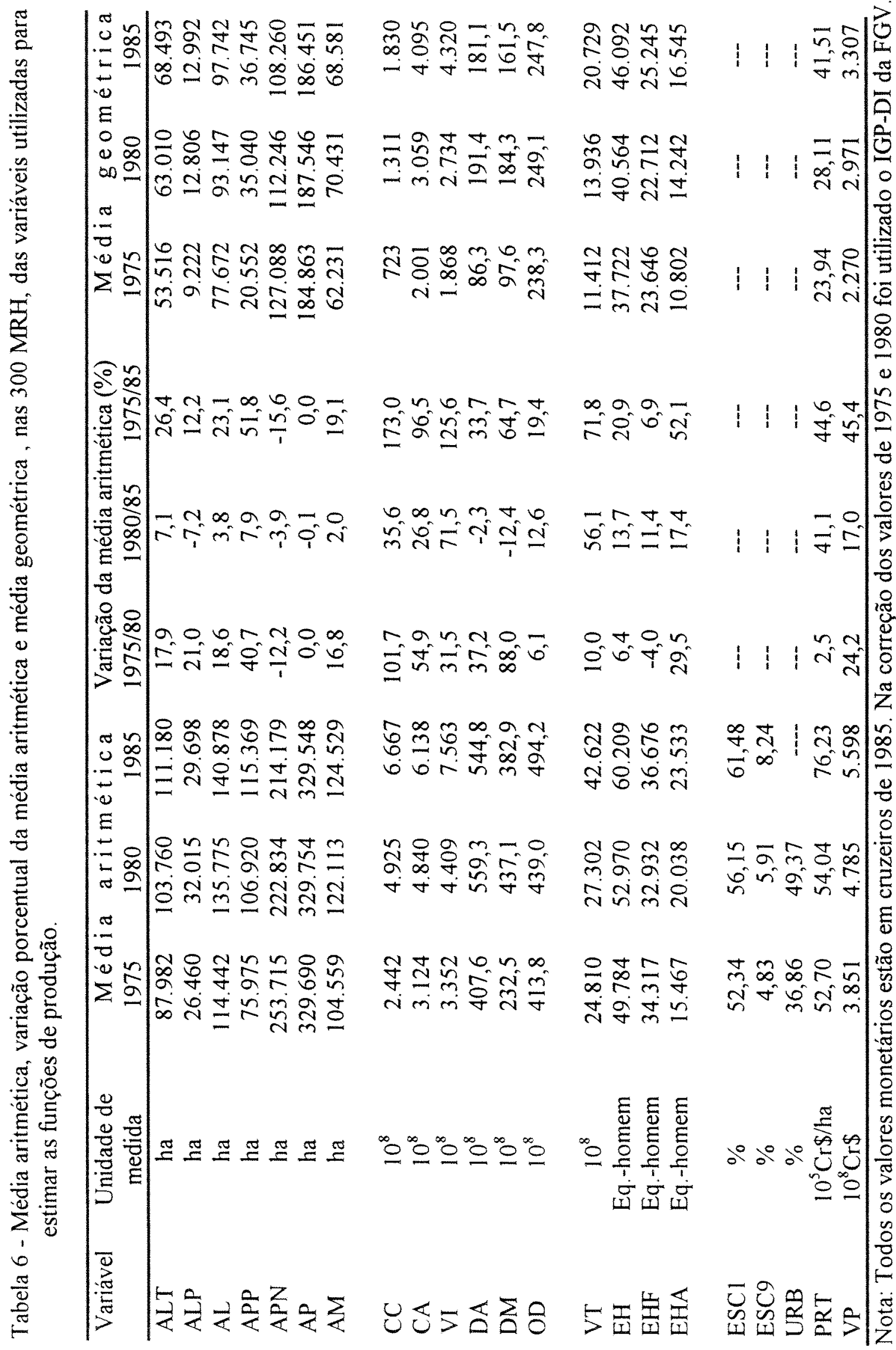


área de lavouras, uma vez que a variação da área média com pastagens, no período 1975/85, foi nula. A relação APN/APP é decrescente, passando de 3,3 em 1975 para 2,1 em 1980, e atingindo 1,8 em 1985. Isto deve-se, por um lado, ao acréscimo na área com pastagens plantadas $(52 \%)$ e, por outro lado, ao decréscimo da área com pastagens naturais, que foi de 15,6\%. Como se observa, apesar desta constatação, entre as pastagens ainda predominam as naturais, representando, em 1985, 65\% da área total de pastagens. A área com matas é apenas um pouco maior do que a área com pastagens plantadas.

Nota-se, ainda na Tabela 6, que em 1975 e 1980 os valores médios dos três componentes do capital fixo $(\mathrm{CC}, \mathrm{CA} \text { e VI })^{21}$ são semelhantes, o que não se observa no ano de 1985. Neste ano, VI é $17 \%$ superior ao valor de CC, e $27 \%$ superior ao de CA. Em média, os valores médios dos componentes do capital circulante (DA, DM e OD) ${ }^{21}$ correspondiam a $12 \%$ do valor médio do capital fixo em 1975 , a $10 \%$ em 1980 , e a $6,9 \%$ em 1985. Este decréscimo deve-se, principalmente, ao aumento do valor dos componentes do capital fixo, que foi quase sempre superior a $100 \%$, enquanto que o valor médio do capital circulante apresentou um acréscimo sempre inferior a $65 \%$, destacando-se o componente "outras despesas" (OD), o qual sofreu um acréscimo de apenas $19,4 \%$ entre 1975 e 1985 . Por outro lado, os aumentos do valor do capital em culturas (CC) e do valor dos investimentos em instalações e outras benfeitorias, instrumentos agrícolas, veículos e outros meios de transporte (VI) foram de 173,0 e $125,6 \%$, respectivamente, no mesmo período. O número de equivalentes-homem cresceu

\footnotetext{
${ }^{21}$ Ver definições a partir da página 49.
} 
$20,9 \%$, sendo que a força de trabalho fornecida pela categoria "Responsável e membros não remunerados da familia" (EHF) aumentou $6,9 \%$, enquanto que a força de trabalho correspondente às demais categorias, com predominância de assalariados (EHA), cresceu $52,1 \%$.

Vale destacar a redução de $4,0 \%$ na disponibilidade da força de trabalho familiar entre os anos de 1975 e 1980, enquanto que, paralelamente, houve um acréscimo de $29,5 \%$ da força de trabalho assalariada. Porém, ambas as categorias obtiveram, individualmente, no qüinqüênio subsequente, um aumento absoluto de mais de 3.400 equivalentes-homem. Note-se entretanto que, em 1985 as famílias dos responsáveis pelos estabelecimentos ainda são a principal fonte da força de trabalho disponivel, correspondendo a quase $61 \%$ do total de equivalentes-homem dos estabelecimentos.

Segundo o Censo Demográfico de 1980, $65 \%$ das pessoas com 5 anos ou mais de idade tinham pelo menos 1 ano de escolaridade. No entanto, o valor médio da proporção de pessoas com pelo menos 1 ano de escolaridade no total de pessoas com 5 anos de idade ou mais (ESC1) para as 300 microrregiões homogêneas (MRH) é 56,15\%. Esta diferença ocorre porque no cálculo dessa média o valor de ESC1 não foi ponderado pela correspondente população, e as MRH com maior população tendem a apresentar maior nivel de escolaridade. Fenômeno semelhante ocorre com a proporção de pessoas de 10 anos ou mais que trabalharam em atividades que não fossem agropecuária, extração vegetal e pesca (URB). No Censo Demográfico de 1980, para o Brasil essa proporção era $70 \%$. Entretanto, a média observada da variável URB nas $300 \mathrm{MRH}$ foi de apenas 
$49,37 \%$. Isto também se dá pelo fato de a média não ser ponderada, e as MRH mais urbanizadas tendem a ser, em geral, as mais populosas.

Observa-se, ainda, na Tabela 6, que houve um aumento no nivel de escolaridade das pessoas nas 300 microrregiões homogêneas. Em 1975, a proporção das pessoas com 5 ou mais anos de idade e com pelo menos 1 ano de escolaridade (ESC1) era 52,34\%, e em 1985 alcançou $61,48 \%$. O maior avanço, porém, ocorreu na categoria das pessoas com 9 ou mais anos de estudo (ESC9). Em 1975 esta categoria representava 4,83\% do total das pessoas com 5 ou mais anos de idade e com anos de estudo determinados, e em 1985 este contingente correspondia a $8,24 \%$ daquele total. Isto significa que mais pessoas conseguiram atingir o $2^{\underline{o}}$ grau. Finalmente, um outro dado a considerar nesta Tabela é o crescimento de $44,6 \%$ no preço real da terra (PRT) durante o período $1975 / 85$

No ajustamento das funções de produção utilizou-se, geralmente, os logaritmos neperianos das variáveis, excluindo-se ESC1 e URB, por tratar-se de variáveis que são proporção, cujos valores estão compreendidos entre 0 e 1 . Na apresentação dos resultados, ao se tratar do logaritmo, coloca-se um L no início do símbolo da variável. Então, LAL indica o logaritmo da área de lavoura e LEH indica o logaritmo do número de equivalentes-homem.

As Tabelas 7,8 e 9 contêm os coeficientes de correlação simples entre as variáveis utilizadas nesta pesquisa, para 1985, 1980 e 1975, respectivamente. Nestas Tabelas temos na última coluna (ou na última linha) as correlações entre LVP (logaritmo do valor da produção) e o logaritmo dos vários fatores de produção. Assim, observa-se 
Tabela 7 - Matriz das correlações simples entre as variáveis em 1985.

\begin{tabular}{lrrrrrrrrr}
\hline Var. & LAL & LAPP & LAPN & LAP & LAM & LCC & LCA & LVI & LDA \\
\hline LAL & $\mathbf{1 , 0 0 0}$ & 0,437 & 0,291 & 0,471 & 0,358 & 0,401 & 0,629 & 0,733 & 0,591 \\
LAPP & 0,437 & $\mathbf{1 , 0 0 0}$ & 0,338 & 0,728 & 0,319 & 0,350 & 0,724 & 0,570 & 0,486 \\
LAPN & 0,291 & 0,338 & $\mathbf{1 , 0 0 0}$ & 0,836 & 0,629 & 0,034 & 0,581 & 0,316 & 0,008 \\
LAP & 0,471 & 0,728 & 0,836 & $\mathbf{1 , 0 0 0}$ & 0,574 & 0,207 & 0,823 & 0,542 & 0,250 \\
LAM & 0,358 & 0,319 & 0,629 & 0,574 & $\mathbf{1 , 0 0 0}$ & 0,051 & 0,360 & 0,235 & $-0,014$ \\
LCC & 0,401 & 0,350 & 0,034 & 0,207 & 0,051 & $\mathbf{1 , 0 0 0}$ & 0,431 & 0,604 & 0,726 \\
LCA & 0,629 & 0,724 & 0,581 & 0,823 & 0,360 & 0,431 & $\mathbf{1 , 0 0 0}$ & 0,789 & 0,535 \\
LVI & 0,733 & 0,570 & 0,316 & 0,542 & 0,235 & 0,604 & 0,789 & $\mathbf{1 , 0 0 0}$ & 0,815 \\
LDA & 0,591 & 0,486 & 0,008 & 0,250 & $-0,014$ & 0,726 & 0,535 & 0,815 & $\mathbf{1 , 0 0 0}$ \\
LDM & 0,483 & 0,378 & 0,188 & 0,341 & 0,050 & 0,592 & 0,672 & 0,784 & 0,713 \\
LOD & 0,669 & 0,550 & 0,108 & 0,354 & 0,081 & 0,683 & 0,641 & 0,860 & 0,919 \\
LVT & 0,587 & 0,606 & 0,190 & 0,459 & 0,035 & 0,714 & 0,742 & 0,876 & 0,887 \\
LEH & 0,741 & 0,418 & 0,404 & 0,517 & 0,451 & 0,142 & 0,614 & 0,454 & 0,226 \\
LEHA & 0,669 & 0,476 & 0,384 & 0,556 & 0,321 & 0,323 & 0,627 & 0,497 & 0,335 \\
LEHF & 0,549 & 0,265 & 0,371 & 0,404 & 0,470 & $-0,067$ & 0,450 & 0,249 & 0,007 \\
ESC1 & 0,075 & 0,067 & $-0,167$ & $-0,083$ & $-0,211$ & 0,506 & 0,159 & 0,444 & 0,613 \\
LPRT & 0,146 & 0,182 & $-0,334$ & $-0,141$ & $-0,508$ & 0,615 & 0,258 & 0,518 & 0,738 \\
LVP & 0,738 & 0,504 & 0,136 & 0,371 & 0,090 & 0,709 & 0,714 & 0,883 & 0,888 \\
\hline
\end{tabular}

Tabela 7 (continuação).

\begin{tabular}{lrrrrrrrrr}
\hline Var. & LDM & LOD & LVT & LEH & LEHA & LEHF & ESC1 & LPRT & LVP \\
\hline LAL & 0,483 & 0,669 & 0,587 & 0,741 & 0,669 & 0,549 & 0,075 & 0,146 & 0,738 \\
LAPP & 0,378 & 0,550 & 0,606 & 0,418 & 0,476 & 0,265 & 0,067 & 0,182 & 0,504 \\
LAPN & 0,188 & 0,108 & 0,190 & 0,404 & 0,384 & 0,371 & $-0,168$ & $-0,334$ & 0,136 \\
LAP & 0,341 & 0,354 & 0,459 & 0,517 & 0,556 & 0,404 & $-0,083$ & $-0,141$ & 0,371 \\
LAM & 0,050 & 0,081 & 0,035 & 0,451 & 0,321 & 0,470 & $-0,211$ & $-0,508$ & 0,090 \\
LCC & 0,592 & 0,683 & 0,714 & 0,142 & 0,323 & $-0,067$ & 0,506 & 0,615 & 0,709 \\
LCA & 0,672 & 0,641 & 0,742 & 0,614 & 0,627 & 0,450 & 0,159 & 0,258 & 0,714 \\
LVI & 0,784 & 0,860 & 0,876 & 0,454 & 0,497 & 0,249 & 0,444 & 0,518 & 0,883 \\
LDA & 0,713 & 0,919 & 0,887 & 0,226 & 0,335 & 0,007 & 0,613 & 0,738 & 0,888 \\
LDM & $\mathbf{1 , 0 0 0}$ & 0,754 & 0,803 & 0,288 & 0,329 & 0,131 & 0,622 & 0,636 & 0,826 \\
LOD & 0,754 & $\mathbf{1 , 0 0 0}$ & 0,893 & 0,350 & 0,487 & 0,081 & 0,549 & 0,655 & 0,922 \\
LVT & 0,803 & 0,893 & $\mathbf{1 , 0 0 0}$ & 0,299 & 0,462 & 0,044 & 0,576 & 0,767 & 0,912 \\
LEH & 0,288 & 0,350 & 0,299 & $\mathbf{1 , 0 0 0}$ & 0,790 & 0,892 & $-0,302$ & $-0,160$ & 0,496 \\
LEHA & 0,329 & 0,487 & 0,462 & 0,790 & $\mathbf{1 , 0 0 0}$ & 0,464 & $-0,222$ & 0,043 & 0,558 \\
LEHF & 0,131 & 0,081 & 0,044 & 0,892 & 0,464 & $\mathbf{1 , 0 0 0}$ & $-0,355$ & $-0,345$ & 0,246 \\
ESC1 & 0,622 & 0,549 & 0,576 & $-0,302$ & $-0,222$ & $-0,355$ & $\mathbf{1 , 0 0 0}$ & 0,708 & 0,505 \\
LPRT & 0,636 & 0,655 & 0,767 & $-0,160$ & 0,043 & $-0,345$ & 0,708 & $\mathbf{1 , 0 0 0}$ & 0,659 \\
LVP & 0,826 & 0,922 & 0,912 & 0,496 & 0,558 & 0,246 & 0,505 & 0,659 & $\mathbf{1 , 0 0 0}$ \\
\hline
\end{tabular}


Tabela 8 - Matriz das correlações simples entre as variáveis em 1980.

\begin{tabular}{lrrrrrrrrr}
\hline Var. & LAL & LAPP & LAPN & LAP & LAM & LCC & LCA & LVI & LDA \\
\hline LAL & $\mathbf{1 , 0 0 0}$ & 0,382 & 0,319 & 0,449 & 0,393 & 0,364 & 0,601 & 0,723 & 0,557 \\
LAPP & 0,382 & $\mathbf{1 , 0 0 0}$ & 0,351 & 0,719 & 0,268 & 0,291 & 0,726 & 0,568 & 0,453 \\
LAPN & 0,319 & 0,351 & $\mathbf{1 , 0 0 0}$ & 0,854 & 0,626 & 0,064 & 0,584 & 0,352 & 0,044 \\
LAP & 0,449 & 0,719 & 0,854 & $\mathbf{1 , 0 0 0}$ & 0,550 & 0,203 & 0,810 & 0,553 & 0,244 \\
LAM & 0,393 & 0,268 & 0,626 & 0,550 & $\mathbf{1 , 0 0 0}$ & 0,038 & 0,313 & 0,249 & $-0,048$ \\
LCC & 0,364 & 0,291 & 0,064 & 0,203 & 0,038 & $\mathbf{1 , 0 0 0}$ & 0,418 & 0,569 & 0,663 \\
LCA & 0,601 & 0,726 & 0,584 & 0,810 & 0,313 & 0,418 & $\mathbf{1 , 0 0 0}$ & 0,805 & 0,568 \\
LVI & 0,723 & 0,568 & 0,352 & 0,553 & 0,249 & 0,569 & 0,805 & $\mathbf{1 , 0 0 0}$ & 0,793 \\
LDA & 0,557 & 0,453 & 0,044 & 0,244 & $-0,048$ & 0,663 & 0,568 & 0,793 & $\mathbf{1 , 0 0 0}$ \\
LDM & 0,450 & 0,256 & 0,188 & 0,275 & 0,010 & 0,523 & 0,649 & 0,736 & 0,646 \\
LOD & 0,631 & 0,524 & 0,180 & 0,373 & 0,096 & 0,659 & 0,689 & 0,848 & 0,895 \\
LVT & 0,535 & 0,572 & 0,140 & 0,390 & $-0,028$ & 0,678 & 0,750 & 0,850 & 0,873 \\
LEH & 0,752 & 0,461 & 0,391 & 0,509 & 0,456 & 0,151 & 0,610 & 0,504 & 0,290 \\
LEHA & 0,662 & 0,477 & 0,414 & 0,563 & 0,347 & 0,314 & 0,597 & 0,491 & 0,336 \\
LEHF & 0,592 & 0,332 & 0,325 & 0,390 & 0,454 & $-0,030$ & 0,466 & 0,338 & 0,110 \\
ESC1 & 0,045 & 0,023 & $-0,143$ & $-0,098$ & $-0,271$ & 0,490 & 0,243 & 0,427 & 0,619 \\
LPRT & 0,074 & 0,127 & $-0,407$ & $-0,228$ & $-0,559$ & 0,539 & 0,239 & 0,435 & 0,677 \\
LVP & 0,691 & 0,504 & 0,177 & 0,375 & 0,076 & 0,631 & 0,763 & 0,864 & 0,869 \\
\hline
\end{tabular}

Tabela 8 (continuação).

\begin{tabular}{lrrrrrrrrr}
\hline Var. & LDM & LOD & LVT & LEH & LEHA & LEHF & ESC1 & LPRT & LVP \\
\hline LAL & 0,450 & 0,631 & 0,535 & 0,752 & 0,662 & 0,592 & 0,045 & 0,074 & 0,691 \\
LAPP & 0,256 & 0,524 & 0,572 & 0,461 & 0,477 & 0,332 & 0,023 & 0,127 & 0,504 \\
LAPN & 0,188 & 0,180 & 0,140 & 0,391 & 0,414 & 0,325 & $-0,143$ & $-0,407$ & 0,177 \\
LAP & 0,275 & 0,373 & 0,390 & 0,509 & 0,563 & 0,390 & $-0,098$ & $-0,228$ & 0,375 \\
LAM & 0,010 & 0,096 & $-0,028$ & 0,456 & 0,347 & 0,454 & $-0,271$ & $-0,559$ & 0,076 \\
LCC & 0,523 & 0,659 & 0,678 & 0,151 & 0,314 & $-0,030$ & 0,490 & 0,539 & 0,631 \\
LCA & 0,649 & 0,689 & 0,750 & 0,610 & 0,597 & 0,466 & 0,243 & 0,239 & 0,763 \\
LVI & 0,736 & 0,848 & 0,850 & 0,504 & 0,491 & 0,338 & 0,427 & 0,435 & 0,864 \\
LDA & 0,646 & 0,895 & 0,873 & 0,290 & 0,336 & 0,110 & 0,619 & 0,677 & 0,869 \\
LDM & $\mathbf{1 , 0 0 0}$ & 0,713 & 0,762 & 0,293 & 0,293 & 0,170 & 0,614 & 0,596 & 0,782 \\
LOD & 0,713 & $\mathbf{1 , 0 0 0}$ & 0,892 & 0,416 & 0,503 & 0,186 & 0,523 & 0,597 & 0,911 \\
LVT & 0,762 & 0,892 & $\mathbf{1 , 0 0 0}$ & 0,311 & 0,395 & 0,118 & 0,624 & 0,759 & 0,912 \\
LEH & 0,293 & 0,416 & 0,311 & $\mathbf{1 , 0 0 0}$ & 0,774 & 0,903 & $-0,263$ & $-0,160$ & 0,542 \\
LEHA & 0,293 & 0,503 & 0,395 & 0,774 & $\mathbf{1 , 0 0 0}$ & 0,463 & $-0,232$ & $-0,046$ & 0,529 \\
LEHF & 0,170 & 0,186 & 0,118 & 0,903 & 0,463 & $\mathbf{1 , 0 0 0}$ & $-0,299$ & $-0,274$ & 0,349 \\
ESC1 & 0,614 & 0,523 & 0,624 & $-0,263$ & $-0,232$ & $-0,299$ & $\mathbf{1 , 0 0 0}$ & 0,735 & 0,530 \\
LPRT & 0,596 & 0,597 & 0,759 & $-0,160$ & $-0,046$ & $-0,274$ & 0,735 & $\mathbf{1 , 0 0 0}$ & 0,611 \\
LVP & 0,782 & 0,911 & 0,912 & 0,542 & 0,529 & 0,349 & 0,530 & 0,611 & $\mathbf{1 , 0 0 0}$ \\
\hline
\end{tabular}


Tabela 9 - Matriz das correlações simples entre as variáveis em 1975.

\begin{tabular}{lrrrrrrrrr}
\hline Var. & LAL & LAPP & LAPN & LAP & LAM & LCC & LCA & LVI & LDA \\
\hline LAL & $\mathbf{1 , 0 0 0}$ & 0,388 & 0,271 & 0,391 & 0,310 & 0,435 & 0,575 & 0,674 & 0,559 \\
LAPP & 0,388 & $\mathbf{1 , 0 0 0}$ & 0,279 & 0,609 & 0,217 & 0,262 & 0,641 & 0,560 & 0,408 \\
LAPN & 0,271 & 0,279 & $\mathbf{1 , 0 0 0}$ & 0,888 & 0,514 & 0,057 & 0,621 & 0,357 & 0,041 \\
LAP & 0,391 & 0,609 & 0,888 & $\mathbf{1 , 0 0 0}$ & 0,470 & 0,167 & 0,790 & 0,527 & 0,186 \\
LAM & 0,310 & 0,217 & 0,514 & 0,470 & $\mathbf{1 , 0 0 0}$ & $-0,028$ & 0,258 & 0,172 & $-0,103$ \\
LCC & 0,435 & 0,262 & 0,057 & 0,167 & $-0,028$ & $\mathbf{1 , 0 0 0}$ & 0,411 & 0,571 & 0,709 \\
LCA & 0,575 & 0,641 & 0,621 & 0,790 & 0,258 & 0,411 & $\mathbf{1 , 0 0 0}$ & 0,792 & 0,523 \\
LVI & 0,674 & 0,560 & 0,357 & 0,527 & 0,172 & 0,571 & 0,792 & $\mathbf{1 , 0 0 0}$ & 0,768 \\
LDA & 0,559 & 0,408 & 0,041 & 0,186 & $-0,103$ & 0,709 & 0,523 & 0,768 & $\mathbf{1 , 0 0 0}$ \\
LDM & 0,463 & 0,327 & 0,288 & 0,373 & 0,026 & 0,652 & 0,737 & 0,775 & 0,719 \\
LOD & 0,710 & 0,499 & 0,170 & 0,331 & 0,042 & 0,674 & 0,697 & 0,837 & 0,891 \\
LVT & 0,522 & 0,532 & 0,243 & 0,407 & $-0,028$ & 0,693 & 0,744 & 0,861 & 0,860 \\
LEH & 0,746 & 0,396 & 0,342 & 0,442 & 0,387 & 0,099 & 0,581 & 0,422 & 0,206 \\
LEHA & 0,651 & 0,410 & 0,445 & 0,572 & 0,291 & 0,303 & 0,607 & 0,448 & 0,264 \\
LEHF & 0,605 & 0,293 & 0,254 & 0,317 & 0,378 & $-0,057$ & 0,435 & 0,278 & 0,070 \\
ESC1 & 0,118 & 0,044 & $-0,091$ & $-0,072$ & $-0,249$ & 0,562 & 0,249 & 0,469 & 0,697 \\
LPRT & 0,169 & 0,205 & $-0,233$ & $-0,119$ & $-0,458$ & 0,620 & 0,329 & 0,555 & 0,762 \\
LVP & 0,745 & 0,497 & 0,222 & 0,395 & 0,070 & 0,666 & 0,774 & 0,868 & 0,851 \\
\hline
\end{tabular}

Tabela 9 (continuação).

\begin{tabular}{lrrrrrrrrr}
\hline Var. & LDM & LOD & LVT & LEH & LEHA & LEHF & ESC1 & LPRT & LVP \\
\hline LAL & 0,463 & 0,710 & 0,522 & 0,746 & 0,651 & 0,605 & 0,118 & 0,169 & 0,745 \\
LAPP & 0,327 & 0,499 & 0,532 & 0,396 & 0,410 & 0,293 & 0,044 & 0,205 & 0,497 \\
LAPN & 0,288 & 0,170 & 0,243 & 0,342 & 0,445 & 0,254 & $-0,091$ & $-0,233$ & 0,222 \\
LAP & 0,373 & 0,331 & 0,407 & 0,442 & 0,572 & 0,317 & $-0,072$ & $-0,119$ & 0,395 \\
LAM & 0,026 & 0,042 & $-0,028$ & 0,387 & 0,291 & 0,378 & $-0,249$ & $-0,458$ & 0,070 \\
LCC & 0,652 & 0,674 & 0,693 & 0,099 & 0,303 & $-0,057$ & 0,562 & 0,620 & 0,666 \\
LCA & 0,737 & 0,697 & 0,744 & 0,581 & 0,607 & 0,435 & 0,249 & 0,329 & 0,774 \\
LVI & 0,775 & 0,837 & 0,861 & 0,422 & 0,448 & 0,278 & 0,469 & 0,555 & 0,868 \\
LDA & 0,719 & 0,891 & 0,860 & 0,206 & 0,264 & 0,070 & 0,697 & 0,762 & 0,851 \\
LDM & $\mathbf{1 , 0 0 0}$ & 0,782 & 0,829 & 0,280 & 0,361 & 0,134 & 0,631 & 0,654 & 0,816 \\
LOD & 0,782 & $\mathbf{1 , 0 0 0}$ & 0,885 & 0,468 & 0,475 & 0,305 & 0,564 & 0,670 & 0,955 \\
LVT & 0,829 & 0,885 & $\mathbf{1 , 0 0 0}$ & 0,246 & 0,376 & 0,079 & 0,647 & 0,820 & 0,893 \\
LEH & 0,280 & 0,468 & 0,246 & $\mathbf{1 , 0 0 0}$ & 0,706 & 0,932 & $-0,235$ & $-0,130$ & 0,528 \\
LEHA & 0,361 & 0,475 & 0,376 & 0,706 & $\mathbf{1 , 0 0 0}$ & 0,438 & $-0,201$ & $-0,003$ & 0,543 \\
LEHF & 0,134 & 0,305 & 0,079 & 0,932 & 0,438 & $\mathbf{1 , 0 0 0}$ & $-0,270$ & $-0,233$ & 0,358 \\
ESC1 & 0,631 & 0,564 & 0,647 & $-0,235$ & $-0,201$ & $-0,270$ & $\mathbf{1 , 0 0 0}$ & 0,743 & 0,536 \\
LPRT & 0,654 & 0,670 & 0,820 & $-0,130$ & $-0,003$ & $-0,233$ & 0,743 & $\mathbf{1 , 0 0 0}$ & 0,642 \\
LVP & 0,816 & 0,955 & 0,893 & 0,528 & 0,543 & 0,358 & 0,536 & 0,642 & $\mathbf{1 , 0 0 0}$ \\
\hline
\end{tabular}


que, nos três anos em análise, as variáveis mais correlacionadas com LVP são LOD (logaritmo das despesas com aluguel de máquinas e equipamentos, transporte da produção, sacaria e outras embalagens, combustiveis, lubrificantes, energia elétrica e outra despesas), LVT (logaritmo do valor da terra), LDA (logaritmo das despesas com adubos, corretivos, sementes, mudas e defensivos agrícolas) e LVI (logaritmo do capital em instalações e outras benfeitorias, máquinas, instrumentos agrários, veículos e outros meios de transporte). Isto mostra uma forte correlação entre o valor da produção e o uso de insumos modernos. De certa forma pode-se inferir que, nestas condições, para se elevar o valor da produção agropecuária não se pode prescindir de investimentos que levem ao uso intensivo desses insumos, principalmente no que se refere àqueles que compõem a variável LOD, pois esta apresentou coeficiente de correlação com LVP sempre superior a 0,9 .

A variável com correlação mais baixa com LVP é LAM (logaritmo da área de matas), o que já era esperado; vem em seguida LAPN (logaritmo da área com pastagens naturais) e LEHF (logaritmo da mão-de-obra familiar). A baixa correlação de LEH (logaritmo do número de equivalentes-homem) com LVP decorre da grande variação da produtividade do trabalho nas microrregiões homogêneas (MRH) ${ }^{22}$.

O valor muito baixo da correlação entre LEHF e LVP é decorrente, além da diversidade da produtividade do trabalho, da dificuldade de se determinar corretamente o número de horas efetivamente trabalhadas pelos membros da familia do proprietário do

\footnotetext{
${ }^{22}$ Hoffmann et al. (1988, p.65-76) apresentam a produtividade do trabalho em 332 MRH para 1975 e 1980. Em 1980, a produtividade do trabalho, medida pela relação entre o valor agregado da produção e o número de equivalentes-homem, varia de Cr\$4,53 por EH (na MRH “ Alto Parnaíba Piauiense" - $\mathrm{PI}$ ), a Cr\$208.27 por EH (na MRH “Grande São Paulo" -SP). As MRH do Nordeste são as que apresentam, sistematicamente, as menores produtividades.
} 
estabelecimento, e da falta de controle no uso desta força de trabalho. Note-se que a correlação entre a mão-de-obra não-familiar (LEHA) e LVP é mais de 1,5 vez superior à observada entre LEHF e LVP.

Como APN (área com pastagens naturais) representa, em 1985, 65\% do total de AP (área com pastagens), não causa surpresa a alta correlação entre APN e AP $(0,836$ em 1985; 0,854 em 1980 e 0,888 em 1975).

Constata-se, ainda, nas referidas Tabelas, altas correlações entre LCA (logaritmo do valor do capital em animais) e LAPP (logaritmo da área com pastagens plantadas), e, principalmente, com LAP.

Como entre as atividades agropecuárias as lavouras são, em geral, as que mais empregam mão-de-obra, é de se esperar que LEH e LAL (área com lavouras) estejam altamente correlacionadas (com $\mathbf{r}$ sempre superior a 0,7 ).

Finalmente, pode-se observar que LVT (logaritmo do valor da terra) está fortemente correlacionado com LVI (logaritmo do valor das instalações, benfeitorias, máquinas, instrumentos agrários, veículos e outros meios de transporte), LOD (logaritmo das despesas com máquinas, equipamentos, combustiveis, lubrificante, energia elétrica e outras despesas), LDM (logaritmo das despesas com medicamentos para animais, sal e rações) e LDA. Este fato também era esperado, uma vez que o valor da terra é influenciado também pelos investimentos em infra-estrutura (capital fundiário) $)^{23}$ e pelo valor do "capital de exploração"23.

\footnotetext{
23 Ver definições em Hoffmann et al. (1978, p.6).
} 


\subsection{A Função de Produção Cobb-Douglas em 1985}

\subsubsection{A Função de Produção para as $300 \mathrm{MRH}$}

Ao estimar uma função de produção agregada, o pesquisador, uma vez tendo definido a forma da função de produção a ser empregada, enfrenta um outro problema que é a escolha das variáveis a serem utilizadas no modelo. O procedimento usual consiste em se ajustar vários modelos, na tentativa de se obter um que apresente de forma mais realista possivel as relações existentes entre as variáveis explanatórias e a variável dependente.

A escolha do modelo mais "representativo" - aquele que expresse satisfatoriamente a lógica do processo produtivo - é definida, em geral, segundo critérios puramente econométricos, tais como: o grau de ajustamento da função (coeficiente de determinação múltipla relativamente alto $-\mathrm{R}^{2}$ ), a significância da regressão (através do teste 'F" de Snedecor) e a significância das estimativas dos parâmetros da regressão (através do teste " " " de Student). Porém, além destes critérios, deve-se observar a coerência dos sinais dos coeficientes de regressão com os princípios econômicos e a importância das variáveis no processo produtivo. Com base, principalmente, neste último critério, algumas variáveis foram mantidas nos modelos selecionados, mesmo não tendo atendido a todos os critérios econométricos mencionados.

As Tabelas 10 a 12 mostram as equações estimadas para as 300 microrregiões homogêneas (MRH) consideradas nesta pesquisa para 1985. Com base nos coeficientes 
de determinação, pode-se observar que os ajustamentos foram muito bons, com $\mathrm{R}^{2}$ superiores a $95 \%$.

A Tabela 10 mostra duas equações estimadas. Na equação 1 , onde as variáveis selecionadas foram utilizadas na forma mais agregada, nota-se que a maioria das estimativas dos parâmetros é significativa ao nível de significância de $5 \%$. Isto mostra a importância das variáveis correspondentes na determinação do valor da produção

Tabela 10 - Equações de regressão para as $300 \mathrm{MRH}$, com 12 ou 13 variáveis explanatórias, em 1985.

\begin{tabular}{|c|c|c|c|c|}
\hline \multirow[b]{2}{*}{ Variável } & \multicolumn{2}{|c|}{ Equação 1} & \multicolumn{2}{|c|}{ Equação 2} \\
\hline & Coeficiente & Teste $\mathrm{t}$ & Coeficiente & Teste $\mathrm{t}$ \\
\hline Intercepto & $-0,2051$ & $-2,25^{*}$ & $-1,4055$ & $-2,67^{*}$ \\
\hline LAL & 0,1574 & $4,95^{*}$ & 0,1383 & $4,29 *$ \\
\hline LAP & $-0,0670$ & $-2,36^{*}$ & $-\cdots$ &.-- \\
\hline LAPP & --- & ---- & $-0,0419$ & $-3,26^{*}$ \\
\hline LAPN & --- & --. & $-0,0328$ & $-1,87$ \\
\hline LAM & 0,0241 & 1,22 & 0,0327 & 1,63 \\
\hline LCC & 0,0474 & $4,11^{*}$ & 0,0448 & $3,91 *$ \\
\hline LCA & 0,1046 & $2,32^{*}$ & 0,1122 & $2,89 *$ \\
\hline LVI & 0,0381 & 1,18 & 0,0281 & 0,87 \\
\hline LDA & 0,0938 & $3,98^{*}$ & 0,1032 & $4,36^{*}$ \\
\hline LDM & 0,1172 & $5,81^{*}$ & 0,1102 & $5,42 *$ \\
\hline LOD & 0,1957 & $6,26^{*}$ & 0,2141 & $6,78^{*}$ \\
\hline LEH & 0,3119 & $9,00^{*}$ & 0,3194 & 9,51 * \\
\hline LPRT & 0,1789 & $5,63^{*}$ & 0,1895 & $6,17^{*}$ \\
\hline $\mathrm{ESCl}$ & 0,1893 & 1,55 & 0,1473 & 1,21 \\
\hline$\overline{\mathrm{R}^{2}}$ & \multicolumn{2}{|c|}{0,9606} & \multicolumn{2}{|c|}{0,9614} \\
\hline $\mathrm{F}$ & \multicolumn{2}{|c|}{$583,46^{*}$} & \multicolumn{2}{|c|}{$548,44^{*}$} \\
\hline$\varepsilon$ & \multicolumn{2}{|c|}{1,0233} & \multicolumn{2}{|c|}{1,0284} \\
\hline $\mathrm{F}(\varepsilon=1)$ & \multicolumn{2}{|c|}{1,68} & \multicolumn{2}{|c|}{2,42} \\
\hline
\end{tabular}

$\left({ }^{*}\right)$ - significativo ao nível de $5 \%$ de significância. 
agropecuária das microrregiões. Deve-se mencionar aqui que, tendo em vista que esta regressão tem 287 graus de liberdade no resíduo, basta que o valor absoluto de “价 seja pelo menos igual a 2 para que o coeficiente estimado seja significativo ao nível de $5 \%$ de significância.

Um fato inesperado é o coeficiente negativo e estatisticamente significativo para a variável LAP (logaritmo da área de pastagens). Este coeficiente não pode ser aceito como uma estimativa da elasticidade de produção da área de pastagens, pois é inadmissível que um aumento da área de pastagens, mantidos constantes os demais fatores de produção, provoque uma redução do valor da produção.

Uma explicação razoável para este coeficiente negativo é admitir que isto ocorreu, em parte, pela não inclusão na regressão de variáveis importantes, tais como: qualidades edafo-climáticas do solo de cada $\mathrm{MRH}$, proximidade das MRH aos mercados de insumos e produtos, existência e qualidade de vias de acesso a estes mercados, proximidade de agroindústrias, existência de assistência técnica, etc., as quais constituem um conjunto de variáveis não-disponiveis. A ausência destas variáveis faz com que as estimativas dos coeficientes sejam viesadas.

Como, em geral, à medida que as MRH se situam mais afastadas desses mercados tendem a possuir maior área de pastagens, é possível que a relação entre aquelas variáveis não incluidas na equação de regressão e a variável LAP determine o valor negativo da estimativa do respectivo coeficiente.

Ainda com relação à equação 1 , nota-se que os coeficientes das variáveis LAM, LVI e ESC1 não são significativos, porém são positivos, isto é, têm o sinal esperado. O 
valor do coeficiente de determinação mostra que $96 \%$ da soma de quadrados total de LVP das 300 MRH é "explicada" pelas variáveis incluídas nesta equação.

No ajuste da equação 2 manteve-se as variáveis incluídas na equação 1 e desagregou-se a área com pastagens (AP) em área com pastagens plantadas (APP) e área com pastagens naturais $(\mathrm{APN})^{24}$. Nota-se que todos os parâmetros mantiveram-se significativos e bastante semelhantes, em valor absoluto, aos obtidos com a equação 1.0 coeficiente relativo à variável APP é negativo e significativo, certamente pelas mesmas razões descritas para AP.

Os coeficientes da regressão 2 , isto é, as elasticidades parciais de produção estimadas, demonstram que, exceto APP e APN, todos os demais fatores produtivos estão sendo utilizados, segundo a teoria neoclássica da produção, no estágio racional de produção, onde as elasticidades parciais de produção assumem valores compreendidos entre 0 e 1 .

Tendo como referência os valores contidos na Tabela 10 pode-se inferir que, entre os fatores produtivos considerados, a força de trabalho, representada pelo número médio de equivalentes-homem (EH), é o fator que contribui mais fortemente para a formação do valor da produção. Mantidos constantes todos os demais fatores produtivos, uma variação de $10 \%$ na quantidade deste fator provocaria alteração de um pouco mais de $3,1 \%$ no valor da produção agropecuária das MRH. Entre as variáveis cujo efeito se mostra estatisticamente significativo, aquela que exerce menor influência sobre a

${ }^{24}$ Como a qualidade das informações dos Censos sobre a área de pastagens plantadas é, a princípio, mais precisa do que a da área de pastagens naturais, espera-se que a desagregação revele uma relaçâo positiva entre APP e VP 
produção é CC (capital em culturas, que corresponde ao valor das culturas permanentes e matas plantadas). Uma variação de $10 \%$ na utilização deste fator, mantidos todos os demais constantes, acarretaria uma variação em torno de apenas $0,5 \%$ no valor da produção. A variável ESC9 não vai aparecer nos diferentes modelos apresentados neste trabalho porque, quando incluida nas regressões, seu coeficiente foi negativo e altamente significativo, e sempre que foi excluida melhorou a qualidade dos ajustamentos.

O teste "F" para retornos à escala não foi significativo ao nivel de $5 \%$ de significância, indicando que a elasticidade de escala " $\varepsilon$ " não é estatisticamente diferente de $1, \mathrm{e}$, consequentemente, pode-se afirmar que há rendimentos constantes à escala. Isto significa dizer que, ao se multiplicar todas as variáveis incluídas nestas equações por uma constante positiva $\mathrm{k}$, o valor da produção também será multiplicado pelo valor desta constante.

Ao excluir a variável LAM da equação 1 obteve-se a equação 3 da Tabela 11. Isto não alterou a significância dos parâmetros das demais variáveis. Os coeficientes que se apresentaram significativos no modelo anterior, mantiveram-se significativos neste, indicando a pouca influência da variável área com matas (plantadas e naturais) sobre a determinação do valor da produção, seja de forma direta ou conjuntamente com as demais variáveis. Por isto esta variável não foi incorporada aos demais modelos ajustados $^{25}$.

Considerando-se os coeficientes de regressão da equação 3 cujos testes estatísticos foram significativos, pode-se observar que os fatores de produção mais

${ }^{25}$ Além disso, observar que o coeficiente de correlação simples entre LAM e LVP é o menor (sempre inferior a 0.10 - ver Tabelas 7.8 e 9) entre todos os coeficientes das variáveis incluídas nas regressões. 
Tabela 11 - Equações de regressão para as $300 \mathrm{MRH}$, com 11 ou 12 variáveis explanatórias, em 1985.

\begin{tabular}{|c|c|c|c|c|}
\hline \multirow[b]{2}{*}{ Variável } & \multicolumn{2}{|c|}{ Equação 3} & \multicolumn{2}{|c|}{ Equação 4} \\
\hline & Coeficiente & Teste $t$ & Coeficiente & Teste $t$ \\
\hline Intercepto & $-0,8047$ & $-1,90$ & $-0,1448$ & $-0,32$ \\
\hline LAL & 0,1528 & $4,84^{*}$ & 0,1770 & $5,58^{*}$ \\
\hline LAP & $-0,0634$ & $-2,24^{*}$ & $-0,1005$ & $-3,30^{*}$ \\
\hline $\mathrm{LCC}$ & 0,0517 & $4,69 *$ & 0,0445 & $3,83 *$ \\
\hline LCA & 0,1037 & $2,30^{*}$ & 0,1399 & $2,96^{*}$ \\
\hline LVI & 0,0455 & 1,43 & 0,0483 & 1,47 \\
\hline LDA & 0,0966 & $4,12^{*}$ & 0,1122 & $4,44^{*}$ \\
\hline LDM & 0,1190 & $5,91^{*}$ & 0,1239 & $6,00^{*}$ \\
\hline LOD & 0,1977 & $6,33 *$ & 0,1805 & $5,09 *$ \\
\hline LEH & 0,3156 & $9,14^{*}$ & $\cdots$ & --- \\
\hline LEHF & $-\cdots$ & $-\cdots$ & 0,1339 & $5,51^{*}$ \\
\hline LEHA & $\cdots$ & $-\cdots$ & 0,1497 & $5,76^{*}$ \\
\hline LPRT & 0,1543 & $6,29 *$ & 0,1297 & $4,79^{*}$ \\
\hline $\mathrm{ESC} 1$ & 0,2119 & 1,76 & 0,2466 & 1,87 \\
\hline$\overline{\mathrm{R}^{2}}$ & \multicolumn{2}{|c|}{0,9604} & \multicolumn{2}{|c|}{0,9585} \\
\hline $\mathrm{F}$ & \multicolumn{2}{|c|}{$635,29 *$} & \multicolumn{2}{|c|}{$552,21^{*}$} \\
\hline$\varepsilon$ & \multicolumn{2}{|c|}{1,0191} & \multicolumn{2}{|c|}{1,0094} \\
\hline $\mathrm{F}(\varepsilon=1)$ & \multicolumn{2}{|c|}{1,16} & \multicolumn{2}{|c|}{0,26} \\
\hline
\end{tabular}

(*) - significativo ao nível de $5 \%$ de significância.

importantes na determinação - ou na "explicação" - do valor da produção agropecuária nas 300 MRH são a mão-de-obra (EH), outras despesas (OD), preço da terra (PRT) e área de lavouras (AL), com destaque para o fator de produção mão-de-obra, cuja elasticidade é 0,31 .

O ajustamento do modelo foi muito bom. Dos doze parâmetros estimados, incluindo-se o intercepto, nove são estatisticamente significativos. O teste "F" para qualidade do ajustamento é altamente significativo, e o coeficiente de determinação é 
superior a 0,96 , o que significa dizer que mais de $96 \%$ da soma de quadrados total de LVP é "explicada" pelas variáveis explanatórias incluídas neste modelo.

Por outro lado, o fator de produção área de pastagens (AP), que inclui pastagens plantadas e naturais, apresenta uma relação negativa com VP, o que não pode ser aceito, conforme o que foi discutido anteriormente. O coeficiente de regressão de $\mathrm{ESC1}$, que representa a proporção das pessoas com 5 ou mais anos de idade e com pelo menos 1 ano de estudo, não apresenta significância estatística. Sabe-se, porém, que esta variável representa uma condicionante de grande importância, seja de forma direta ou indireta, em todo processo produtivo. Esta importância, porém, não foi evidenciada através destes modelos. Isto pode ter ocorrido porque a influência que este fator exerce sobre a produção deve se expressar não de forma direta, como se tem considerado até o presente momento, mas sim de modo indireto, através de outras variáveis incluídas no modelo ${ }^{26}$.

Apesar destas considerações, a variável ESC1 foi mantida nos demais modelos porque, nas várias tentativas de ajustamentos, sempre que se excluiu esta variável a qualidade das equações de regressão, sob o ponto de vista estatístico, foi reduzida.

Ainda com relação à variável mão-de-obra, constatou-se a grande influência que este fator exerceu sobre o valor da produção das $300 \mathrm{MRH}$ no ano de 1985. Esta variável, porém, foi empregada de forma bastante agregada, ao se considerar o total de equivalentes-homem utilizados nas microrregiões. No entanto, a participação efetiva da mão-de-obra familiar e da mão-de-obra assalariada na produção agrícola é bastante diferenciada, tanto no que se refere à qualidade quanto ao uso efetivo deste fator

${ }^{26}$ Para se verificar esta segunda hipótese empregou-se modelos alternativos cujas análises são apresentadas na seção 4.6 
(Kageyama, 1985, p.175-8 e 225-7; 1992, p.1-19). Deste modo, ao se desagregar a variável $\mathrm{EH}$ em EHF (número de equivalentes-homem do responsável e membros não remunerados da família) e EHA (número de equivalentes-homem das demais categorias, com predominância de assalariados), obteve-se o modelo representado pela equação 4 . Nota-se que o ajustamento é muito bom, com $\mathrm{R}^{2}=0,958$ e o teste 'F" para qualidade do ajustamento altamente significativo.

A significância dos coeficientes de regressão não foi alterada, e os seus valores são, em valor absoluto, próximos aos estimados através do modelo 3. A estimativa do coeficiente de AP permanece estatisticamente significativa e com sinal negativo, cujas prováveis causas foram mencionadas anteriormente. Os coeficientes das variáveis ESC1 e VI (valor de instalações e outras benfeitorias, máquinas, instrumentos agrários, veículos e outros meios de transporte) não são significativos, porém apresentam uma relação positiva com o valor da produção (VP), e portanto coerente com o esperado.

Pode-se observar, ainda, na equação 4, que as variáveis EHF e EHA mantêm uma relação muito forte com VP, pois as estimativas de seus respectivos coeficientes são relativamente altas e estatisticamente significativas, confirmando a influência que estes fatores exercem na determinação do valor da produção.

Como a variável área de pastagens (AP) tem apresentado uma relação sempre negativa, e significativa, com VP, optou-se por excluí-la das equações 3 e 4, obtendo-se assim as equações 5 e 6 , respectivamente, as quais encontram-se na Tabela 12. Os ajustamentos assim obtidos continuam bons. 
Tabela 12 - Equações de regressão para as $300 \mathrm{MRH}$, com 10 ou 11 variáveis explanatórias, em 1985.

\begin{tabular}{|c|c|c|c|c|}
\hline \multirow[b]{2}{*}{ Variável } & \multicolumn{2}{|c|}{ Equação 5} & \multicolumn{2}{|c|}{ Equação 6} \\
\hline & Coeficiente & Teste $t$ & Coeficiente & Teste $t$ \\
\hline Intercepto & $-0,2162$ & $-3,16^{*}$ & $-0,8497$ & $-2,13^{*}$ \\
\hline LAL & 0,1589 & $5,02^{*}$ & 0,1929 & $6,05^{*}$ \\
\hline LCC & 0,0492 & $4,45^{*}$ & 0,0435 & $3,69 *$ \\
\hline LCA & 0,0223 & 0,83 & 0,0148 & 0,51 \\
\hline LVI & 0,0409 & 1,28 & 0,0370 & 1,11 \\
\hline LDA & 0,0875 & $3,76^{*}$ & 0,0907 & $3,66^{*}$ \\
\hline LDM & 0,1265 & $6,33^{*}$ & 0,1352 & $6,53^{*}$ \\
\hline LOD & 0,1991 & $6,33^{*}$ & 0,2005 & $5,65^{*}$ \\
\hline LEH & 0,3354 & $9,98^{*}$ & $-\cdots$ & --- \\
\hline LEHF & ---- & ---- & 0,1624 & $7,02^{*}$ \\
\hline LEHA & $-\cdots$ & $-\cdots$ & 0,1341 & $5,16^{*}$ \\
\hline LPRT & 0,1871 & $9,44^{*}$ & 0,1869 & $8,86^{*}$ \\
\hline $\mathrm{ESCl}$ & 0,2140 & 1,76 & 0,1912 & 1,44 \\
\hline $\mathrm{R}^{2}$ & \multicolumn{2}{|c|}{0,9597} & \multicolumn{2}{|c|}{0,9569} \\
\hline $\mathrm{F}$ & \multicolumn{2}{|c|}{$688,70^{*}$} & \multicolumn{2}{|c|}{$581,50 *$} \\
\hline$\varepsilon$ & \multicolumn{2}{|c|}{1,0199} & \multicolumn{2}{|c|}{1,0112} \\
\hline$F(\varepsilon=1)$ & \multicolumn{2}{|c|}{1,25} & \multicolumn{2}{|c|}{0,36} \\
\hline
\end{tabular}

(*) - significativo ao nível de $5 \%$ de significância.

Com a exclusão de AP, a estimativa do coeficiente de elasticidade da variável capital em animais (CA) torna-se não-significativa (equação 5), e passa a corresponder, em valor absoluto, a $21,5 \%$ do valor estimado através da equação 3 .

O ajustamento da equação 6 também foi muito bom, com $R^{2}=0,957$ e o teste 'F"' altamente significativo. Assim como ocorreu na equação 5, o coeficiente de elasticidade da variável CA é positivo, porém não-significativo, e seu valor corresponde a $10,6 \%$ do obtido com a equação 4. Observa-se que a exclusão de AP nos modelos contidos na Tabela 11 provocou alteração significativa somente na estimativa do coeficiente da 
variável $\mathrm{CA}$. Os demais coeficientes sofrem alterações pequenas, e as estimativas dos coeficientes das variáveis VI e ESC1 continuam não-significativas, porém com sinais positivos.

De um modo geral, pode-se concluir que os fatores de produção mais importantes na determinação do valor da produção agropecuária das $300 \mathrm{MRH}$, em 1985, foram a área de lavoura (AL), despesas com medicamentos para animais, sal e rações (DM), despesas com adubos, sementes e outros insumos (DA), outras despesas (OD), preço da terra (PRT) e a mão-de-obra (EH); como também suas formas desagregadas EHF (mãode-obra familiar) e EHA (outras categorias de força de trabalho com predominância de assalariados). Os coeficientes de elasticidade destas variáveis foram positivos e altamente significativos nos seis modelos apresentados.

Os coeficientes das variáveis VI (valor de instalações e outras benfeitorias, máquinas, instrumentos agrários e veículos para transporte) e escolaridade (ESC1), apesar de positivos, não foram significativos em nenhum modelo. Por outro lado, a estimativa do parâmetro da área de pastagens (AP) foi sempre significativa, porém com sinal negativo, e a sua exclusão dos modelos 3 e 4 tornou o coeficiente de CA (capital em animais) não-significativo, porém positivo.

Todos os modelos apresentados são, sob o ponto de vista estatístico, altamente significativos. Os coeficientes de determinação são superiores a 0,95 , indicando que mais de $95 \%$ da soma de quadrados total do logaritmo do valor da produção agropecuária do Brasil, aqui representado pelas $300 \mathrm{MRH}$, é "explicada" pelos fatores de produção incluidos nos respectivos modelos. 
Em geral, a função de produção tipo Cobb-Douglas apresenta bom ajustamento quando empregada a dados agregados. Os modelos ajustados por Hayami e Ruttan (1970, p.903) apresentam coeficientes de determinação superiores a 0,92; Thompson (1970, p.53 e 59) obteve $\mathrm{R}^{2}$ superiores a 0,96 . Os coeficientes de determinação obtidos nos modelos ajustados por Headley (1968, p.17) são superiores a $96 \%$, e os obtidos por Griliches (1963, p.424 e 426) são superiores a 97\%.

Finalmente, de acordo com estes modelos e seus respectivos testes 'F" para retornos à escala, pode-se concluir que o setor agropecuário brasileiro apresentou retornos constantes à escala em 1985, pois a elasticidade de escala " $E$ " em nenhum caso se mostrou estatisticamente diferente da unidade.

Apesar da importância em se estudar as relações entre os vários fatores de produção e o valor da produção agropecuária do Brasil como um todo, devido à diversidade existente entre as regiões brasileiras no que se refere às características edafoclimáticas, tipos de exploração, métodos e técnicas empregadas, surge a necessidade de se verificar como aquelas relações ocorrem a nível regional. Será possível, então, fazer comparações entre as funções de produção regionais. Isso será feito na próxima seção.

\subsubsection{As Funções de Produção Regionais}

Foram estimadas funções de produção para 4 regiões: Nordeste, Sudeste (exclusive SP), São Paulo e Sul ${ }^{27}$. Para isso 6 modelos foram utilizados nos ajustamentos

\footnotetext{
${ }^{27}$ A exclusão das regiões Norte e Centro-Oeste deve-se à impossibilidade em se comparar as funções de produção regionais, dadas as mudanças ocorridas na Divisão Político-Administrativa e Regional, no Brasil, principalmente na década de 80 (FIBGE - Anuário Estatístico do Brasil, 1994, p.1-30).
} 
para as $300 \mathrm{MRH}$, apresentados na seção anterior. Porém, os ajustamentos selecionados para serem analisados aqui correspondem aos modelos das equações 5 e 6 . Para esta seleção empregou-se os critérios descritos na página 65 .

A Tabela 13 apresenta as equações para as quatro regiões, adotando-se o modelo da equação 5. Verifica-se que o ajustamento foi melhor para São Paulo e para a região Sul, com $\mathrm{R}^{2}$ superiores a $97 \%$. No entanto, como se observa, este alto coeficiente de determinação é acompanhado de várias estimativas dos coeficientes estatisticamente iguais a zero, indicando que há sérios problemas de multicolinearidade, o que implica em estimadores imprecisos, apesar de não-tendenciosos.

A estimativa da equação de regressão para a região Nordeste apresenta um coeficiente de determinação de $92,6 \%$, configurando-se também como um bom ajustamento. Dos 11 coeficientes deste modelo, 5 apresentam-se significativos ao nivel de $5 \%$ de significância, sendo que quatro correspondem a fatores de produção convencionais (CC, DM, OD e EH), e somente um a fator de produção não-convencional (PRT). Nota-se que em nenhuma região as estimativas dos coeficientes das variáveis CA e $\mathrm{ESCl}$ são estatisticamente significativas. A variável correspondente ao valor das instalações e outras benfeitorias, máquinas, instrumentos agrários, veículos e outros meios de transporte (VI) apresenta coeficiente de elasticidade significativo somente na região Sul. Para a região Sudeste este coeficiente é negativo, mas não difere estatisticamente de zero. 


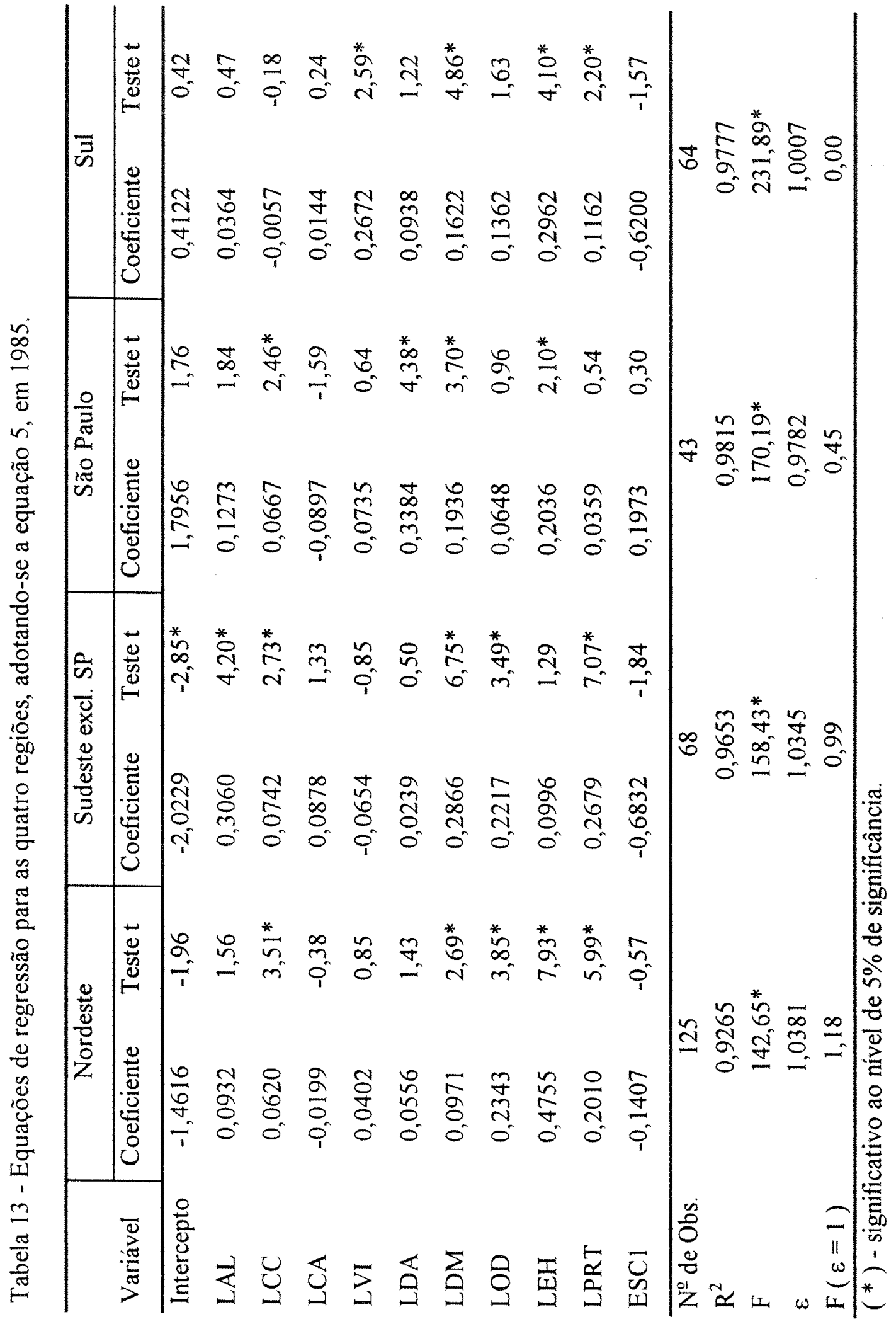


A escolaridade (ESC1) mantém, à exceção de São Paulo, uma relação negativa com o valor da produção; no entanto, seus coeficientes de regressão são estatisticamente nulos $^{28}$. Nas quatro regiões, todas as variáveis que mantêm uma relação negativa com VP apresentam coeficientes de elasticidade que não são estatisticamente diferentes de zero.

Uma diferença marcante entre as regiões diz respeito ao coeficiente de elasticidade da área de lavouras (AL), o qual é estatisticamente diferente de zero somente para a região Sudeste. Este fator se constitui no mais importante na determinação do valor da produção desta região, vindo em seguida DM (despesas com medicamentos para animais, sal e rações) e PRT (preço da terra), cujos coeficientes de elasticidade são, respectivamente, iguais a 0,2866 e 0,2679 .

A estimativa da elasticidade de escala " $\varepsilon$ " não é estatisticamente diferente de $1 \mathrm{em}$ nenhuma das quatro regiões, indicando que há retornos constantes à escala em todas as regiões.

A desagregação da força-de-trabalho $(E H)$ em EHF (mão-de-obra familiar) e EHA (mão-de-obra das demais categorias, com predominância de assalariados) não alterou de forma significativa as estimativas das equações de regressão das regiões. Notase, na Tabela 14, que os valores dos coeficientes de determinação das regressões estão

\footnotetext{
${ }^{28}$ A exclusão desta variável nos modelos, a exemplo do que ocorreu com as $300 \mathrm{MRH}$, não melhorou a qualidade dos ajustamentos das equações de regressão das regiôes.
} 


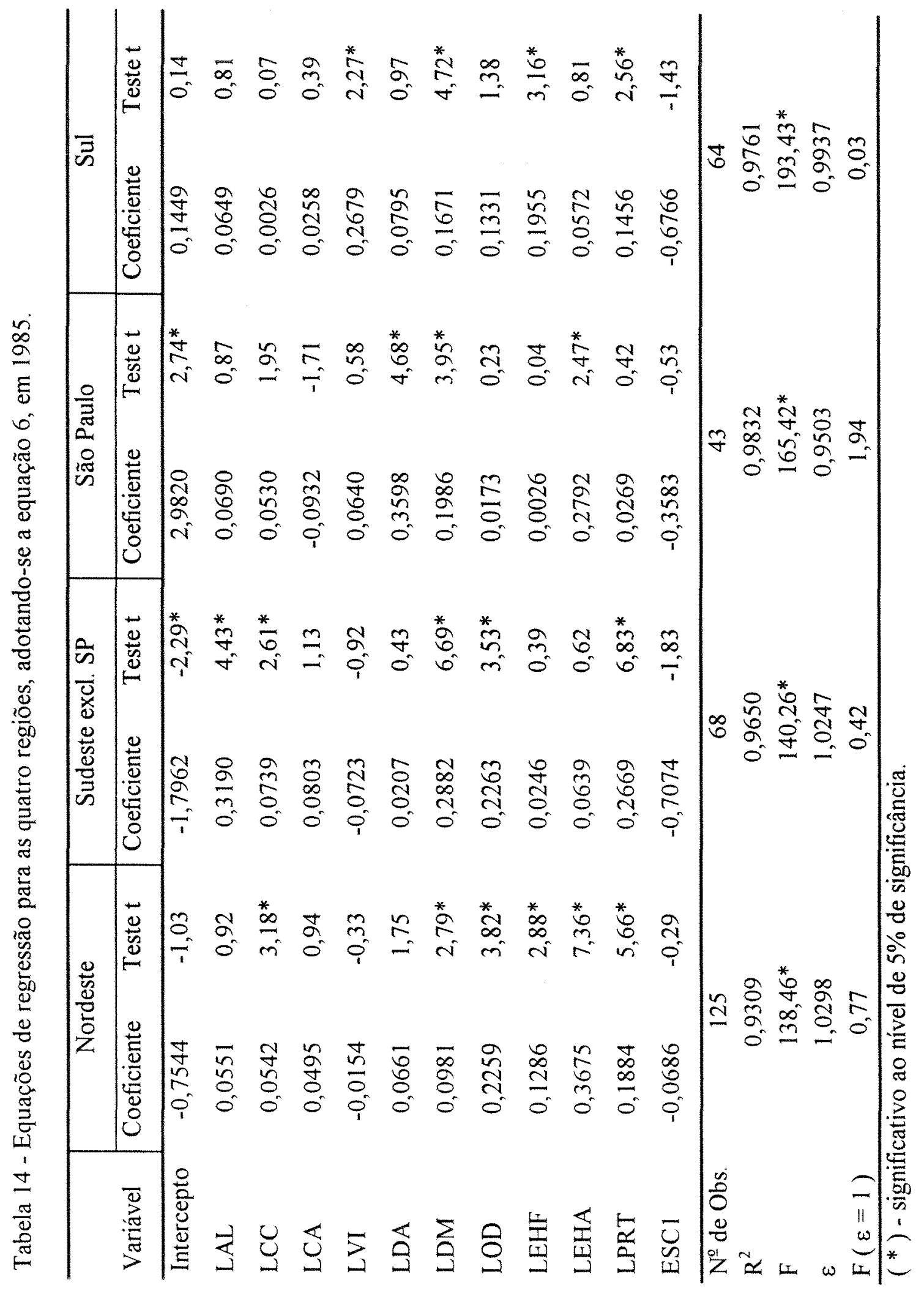


muito próximos aos obtidos com os modelos contidos na Tabela 13. Os testes "F" para qualidade dos ajustamentos são altamente significativos, e os coeficientes de determinação são na maioria superiores a $96 \%$.

Para as regiões Nordeste e Sudeste as estimativas dos parâmetros não sofreram grandes variações. O fator de produção mão-de-obra continua sendo muito importante na determinação do valor da produção da região Nordeste, pois as estimativas dos coeficientes de elasticidade da força de trabalho familiar e assalariada são estatisticamente diferentes de zero. Por outro lado, para a região Sudeste estas estimativas são estatisticamente nulas. Observa-se ainda, na região Nordeste, que o valor da estimativa do coeficiente de elasticidade da mão-de-obra assalariada (EHA) é 2,8 vezes superior ao da mão-de-obra familiar (EHF). Isto, porém, não significa dizer que um acréscimo no emprego de mão-de-obra assalariada provoque um aumento no valor da produção desta região equivalente a 2,8 vezes ao que se obteria com um acréscimo igual no uso de mãode-obra familiar, tendo em vista se tratar de porcentagens aplicadas a bases diferentes. Adicionalmente, as informações relativas ao emprego efetivo da mão-de-obra do responsável e membros não-remunerados da família são reconhecidamente mais imprecisas. Portanto, qualquer interpretação relacionada com este fator de produção requer, por parte do pesquisador, uma certa cautela.

Em São Paulo, onde há predominância do emprego de mão-de-obra assalariada na agricultura, a estimativa do coeficiente da variável EHF, que corresponde à mão-de-obra do responsável pelo estabelecimento e membros não-remunerados da família, não foi estatisticamente diferente de zero, indicando que este fator de produção apresenta, 
relativamente, baixa participação na determinação do valor da produção agropecuária do Estado. Por outro lado, na região Sul, onde a participação da mão-de-obra familiar na agricultura é mais efetiva, a estimativa do coeficiente de elasticidade de EHF é estatisticamente diferente de zero, o que não ocorre com a variável correspondente a outras categorias de força-de-trabalho (EHA).

Analisando-se os dados contidos na Tabela 1 do Apêndice, pode-se observar que, em 1985, do total de equivalentes-homem empregados na agropecuária de São Paulo, $65,6 \%$ correspondiam à mão-de-obra contratada (EHA), enquanto que na região Sul esta porcentagem era de apenas $27 \%$. Isto deve-se, principalmente, à predominância nesta região de propriedades cuja base de exploração é predominantemente familiar.

De um modo geral pode-se concluir que os dois modelos selecionados para "explicar" a possível relação existente entre os principais fatores produtivos e o valor da produção agropecuária das quatro regiões, em 1985, são bastante representativos, uma vez que, segundo os coeficientes de determinação estimados, mais de $95 \%$ da soma de quadrados do logaritmo do valor da produção agropecuária destas regiões é "explicada" pelas variáveis explanatórias contidas nestes modelos. O coeficiente da variável $\mathrm{ESCl}$, que representa o grau de escolaridade das pessoas com 5 ou mais anos de idade, não apresentou significância estatística em nenhuma região, nos dois modelos ajustados. No entanto, esta variável foi mantida nos modelos, uma vez que sua exclusão reduziu a qualidade dos ajustamentos das equações de regressão estimadas. 
Finalmente, com o objetivo de verificar a existência de diferenças entre as funções de produção das quatro regiões, foi ajustado o modelo apresentado a partir da página 45 . No ajustamento deste modelo utilizou-se as mesmas variáveis contidas na equação $6^{29}$.

Os testes " $F$ " para diferenças interregionais na função de produção apresentados na Tabela 15, todos com 12 e 252 graus de liberdade, mostram que há diferenças significativas entre a função de produção do Nordeste e as das demais regiões consideradas. O valor de "F" que testa a diferença entre a região Nordeste e São Paulo está muito próximo do valor crítico.

A região Sul não apresenta diferença significativa com a região Sudeste (exclusive SP) e com São Paulo. Entretanto a função de produção para São Paulo é estatisticamente diferente da função de produção estimada para a região Sudeste, no ano de 1985 .

Tabela 15 - Testes das diferenças interregionais na função de produção, adotando-se o modelo da equação 6, em 1985.

\begin{tabular}{ll}
\hline Regiões comparadas & $F$ \\
\hline NE com SE excl. SP & $2,67^{*}$ \\
NE com SP & $1,86^{*}$ \\
NE com Sul & $4,94^{*}$ \\
SE excl. SP com SP & $2,24^{*}$ \\
SE excl. SP com Sul & 1,49 \\
SP com Sul & 1,52 \\
\hline
\end{tabular}

$(*)$ - significativo ao nivel de $5 \%$ de significância.

29 A Tabela 3 do Apêndice contém a estimativa da equação de regressão ajustada para comparar as funções de produção regionais, em 1985. 


\subsection{A Função de Produção Cobb-Douglas em 1980}

\subsubsection{A Função de Produção para as 300 MRH}

Todos os modelos selecionados para 1985 foram também ajustados aos dados das $300 \mathrm{MRH}$ para os anos de 1980 e 1975. Isto foi realizado para verificar, inicialmente, se houve alterações importantes nas relações entre as variáveis explanatórias e o valor da produção nos referidos anos, assim como para se comparar as funções de produção dos anos de 1975, 1980 e 1985.

Deste modo, a Tabela 16 contém os modelos 1 e 2 ajustados aos dados de 1980. Como se observa, a exemplo do que se verificou para o ano de 1985, estes modelos apresentam um bom ajustamento a esses dados, com os coeficientes de determinação ligeiramente inferiores aos observados para 1985, porém altamente significativos. De acordo com estes coeficientes, pode-se afirmar que mais de $95 \%$ da soma de quadrados total de LVP é "explicada" pelas equações ajustadas. A maioria das estimativas dos coeficientes de regressão é significativa ao nível de $5 \%$ de significância. A variável área de pastagens (AP), na equação 1, apresenta um coeficiente negativo e significativo.

Ao se desagregar a área de pastagens (AP) em área com pastagens plantadas (APP) e em área com pastagens naturais (APN), conforme a equação 2 , o coeficiente da variável APP também é negativo e estatisticamente diferente de zero.

Nota-se que a variável $\mathrm{ESC} 1$ tem uma relação positiva e significativa com o valor da produção. Seu coeficiente, porém, assim como o da variável URB ${ }^{30}$, não é diretamente

\footnotetext{
${ }^{30}$ Ver definição à página 52 , e nota de rodapé da página 89 . Esta variável é analisada na página 89
} 
comparável com os das demais variáveis, por não se tratar de elasticidade. Sabe-se, porém, que o teste ' $\mathfrak{t}$ ” para verificar a significância de um parâmetro é diretamente associado ao coeficiente de correlação parcial entre a correspondente variável e LVP. Portanto, pode ser utilizado para constatar o grau de importância da associação de cada variável explanatória com o valor da produção. Assim, de acordo com os valores de $t$ calculados, observa-se que a mão-de-obra $(\mathrm{EH})$ é o fator de produção que mais contribui

Tabela 16 - Equações de regressão para as $300 \mathrm{MRH}$, com 12 ou 13 variáveis explanatórias, em 1980.

\begin{tabular}{|c|c|c|c|c|}
\hline \multirow[b]{2}{*}{ Variável } & \multicolumn{2}{|c|}{ Equação 1} & \multicolumn{2}{|c|}{ Equação 2} \\
\hline & Coeficiente & Teste $\mathrm{t}$ & Coeficiente & Teste $t$ \\
\hline Intercepto & $-0,9544$ & $-1,69$ & $-1,7312$ & $-3,03 *$ \\
\hline $\mathrm{LAL}$ & 0,0974 & $3,20 *$ & 0,0865 & $2,70^{*}$ \\
\hline LAP & $-0,1127$ & $-3,11^{*}$ & --- & --- \\
\hline LAPP & $--\cdots$ & --- & $-0,0323$ & $-2,16^{*}$ \\
\hline LAPN & $-\cdots$ & $-\cdots$ & $-0,0233$ & $-1,06$ \\
\hline LAM & 0,0244 & 1,16 & 0,0295 & 1,37 \\
\hline $\mathrm{LCC}$ & 0,0131 & 1,13 & 0,0065 & 0,56 \\
\hline LCA & 0,2838 & $5,50^{*}$ & 0,2142 & $4,99 *$ \\
\hline LVI & 0,0076 & 0,21 & $-0,0019$ & $-0,05$ \\
\hline LDA & 0,1117 & $4,82^{*}$ & 0,1110 & $4,69^{*}$ \\
\hline LDM & 0,0470 & $2,47^{*}$ & 0,0416 & $2,02 *$ \\
\hline LOD & 0,1972 & $5,70^{*}$ & 0,2057 & $5,85^{*}$ \\
\hline LEH & 0,3406 & $8,76^{*}$ & 0,3806 & $10,23 *$ \\
\hline LPRT & 0,1481 & $4,52^{*}$ & 0,1919 & $5,93 *$ \\
\hline $\mathrm{ESC} 1$ & 0,5891 & $4,32^{*}$ & 0,6129 & $4,43^{*}$ \\
\hline $\mathrm{R}^{2}$ & \multicolumn{2}{|c|}{0,9515} & \multicolumn{2}{|c|}{0,9507} \\
\hline $\mathrm{F}$ & \multicolumn{2}{|c|}{$468,86^{*}$} & \multicolumn{2}{|c|}{$423,96^{*}$} \\
\hline$\varepsilon$ & \multicolumn{2}{|c|}{1,0102} & \multicolumn{2}{|c|}{1,0219} \\
\hline$F(\varepsilon=1)$ & \multicolumn{2}{|c|}{0,26} & \multicolumn{2}{|c|}{1,16} \\
\hline
\end{tabular}

$(*)$ - significativo ao nivel de $5 \%$ de significância. 
para a determinação do valor da produção agropecuária das 300 MRH em 1980.

Observa-se, ainda, em ambas as equações, que os coeficientes das variáveis AM e CC são positivos, porém não-significativos. Portanto, suas elasticidades, e consequentemente suas respectivas produtividades marginais, não são estatisticamente diferentes de zero. A estimativa do coeficiente da variável correspondente ao valor de instalações e outras benfeitorias, máquinas, instrumentos agrários, veículos e outros meios de transporte (VI), em todos os modelos ajustados para 1980, não é estatisticamente diferente de zero. As variáveis CA, DA, OD, EH e PRT apresentam-se como as mais importantes no modelo, com elasticidades relativamente altas e estatisticamente diferentes de zero.

A equação 3 da Tabela 17 foi obtida excluindo a variável $\mathrm{AM}$ da equação 2 . Nota-se que a maioria das estimativas dos parâmetros é significativa.

Confrontando-se a equação 1 com a 3 , observa-se que não houve alteração na significância dos parâmetros. Aqueles parâmetros que se apresentaram significativos no modelo 1 continuam significativos no modelo 3 . Isto revela a pouca influência do fator de produção área com matas (AM) sobre o valor da produção.

Comparando-se os valores dos testes "q", pode-se concluir que os fatores de produção que mais contribuiram para a formação do valor da produção agropecuária foram mão-de-obra (EH), outras despesas (OD) e capital em animais (CA). Estas constatações ocorrem também no modelo 1 da Tabela 16. 
Tabela 17 - Equações de regressão para as $300 \mathrm{MRH}$, com 11 ou 12 variáveis explanatórias, em 1980.

\begin{tabular}{|c|c|c|c|c|}
\hline \multirow[b]{2}{*}{ Variável } & \multicolumn{2}{|c|}{ Equação 3} & \multicolumn{2}{|c|}{ Equação 4} \\
\hline & Coeficiente & Teste $t$ & Coeficiente & Teste $t$ \\
\hline Intercepto & $-0,6054$ & $-1,26$ & $-0,0406$ & $-0,08$ \\
\hline LAL & 0,0970 & $3,18^{*}$ & 0,1064 & $3,41^{*}$ \\
\hline LAP & $-0,1105$ & $-3,05^{*}$ & $-0,1473$ & $-3,89^{*}$ \\
\hline LCC & 0,0162 & 1,43 & 0,0094 & 0,80 \\
\hline LCA & 0,2806 & $5,45^{*}$ & 0,3105 & $5,83^{*}$ \\
\hline LVI & 0,0159 & 0,44 & 0,0288 & 0,76 \\
\hline LDA & 0,1086 & $4,71^{*}$ & 0,1177 & $4,98^{*}$ \\
\hline LDM & 0,0482 & $2,53^{*}$ & 0,0459 & $2,36^{*}$ \\
\hline LOD & 0,2051 & $6,05^{*}$ & 0,1988 & $5,41^{*}$ \\
\hline LEH & 0,3442 & $8,88^{*}$ & $\cdots$ & ---- \\
\hline LEHF & --- & $-\cdots$ & 0,1701 & $6,48^{*}$ \\
\hline LEHA & ---- & --- & 0,1568 & $5,55^{*}$ \\
\hline LPRT & 0,1270 & $4,66^{*}$ & 0,1087 & $3,83 *$ \\
\hline $\mathrm{ESC} 1$ & 0,6163 & $4,58^{*}$ & 0,6691 & $4,57^{*}$ \\
\hline $\mathrm{R}^{2}$ & \multicolumn{2}{|c|}{0,9512} & \multicolumn{2}{|c|}{0,9494} \\
\hline F & \multicolumn{2}{|c|}{$510,73^{*}$} & \multicolumn{2}{|c|}{$448,73^{*}$} \\
\hline$\varepsilon$ & \multicolumn{2}{|c|}{1,0053} & \multicolumn{2}{|c|}{0,9971} \\
\hline $\mathrm{F}(\varepsilon=1)$ & \multicolumn{2}{|c|}{0,07} & \multicolumn{2}{|c|}{0,02} \\
\hline
\end{tabular}

$(*)$ - significativo ao nivel de $5 \%$ de significância.

A relação da área de pastagens com VP, a exemplo do que ocorreu nos modelos anteriores, continua negativa e com teste estatístico significativo. A qualidade do ajustamento é bom $\left(R^{2} \geq 95 \%\right)$, e o teste para retornos à escala não é significativo.

A substituição de EH por EHF e EHA não resultou em mudanças significativas nas estimativas dos parâmetros. Como pode ser observado na Tabela 17, os valores dos coeficientes de elasticidade contidos no modelo 3 estão muito próximos dos coeficientes contidos no modelo 4 . O coeficiente de determinação deste modelo é praticamente igual a 
0,95, e a qualidade do ajustamento é muito boa, com o valor de 'F"' altamente significativo.

Como as estimativas do coeficiente do logaritmo da área de pastagens foram negativas e significativas, optou-se por excluir essa variável das equações 3 e 4, obtendose, respectivamente, as equações 5 e 6 apresentadas na Tabela 18. A exclusão desta variável provocou uma redução em torno de $50 \%$ no valor da elasticidade de CA (capital em animais $)^{31}$, mas não alterou a significância dos parâmetros. As variáveis cujos coeficientes se mostraram estatisticamente significativos nos ajustamentos contidos na Tabela 17 também o foram nos ajustamentos das equações 5 e 6 (Tabela 18).

As formas desagregadas de EH, ou seja, EHF e EHA, apresentam coeficientes de elasticidade positivos e estatisticamente diferentes de zero. De acordo com o valor das estimativas dos parâmetros destas variáveis, pode-se concluir que a mão-de-obra familiar (EHF) se mostra mais importante na formação do valor da produção agropecuária das MRH do que as outras categorias de mão-de-obra, com predominância de assalariados (EHA).

Em resumo, verifica-se que os 6 modelos ajustados aos dados das $300 \mathrm{MRH}$ para 1980 apresentam bom ajustamento. A maioria das estimativas dos coeficientes de regressão das variáveis incluídas nesses modelos é positiva e estatisticamente diferente de zero. A variável capital em culturas (CC), que corresponde ao valor das culturas permanentes e matas plantadas, não apresenta, em nenhum dos modelos ajustados,

\footnotetext{
${ }^{31}$ Observar que o coeficiente de correlação simples entre essas variáveis é 0,854 (Tabela 7).
} 
Tabela 18 - Equações de regressão para as $300 \mathrm{MRH}$, com 10 ou 11 variáveis explanatórias, em 1980.

\begin{tabular}{|c|c|c|c|c|}
\hline \multirow[b]{2}{*}{ Variável } & \multicolumn{2}{|c|}{ Equação 5} & \multicolumn{2}{|c|}{ Equação 6} \\
\hline & Coeficiente & Teste $t$ & Coeficiente & Teste $t$ \\
\hline Intercepto & $-1,4945$ & $-3,86^{*}$ & $-1,1800$ & $-3,01^{*}$ \\
\hline $\mathrm{LAL}$ & 0,1063 & $3,46^{*}$ & 0,1264 & $4,01^{*}$ \\
\hline $\mathrm{LCC}$ & 0,0093 & 0,83 & 0,0025 & 0,21 \\
\hline LCA & 0,1466 & $5,35^{*}$ & 0,1365 & $4,63^{*}$ \\
\hline LVI & 0,0040 & 0,11 & 0,0052 & 0,13 \\
\hline LDA & 0,0970 & $4,21^{*}$ & 0,1009 & $4,24^{*}$ \\
\hline LDM & 0,0566 & $2,97^{*}$ & 0,0579 & $2,94^{*}$ \\
\hline LOD & 0,2032 & $5,91^{*}$ & 0,2120 & $5,66^{*}$ \\
\hline LEH & 0,3927 & $10,94^{*}$ & $-\cdots$ & --- \\
\hline LEHF & $-\cdots$ & --- & 0,2160 & $8,99 *$ \\
\hline LEHA & $-\cdots$ & $-\cdots$ & 0,1532 & $5,30^{*}$ \\
\hline LPRT & 0,1840 & $9,13^{*}$ & 0,1858 & $8,92^{*}$ \\
\hline $\mathrm{ESCl}$ & 0,7097 & $5,34^{*}$ & 0,7386 & $4,96^{*}$ \\
\hline $\mathrm{R}^{2}$ & \multicolumn{2}{|c|}{0,9497} & \multicolumn{2}{|c|}{0,9467} \\
\hline $\mathrm{F}$ & \multicolumn{2}{|c|}{$545,15^{*}$} & \multicolumn{2}{|c|}{$465,36^{*}$} \\
\hline$\varepsilon$ & \multicolumn{2}{|c|}{1,0158} & \multicolumn{2}{|c|}{1,0108} \\
\hline $\mathrm{F}(\varepsilon=1)$ & \multicolumn{2}{|c|}{0,66} & \multicolumn{2}{|c|}{0,29} \\
\hline
\end{tabular}

$(*)$ - significativo ao nível de $5 \%$ de significância.

coeficiente de elasticidade diferente de zero. Isto, porém, não ocorre em 1985 (ver Tabelas 10 a 12), onde, contrariamente ao observado em 1980, todas as estimativas dos coeficientes de elasticidade relativos a esta variável são positivas e estatisticamente significativas ao nível de $5 \%$ de significância.

Finalmente, pode-se concluir que a agropecuária brasileira apresentou em 1980 retornos constantes à escala, pois os testes 'F" para retornos à escala são nãosignificativos em todos os modelos ajustados. 
Os Censos Demográficos de 1970 e 1980 apresentam o número de pessoas empregadas por setor de atividade. Assim, com base nesta informação, definiu-se a variável "grau de urbanização" (URB) ${ }^{32}$ como a proporção de pessoas de 10 ou mais anos de idade que trabalharam, no ano de referência, em atividades que não fossem agropecuária, extração vegetal ou pesca.

A Tabela 19 mostra as equações 7 e 8 , as quais correspondem às equações 5 e 6 , respectivamente, acrescidas da variável URB. Nota-se que os valores das estimativas dos parâmetros estão muito próximos dos obtidos com os ajustamentos apresentados na Tabela 18. Os coeficientes de elasticidade de CC e VI continuam não-significativos. A variável URB apresenta coeficiente de regressão estatisticamente diferente de zero somente na equação 8 . Nota-se que a inclusão desta variável nestes modelos não afeta a significância dos coeficientes das outras variáveis. Os ajustamentos são bons, com $R^{2}$ próximos a $95 \%$, e os testes "F" para a qualidade dos ajustamentos altamente significativos. Finalmente, ambos os modelos apresentam retornos constantes à escala.

Como a variável URB não se constitui efetivamente um insumo que entre diretamente no processo produtivo, mas que representa de certo modo o grau de tecnificação e a proximidade de mercados de insumos modernos e de produtos da agricultura, será empregada, juntamente com ESCl e PRT, em modelos UlvelingFletcher (ver seção 4.6), para se verificar suas possiveis influências sobre a elasticidade de produção de determinados fatores.

\footnotetext{
${ }^{32}$ Esta variável não foi utilizada em 1985, pois os dados publicados no Censo Demográfico de 1991 não possibilitam o seu cálculo.
} 
Tabela 19 - Equações de regressão para as $300 \mathrm{MRH}$, com 11 ou 12 variáveis explanatórias, em 1980.

\begin{tabular}{|c|c|c|c|c|}
\hline \multirow[b]{2}{*}{ Variável } & \multicolumn{2}{|c|}{ Equação 7} & \multicolumn{2}{|c|}{ Equação 8} \\
\hline & Coeficiente & Teste $t$ & Coeficiente & Teste $t$ \\
\hline Intercepto & $-1,5891$ & $-4,06^{*}$ & $-1,3251$ & $-3,34^{*}$ \\
\hline LAL & 0,0961 & $3,05^{*}$ & 0,1091 & $3,36 *$ \\
\hline LCC & 0,0107 & 0,95 & 0,0034 & 0,28 \\
\hline LCA & 0,1422 & $5,17^{*}$ & 0,1274 & $4,30 *$ \\
\hline LVI & $-0,0022$ & $-0,06$ & $-0,0003$ & $-0,01$ \\
\hline LDA & 0,0862 & $3,58^{*}$ & 0,0863 & $3,48^{*}$ \\
\hline LDM & 0,0647 & $3,27^{*}$ & 0,0689 & $3,39 *$ \\
\hline LOD & 0,2241 & $6,05^{*}$ & 0,2360 & $6,03^{*}$ \\
\hline LEH & 0,3868 & $10,74^{*}$ & $\cdots$ & $-\cdots$ \\
\hline LEHF & $-\cdots$ & $\cdots$ & 0,2090 & $8,66^{*}$ \\
\hline LEHA & $\cdots$ & $\cdots$ & 0,1614 & $5,56^{*}$ \\
\hline LPRT & 0,1880 & $9,26^{*}$ & 0,1912 & $9,15^{*}$ \\
\hline $\mathrm{ESCl}$ & 0,8193 & $5,41^{*}$ & 0,9178 & $5,32^{*}$ \\
\hline URB & 0,1772 & 1,50 & 0,2493 & $2,02^{*}$ \\
\hline $\mathrm{R}^{2}$ & \multicolumn{2}{|c|}{0,9500} & \multicolumn{2}{|c|}{0,9475} \\
\hline $\mathrm{F}$ & \multicolumn{2}{|c|}{$497,94^{*}$} & \multicolumn{2}{|c|}{$431,48^{*}$} \\
\hline$\varepsilon$ & \multicolumn{2}{|c|}{1,0086} & \multicolumn{2}{|c|}{1,0011} \\
\hline $\mathrm{F}(\varepsilon=1)$ & \multicolumn{2}{|c|}{0,19} & \multicolumn{2}{|c|}{0,00} \\
\hline
\end{tabular}

(*) - significativo ao nível de $5 \%$ de significância.

\subsubsection{As Funções de Produção Regionais}

A Tabela 20 mostra as estimativas das equações de regressão para as quatro regiões adotando-se o modelo da equação 5 . Todos os ajustamentos são estatisticamente significativos. O coeficiente de determinação para o Nordeste está próximo de $91 \%$, enquanto que os das demais regiões são superiores a $97 \%$. O grande número de 


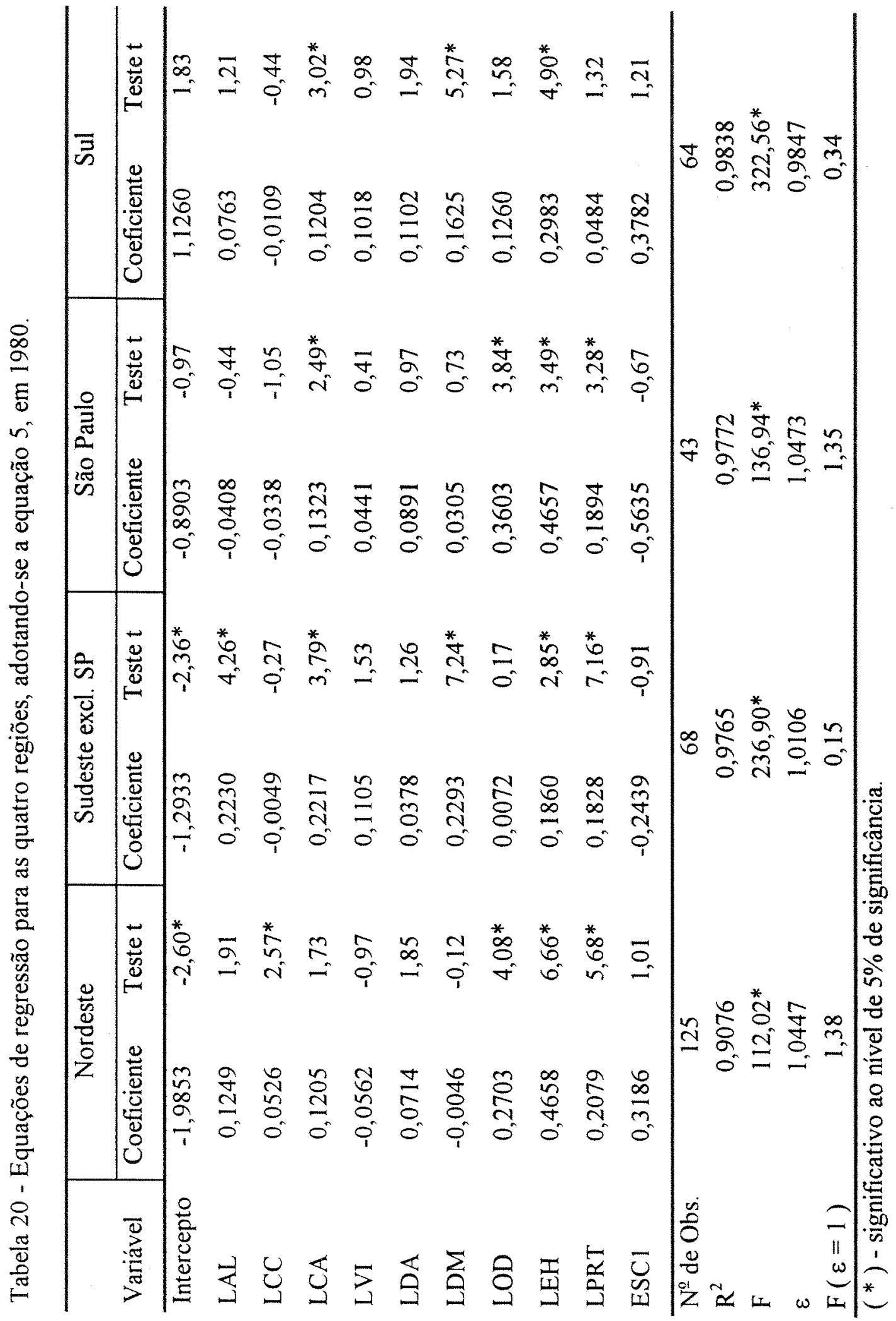


coeficientes não-significativos em equações com elevado coeficiente de determinação em São Paulo e na região Sul indica que há problemas de multicolinearidade entre as variáveis.

Em relação aos parâmetros estimados, observa-se que os coeficientes das variáveis VI, DA e ESCl são estatisticamente iguais a zero nas quatro regiões. O fator de produção capital em culturas (CC) apresenta coeficiente de elasticidade estatisticamente diferente de zero somente na região Nordeste. Por outro lado, o coeficiente de elasticidade da variável capital em animais (CA) é estatisticamente nulo somente nesta região.

Vale destacar que o fator de produção mais importante na formação do valor da produção das regiões Nordeste, São Paulo e Sul é a mão-de-obra. Tendo como referência o valor de seu coeficiente, variações no uso deste fator, mantendo-se todos os demais fatores constantes, ocasionaria, em termos proporcionais, o mesmo impacto sobre o valor da produção do Nordeste e de São Paulo.

Comparando-se as regiões Nordeste e Sudeste (exclusive SP), observa-se que um aumento porcentual no uso da mão-de-obra na agropecuária nordestina ocasionaria, segundo os valores estimados dos coeficientes de elasticidade, um aumento porcentual 2,5 vezes maior do que aquele que se obteria na região Sudeste.

O efeito da variável capital em animais (CA) sobre o valor da produção é mais evidente na região Sudeste, com estimativa da respectiva elasticidade parcial igual a 0,22 , em torno de 1,7 vezes o valor obtido no Nordeste e em São Paulo. 
Confrontando-se as equações estimadas em 1980 (Tabela 20) e em 1985 (Tabela 13), para cada região, nota-se que houve mudanças significativas. Observa-se, em São Paulo, alterações na significância de 6 parâmetros, sendo que a mais expressiva ocorre com a variável CC. O coeficiente dessa variável em 1980 é negativo e não-significativo, e em 1985 é positivo e significativo. Nas demais regiões mudanças desta natureza ocorrem menos intensivamente. Na região Sul, por exemplo, os coeficientes das variáveis VI e PRT são significativos somente em 1985. Isto mostra, de certo modo, que houve mudanças expressivas nas funções de produção agrícolas regionais entre os referidos anos, o que será melhor analisado na seção 4.5 .

O emprego do modelo da equação 6 no ajustamento das funções de produção das regiões ocasionou alterações importantes no valor e na significância das estimativas de alguns parâmetros (Tabela 21). A estimativa do coeficiente de elasticidade de CC (capital em culturas) torna-se não-significativa no Nordeste, e a elasticidade de CA (capital em animais) deixa de ser significativa em São Paulo, mas torna-se significativa no Nordeste.

As estimativas dos coeficientes das variáveis VI, DA e ESC1 permanecem nãosignificativas em todas as regiões. As variáveis DM, OD e PRT não apresentam mudanças quanto à significância estatística de seus coeficientes.

Observando-se a região Nordeste, nota-se que o ajustamento, sob o ponto de vista estatístico, é melhor, com $\mathrm{R}^{2}$ igual a 0,92 . Nas demais regiões não houve mudança significativa no valor de $\mathrm{R}^{2}$. Nas regiões Sudeste e Sul não houve alteração na significância dos parâmetros: aqueles que são significativos no modelo 5 preservam suas significâncias no modelo 6. Situação semelhante ocorre na região Sul. 


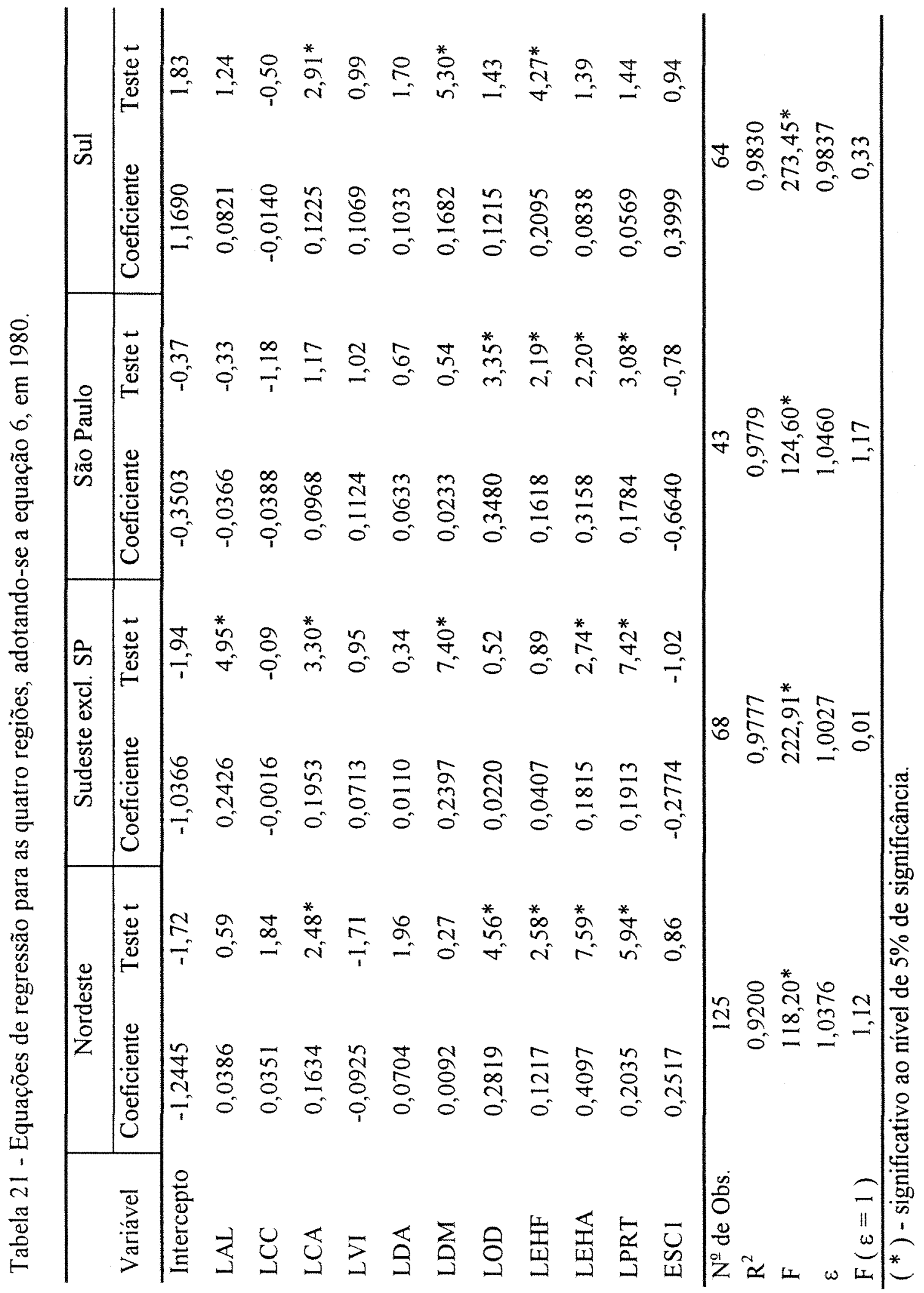


A exemplo do que ocorreu com as funções de produção estimadas adotando-se a equação 5, as estimativas das funções para as quatros regiões, através da equação 6 , são todas altamente significativas, e apresentam retornos constantes à escala.

Para verificar se há diferenças entre as funções de produção dessas regiões foi efetuado o ajustamento de uma regressão múltipla com 48 parâmetros, utilizando-se 3 variáveis binárias para distinguir as quatro regiões, adotando-se o modelo da equação $6^{33}$.

A Tabela 22 contém os resultados dos testes das diferenças interregionais em 1980. Os valores de "F" apresentados, todos com 12 e 252 graus de liberdade, mostram que a função de produção do Nordeste apresenta diferenças, estatisticamente significativas, com as funções de produção do Sudeste (exclusive SP) e da região Sul.

Comparando-se as Tabelas 15 e 22 , observa-se que há mais valores significativos para 1985 do que para 1980, indicando que houve, neste período, um aumento das diferenças das funções de produção agropecuária regionais. Isto ocorreu, certamente, pela difusão de uma modernização que se deu de forma diferenciada, obedecendo, provavelmente, às peculiaridades de cada região.

${ }^{33}$ A Tabela 3 do Apêndice contém a estimativa da equação de regressão ajustada para comparar as funções de produção regionais, em 1980. 
Tabela 22 - Testes das diferenças interregionais na função de produção, adotando-se o modelo da equação 6, em 1980.

\begin{tabular}{ll}
\hline Regiões comparadas & F \\
\hline NE com SE excl. SP & $5,43^{*}$ \\
NE com SP & 1,16 \\
NE com Sul & $8,14^{*}$ \\
SE excl. SP com SP & 1,72 \\
SE excl. SP com Sul & 0,88 \\
SP com Sul & 1,15 \\
\hline
\end{tabular}

(*) - significativo ao nível de $5 \%$ de significância. 
Tabela 23 - Equações de regressão para as $300 \mathrm{MRH}$, com 12 ou 13 variáveis explanatórias, em 1975.

\begin{tabular}{|c|c|c|c|c|}
\hline \multirow[b]{2}{*}{ Variável } & \multicolumn{2}{|c|}{ Equação 1} & \multicolumn{2}{|c|}{ Equação 2} \\
\hline & Coeficiente & Teste $t$ & Coeficiente & Teste t \\
\hline Intercepto & 0,0823 & 0,17 & 0,0951 & 0,21 \\
\hline $\mathrm{LAL}$ & 0,1657 & $5,16^{*}$ & 0,1505 & $4,71^{*}$ \\
\hline LAP & $-0,0744$ & $-2,57^{*}$ & $-\cdots$ & --- \\
\hline LAPP & --- & --- & $-0,0361$ & $-3,18^{*}$ \\
\hline LAPN & $-\cdots$ & $-\cdots$ & $-0,0795$ & $-4,26^{*}$ \\
\hline LAM & 0,0001 & 0,01 & 0,0151 & 0,88 \\
\hline $\mathrm{LCC}$ & 0,0233 & $2,02^{*}$ & 0,0217 & $1,95^{*}$ \\
\hline LCA & 0,2614 & $5,58^{*}$ & 0,3004 & $7,55^{*}$ \\
\hline LVI & 0,0521 & 1,85 & 0,0541 & 1,96 \\
\hline LDA & 0,0302 & 1,66 & 0,0378 & $2,11 *$ \\
\hline LDM & 0,0290 & 1,39 & 0,0179 & 0,84 \\
\hline LOD & 0,3939 & $9,55^{*}$ & 0,4032 & $9,93^{*}$ \\
\hline LEH & 0,1373 & $3,48^{*}$ & 0,1306 & $3,52^{*}$ \\
\hline LPRT & 0,0730 & $2,71^{*}$ & 0,0681 & $2,76^{*}$ \\
\hline $\mathrm{ESCl}$ & 0,3291 & $2,61^{*}$ & 0,2954 & $2,37^{*}$ \\
\hline $\mathrm{R}^{2}$ & \multicolumn{2}{|c|}{0,9584} & \multicolumn{2}{|c|}{0,9605} \\
\hline $\mathrm{F}$ & \multicolumn{2}{|c|}{$550,92^{*}$} & \multicolumn{2}{|c|}{$534,45^{*}$} \\
\hline$\varepsilon$ & \multicolumn{2}{|c|}{1,0186} & \multicolumn{2}{|c|}{1,0158} \\
\hline$F(\varepsilon=1)$ & \multicolumn{2}{|c|}{0,94} & \multicolumn{2}{|c|}{0,69} \\
\hline
\end{tabular}

$\left(^{*}\right)$ - significativo ao nível de $5 \%$ de significância.

APP e APN continuam negativos, fato também observado na equação 2 para 1980 e 1985.

Nestes dois modelos, de acordo com os valores dos testes " $t$ ", a variável que mais contribui com o valor da produção é $O D$, cujo coeficiente de regressão é 0,40 , o que significa dizer que um aumento de $10 \%$ no uso deste fator, mantido constante o uso dos demais fatores, provocaria um acréscimo de aproximadamente $4 \%$ no valor da produção 


\subsection{A Função de Produção Cobb-Douglas em 1975}

\subsubsection{A Função de Produção para as 300 MRH}

A Tabela 23 mostra as equações 1 e 2 (as mesmas que foram aplicadas aos dados de 1980 e 1985) para o ano de 1975. Da mesma forma que nas equações 1 para 1980 e 1985, a estimativa da elasticidade de produção da área de pastagens é negativa e estatisticamente diferente de zero. Os coeficientes das variáveis VI, DA e DM são positivos, porém estatisticamente iguais a zero. A variável AM apresentou elasticidade negativa, no entanto o teste " $t$ " não foi significativo $e$, portanto, sob o ponto de vista estatístico, seu valor é nulo. O ajustamento é muito bom $\left(R^{2}=0,958\right)$, mas, das doze variáveis incluídas no modelo, 4 apresentam coeficientes de elasticidade nãosignificativos.

A desagregação da área de pastagens (AP) em área de pastagens plantadas (APP) e área de pastagens naturais (APN) elevou um pouco o valor do coeficiente de determinação para 0,96 , no entanto não afetou de forma expressiva a maioria dos coeficientes de regressão. A alteração mais expressiva diz respeito à variável DA, cuja elasticidade, apesar de seu valor não mudar muito, passa a ser estatisticamente diferente de zero na equação 2. Observa-se ainda que houve mudança no sinal do coeficiente da variável $\mathrm{AM}$, que continua, entretanto, a não diferir estatisticamente de zero. À exceção das variáveis $\mathrm{AM}$, VI e $\mathrm{DM}$, todos os coeficientes das demais variáveis são estatisticamente diferentes de zero, sendo que os coeficientes das variáveis desagregadas 
das microrregiões homogêneas. Em ordem decrescente de importância seguem as variáveis CA, AL e EH.

Eliminando do modelo 1 a variável AM (área com matas) obtém-se a equação 3 da Tabela 24. A exclusão desta variável não afetou a qualidade do ajustamento, nem proporcionou mudança no valor do coeficiente de determinação, e o teste "F" para qualidade do ajustamento permanece altamente significativo. Os valores das estimativas dos coeficientes de regressão são quase os mesmos, e aqueles coeficientes que apresentaram significância estatística na equação 1 permanecem significativos na equação 3, indicando a pouca importância que a variável AM representa na "explicação" da variação do valor da produção agropecuária entre as microrregiões homogêneas.

Comparando-se as equações 1,2 e $3 \mathrm{com}$ as correspondentes equações obtidas em 1980 e 1985, nota-se que houve uma troca de posição entre as variáveis EH e OD quanto a suas participações na determinação do valor da produção. Em 1975, 0 coeficiente de elasticidade da variável OD (despesas com aluguel de máquinas e equipamentos, transporte da produção, sacaria e outras embalagens, combustiveis, energia elétrica e outras despesas) está em torno de 0,40 , e nos anos subsequentes (1980 e 1985) este valor diminui em $49 \%$. Por outro lado, o valor do coeficiente de elasticidade da mão-de-obra $(\mathrm{EH})$, que em 1975 era aproximadamente 0,14 , quase 1/3 do valor do coeficiente de elasticidade de OD, passa a representar 2,5 vezes o valor da elasticidade de OD em 1980, caindo para 2,3 vezes em 1985. Esta constatação leva a crer que houve mudanças importantes no processo produtivo das $300 \mathrm{MRH}$. 
Tabela 24 - Equações de regressão para as $300 \mathrm{MRH}$, com 11 ou 12 variáveis explanatórias, em 1975.

\begin{tabular}{|c|c|c|c|c|}
\hline \multirow[b]{2}{*}{ Variável } & \multicolumn{2}{|c|}{ Equação 3} & \multicolumn{2}{|c|}{ Equação 4} \\
\hline & Coeficiente & Teste $t$ & Coeficiente & Teste $t$ \\
\hline Intercepto & 0,0836 & 0,20 & 0,4516 & 1,13 \\
\hline LAL & 0,1657 & $5,17^{*}$ & 0,1362 & $4,33^{*}$ \\
\hline LAP & $-0,0744$ & $-2,59^{*}$ & $-0,1147$ & $-4,01^{*}$ \\
\hline LCC & 0,0233 & $2,05^{*}$ & 0,0121 & 1,08 \\
\hline LCA & 0,2613 & $5,60^{*}$ & 0,2752 & $6,13^{*}$ \\
\hline LVI & 0,0522 & 1,90 & 0,0778 & $2,86^{*}$ \\
\hline LDA & 0,0302 & 1,67 & 0,0341 & 1,94 \\
\hline LDM & 0,0290 & 1,40 & 0,0143 & 0,70 \\
\hline LOD & 0,3939 & $9,64 *$ & 0,3794 & $9,67^{*}$ \\
\hline LEH & 0,1373 & $3,49^{*}$ & $\ldots$ & $-\cdots$ \\
\hline LEHF & $\cdots$ & $\cdots$ & 0,0659 & $2,61^{*}$ \\
\hline LEHA & $\cdots$ & $-\cdots$ & 0,1395 & $5,57^{*}$ \\
\hline LPRT & 0,0729 & $3,04^{*}$ & 0,0528 & $2,25 *$ \\
\hline ESC1 & 0,3292 & $2,62^{*}$ & 0,5736 & $4,30^{*}$ \\
\hline$\overline{\mathrm{R}^{2}}$ & \multicolumn{2}{|c|}{0,9584} & \multicolumn{2}{|c|}{0,9611} \\
\hline $\mathrm{F}$ & \multicolumn{2}{|c|}{$603,10^{*}$} & \multicolumn{2}{|c|}{$590,82^{*}$} \\
\hline$\varepsilon$ & \multicolumn{2}{|c|}{1,0186} & \multicolumn{2}{|c|}{1,0198} \\
\hline $\mathrm{F}(\varepsilon=1)$ & \multicolumn{2}{|c|}{1,00} & \multicolumn{2}{|c|}{1,23} \\
\hline
\end{tabular}

(*) - significativo ao nível de $5 \%$ de significância.

A desagregação de EH em EHF e EHA alterou a significância do parâmetro da variável capital em culturas (CC), cuja elasticidade torna-se estatisticamente nula no modelo 4. Os coeficientes de elasticidade de EHF e EHA permanecem altamente significativos, reafirmando a importância do fator de produção mão-de-obra. O valor da elasticidade da mão-de-obra assalariada (EHA) corresponde a 2,1 vezes o valor da elasticidade da mão-de-obra familiar. Observa-se, ainda, que o coeficiente de regressão da variável ESC1 sofreu um acréscimo de $74 \%$. 
Ao excluir a variável AP da equação 3 , visto sua relação negativa com VP, obteve-se a equação 5 (Tabela 25). Nota-se que houve mudanças no valor e na significância do coeficiente de elasticidade de CC, o qual torna-se estatisticamente igual a zero na equação 5. Alterações importantes também ocorreram nos valores dos coeficientes das variáveis $\mathrm{CA}, \mathrm{EH}, \mathrm{PRT}$ e ESC1, sem afetar, entretanto, a significância desses coeficientes. Comparando-se as equações 4 e 6 , pode-se observar que a eliminação da variável AP não ocasionou mudanças na significância estatística das

Tabela 25 - Equações de regressão para as $300 \mathrm{MRH}$, com 10 ou 11 variáveis explanatórias, em 1975.

\begin{tabular}{|c|c|c|c|c|}
\hline \multirow[b]{2}{*}{ Variável } & \multicolumn{2}{|c|}{ Equação 5} & \multicolumn{2}{|c|}{ Equação 6} \\
\hline & Coeficiente & Teste $t$ & Coeficiente & Teste $t$ \\
\hline Intercepto & $-0,5178$ & $-1,45$ & $-0,4144$ & $-1,20$ \\
\hline LAL & 0,1696 & $5,25^{*}$ & 0,1542 & $4,83^{*}$ \\
\hline LCC & 0,0181 & 1,60 & 0,0062 & 0,54 \\
\hline LCA & 0,1642 & $5,87^{*}$ & 0,1348 & $4,67^{*}$ \\
\hline LVI & 0,0417 & 1,52 & 0,0550 & $2,01^{*}$ \\
\hline LDA & 0,0227 & 1,26 & 0,0216 & 1,22 \\
\hline LDM & 0,0399 & 1,95 & 0,0344 & 1,70 \\
\hline LOD & 0,3948 & $9,57^{*}$ & 0,3915 & $9,75^{*}$ \\
\hline LEH & 0,1756 & $4,77^{*}$ & ---- & --- \\
\hline LEHF & --- & $-\cdots$ & 0,1040 & $4,33^{*}$ \\
\hline LEHA & $\cdots$ & ---- & 0,1277 & $5,01^{*}$ \\
\hline LPRT & 0,1109 & $5,78^{*}$ & 0,1112 & $5,88^{*}$ \\
\hline ESCl & 0,3812 & $3,04 *$ & 0,5804 & $4,24^{*}$ \\
\hline $\mathrm{R}^{2}$ & \multicolumn{2}{|c|}{0,9574} & \multicolumn{2}{|c|}{0,9589} \\
\hline $\mathrm{F}$ & \multicolumn{2}{|c|}{$649,92 *$} & \multicolumn{2}{|c|}{611,01 * } \\
\hline$\varepsilon$ & \multicolumn{2}{|c|}{1,0265} & \multicolumn{2}{|c|}{1,0294} \\
\hline$F(\varepsilon=1)$ & \multicolumn{2}{|c|}{2,05} & \multicolumn{2}{|c|}{2,61} \\
\hline
\end{tabular}


estimativas dos coeficientes das variáveis, porém, observa-se mudanças expressivas nas elasticidades de CA, EHF e PRT.

O coeficiente de elasticidade da variável preço da terra (PRT) teve seu valor acrescido em aproximadamente $110 \%$, permanecendo, entretanto, inferior a $1 / 3$ do coeficiente de elasticidade de OD. O valor do coeficiente de elasticidade da variável CA sofreu uma redução de $51 \%$, mas manteve-se significativo na equação 6 , e a elasticidade de EHF cresceu $53 \%$. Os ajustamentos apresentados na Tabela 25 são bons, com $\mathrm{R}^{2}$ próximos a 0,96 e os testes " $F$ " para qualidade dos ajustamentos significativos a $5 \%$. As funções de produção estimadas apresentam rendimentos constantes à escala.

A Tabela 26 mostra as equações 7 e 8, que correspondem às equações 5 e 6 , respectivamente, após a inclusão da variável urbanização (URB). O coeficiente desta variável é positivo e estatisticamente diferente de zero. A inclusão desta variável proporcionou mudanças marcantes nos ajustamentos. $\mathrm{O}$ número de parâmetros estatisticamente significativos é superior ao obtido com os ajustamentos contidos na Tabela 25. Porém, a significância das equações de regressão é bastante semelhante, com $\mathrm{R}^{2}$ muito próximos.

As variáveis $\mathrm{CC}$ e DM, cujos coeficientes de elasticidade não são significativos nas equações 5 e 6 , passam a sê-lo na equação 7 . O efeito mais expressivo, ao se incorporar a variável URB nos ajustamentos, acontece sobre a variável escolaridade (ESC1), elevando o valor de seu coeficiente em aproximadamente 39 e $37 \%$ nas equações 7 e 8 . respectivamente. 
Em geral, pode-se concluir que a variável URB tem se constituído em um fator de grande importância sobre a produção agropecuária das microrregiões, ao manter uma relação positiva e significativa com VP, além de ter influenciado a significância dos coeficientes de outras variáveis incluídas nos modelos. Porém, com base nos valores dos testes " $t$ " contidos na equação 8 , pode-se observar que os fatores mais fortemente associados com o valor da produção são, em ordem decrescente, OD, PRT e EHA.

Tabela 26 - Equações de regressão para as $300 \mathrm{MRH}$, com 11 ou 12 variáveis explanatórias, em 1975.

\begin{tabular}{|c|c|c|c|c|}
\hline \multirow[b]{2}{*}{ Variável } & \multicolumn{2}{|c|}{ Equação 7} & \multicolumn{2}{|c|}{ Equação 8} \\
\hline & Coeficiente & Teste $t$ & Coeficiente & Teste $t$ \\
\hline Intercepto & $-0,5785$ & $-1,62$ & $-0,5266$ & $-1,55$ \\
\hline LAL & 0,1553 & $4,73^{*}$ & 0,1263 & $3,87^{*}$ \\
\hline $\mathrm{LCC}$ & 0,0232 & $2,01^{*}$ & 0,0120 & 1,06 \\
\hline LCA & 0,1552 & $5,52^{*}$ & 0,1149 & $3,95 *$ \\
\hline LVI & 0,0391 & 1,43 & 0,0550 & $2,05^{*}$ \\
\hline LDA & 0,0147 & 0,80 & 0,0100 & 0,56 \\
\hline LDM & 0,0541 & $2,52 *$ & 0,0538 & $2,58^{*}$ \\
\hline LOD & 0,4088 & $9,84^{*}$ & 0,4074 & $10,23^{*}$ \\
\hline LEH & 0,1652 & $4,48^{*}$ & --- & --- \\
\hline LEHF & --- & $-\cdots$ & 0,0932 & $3,91 *$ \\
\hline LEHA & $-\cdots$ & --- & 0,1418 & $5,57^{*}$ \\
\hline LPRT & 0,1135 & $5,94^{*}$ & 0,1152 & $6,17^{*}$ \\
\hline $\mathrm{ESCl}$ & 0,4915 & $3,64^{*}$ & 0,7937 & $5,28^{*}$ \\
\hline URB & 0,3190 & $2,12^{*}$ & 0,4794 & $3,19^{*}$ \\
\hline $\mathrm{R}^{2}$ & \multicolumn{2}{|c|}{0,9581} & \multicolumn{2}{|c|}{0,9603} \\
\hline $\mathrm{F}$ & \multicolumn{2}{|c|}{$598,43^{*}$} & \multicolumn{2}{|c|}{$578,78^{*}$} \\
\hline$\varepsilon$ & \multicolumn{2}{|c|}{1,0157} & \multicolumn{2}{|c|}{1,0145} \\
\hline$F(\varepsilon=1)$ & \multicolumn{2}{|c|}{0,67} & \multicolumn{2}{|c|}{0,62} \\
\hline
\end{tabular}

(*) - significativo ao nivel de 5\% de significância. 
Em resumo, observa-se que a inclusão da variável urbanização (URB), a qual mostrou-se positivamente relacionada com VP, alterou de forma significativa as estimativas de alguns parâmetros, mas não alterou substancialmente o valor dos coeficientes de determinação das regressões.

Todas as regressões estimadas são altamente significativas, com $R^{2}$ sempre superior a 95\%. Os testes "F" para retornos à escala não são estatisticamente significativos, e consequentemente, as elasticidades totais de produção não diferem estatisticamente da unidade.

O fator de produção mão-de-obra, seja na forma agregada (EH) ou desagregada (EHF e EHA), apresenta coeficiente de elasticidade sempre positivo e estatisticamente diferente de zero em todos os modelos. O coeficiente de elasticidade da mão-de-obra assalariada (EHA) é sempre superior ao da mão-de-obra familiar (EHF) ${ }^{34}$, para o Brasil como um todo.

\footnotetext{
${ }^{34}$ Esta relação, porém, se inverte na região Sul, nos três anos analisados.
} 


\subsubsection{As Funções de Produção Regionais}

A Tabela 27 contém as equações estimadas para as quatro regiões, com base no modelo representado pela equação 5 . Os ajustamentos são muito bons, com $\mathrm{R}^{2}$ igual a $92 \%$ para a região Nordeste, e acima de $96 \%$ para as demais regiões. Porém, observa-se problemas sérios de multicolinearidade, principalmente na região Sul e em São Paulo. Este fato é menos preocupante na região Sudeste, onde o modelo ajustado apresenta um $\mathrm{R}^{2}$ igual a $96,4 \%$, e com 6 estimativas dos parâmetros da regressão estatisticamente significativas. As estimativas dos coeficientes de regressão das variáveis CC, DA e ESC1 não são estatisticamente significativas em nenhuma região $0^{35}$. Das variáveis incluídas neste modelo apenas OD apresenta elasticidade positiva e estatisticamente diferente de zero nas quatro regiões.

A desagregação do fator de produção mão-de-obra (EH) em EHF e EHA afetou a significância dos parâmetros da equação de regressão da região Sudeste (Tabela 28). Os coeficientes das variáveis CA e VI tornam-se estatisticamente iguais a zero. Não ocorre nas demais regiões mudança na significância dos parâmetros, porém, observa-se

\footnotetext{
${ }^{35}$ A estimativa do coeficiente de regressão de ESCI também não foi significativa em nenhuma região, em 1980 e 1985. Porém. foi mantida nos modelos porque, além de sua importância como condicionante de todo o processo produtivo. sua exclusão reduziu a qualidade dos ajustamentos.
} 


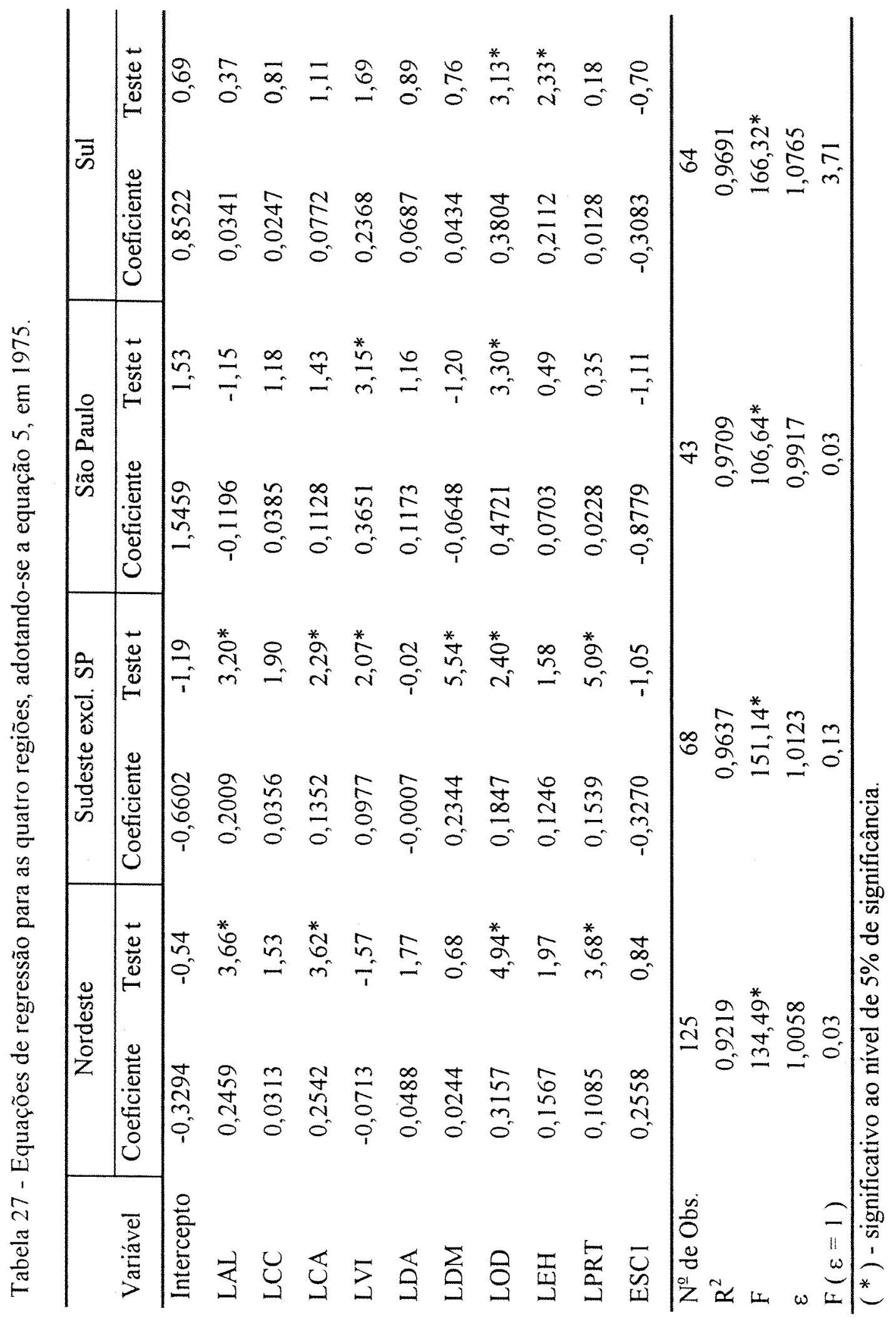




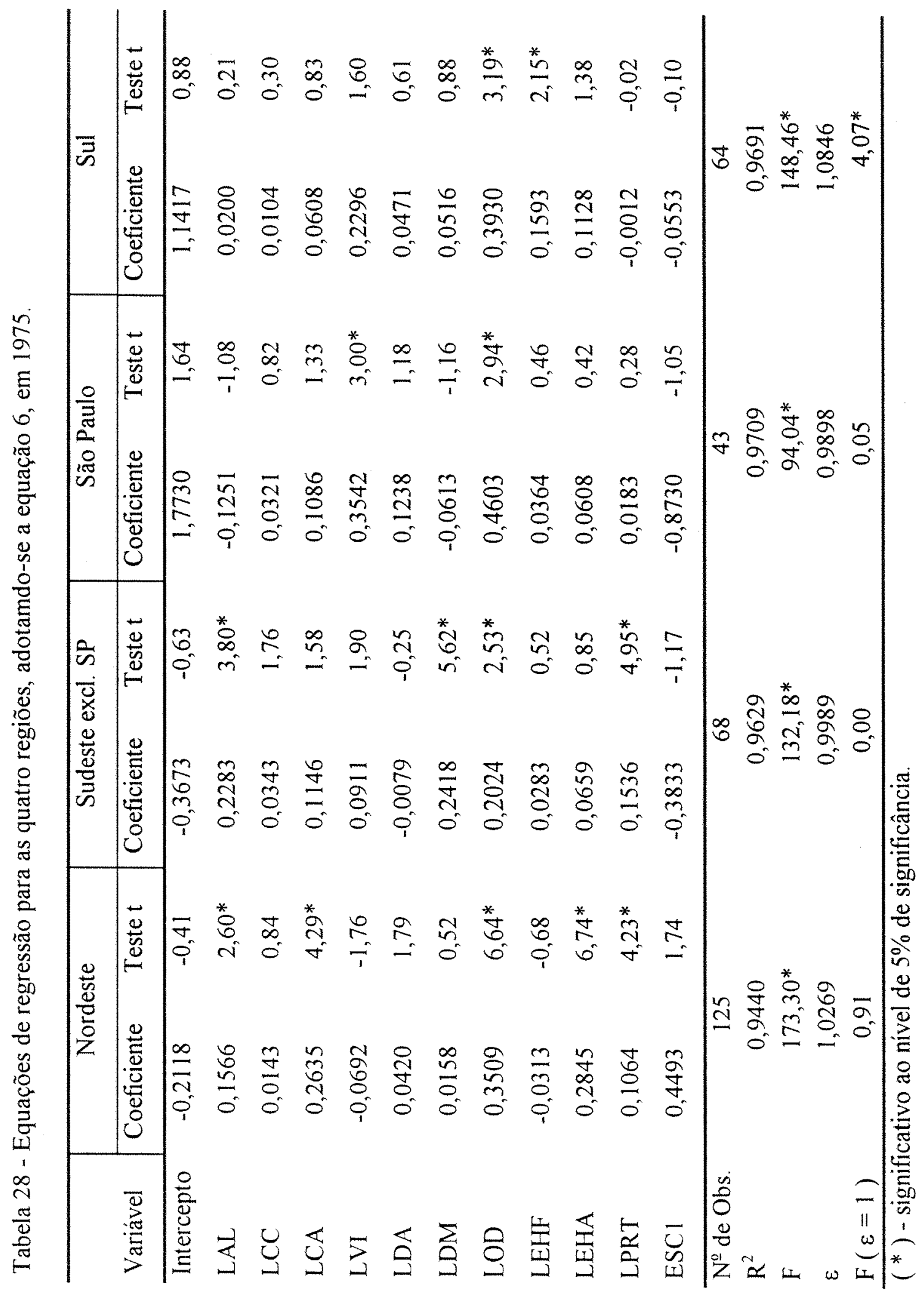


variações significativas no valor das estimativas dos parâmetros. No Nordeste, por exemplo, o valor da elasticidade da área de lavouras (AL) se reduz de $36 \%$, enquanto que o valor do parâmetro de $\mathrm{ESCl}$ cresce $76 \%$.

Observa-se, pela primeira vez, uma elasticidade de escala estatisticamente diferente de 1 ao nível de significância de 5\% (região Sul), indicando a existência de rendimentos crescentes à escala. Isto seria, entretanto, uma conclusão precipitada, por se tratar de um ajustamento em que o coeficiente de determinação é bastante elevado, com $\mathrm{R}^{2}$ praticamente igual a $97 \%$, e apresentar apenas duas estimativas dos parâmetros estatisticamente significativas.

Da mesma forma que para 1980 e 1985, ajustou-se uma regressão múltipla ${ }^{36}$ com 48 parâmetros, utilizando 3 variáveis binárias para distinguir as quatro regiões, a fim de se verificar se há diferença entre as funções de produção das regiões, adotando-se o modelo da equação 6 .

A Tabela 29 mostra os testes "F", todos com 12 e 252 graus de liberdade, para diferenças interregionais nas funções de produção, em 1975. Observa-se, na referida Tabela, que não há diferença estatisticamente significativa entre as funções de produção de São Paulo e da região Sul. Por outro lado, do ponto de vista estatístico, pode-se afirmar que as regiões Nordeste e Sudeste apresentam diferença entre suas respectivas funções de produção e as funções de produção das demais regiões.

\footnotetext{
${ }^{36}$ A estimativa da equação de regressão ajustada para comparar as funções de produção regionais, para 1975, encontra-se na Tabela 3 do Apéndice.
} 
Tabela 29 - Testes das diferenças interregionais na função de produção, adotando-se o modelo da equação 6 , em 1975.

\begin{tabular}{ll}
\hline Regiões comparadas & F \\
\hline NE com SE excl. SP & $2,75^{*}$ \\
NE com SP & $2,74^{*}$ \\
NE com Sul & $3,52^{*}$ \\
SE excl. SP com SP & $2,81^{*}$ \\
SE excl. SP com Sul & $2,27^{*}$ \\
SP com Sul & 0,59 \\
\hline
\end{tabular}

$\left(^{*}\right)$ - significativo ao nível de $5 \%$ de significância. 


\subsection{Produtividades Marginais dos Principais Fatores de Produção}

As produtividades marginais dos principais fatores contidos no processo produtivo das $300 \mathrm{MRH}$ foram calculadas com base nas elasticidades estimadas através das equações 5 e 6, para 1975, 1980 e 1985, no ponto das médias geométricas das variáveis envolvidas (Tabela 6).

Para o fator de produção $\mathrm{CA}$, cujo valor já é medido em cruzeiros, a produtividade marginal, por cruzeiro investido, em 1985, é obtida através do produto da elasticidade de produção do fator $(0,0223$, equação 5 - Tabela 12$)$ pela relação entre as médias geométricas de VP e CA (3.307/4.095 - Tabela 6), obtendo-se a produtividade marginal 0,018 , apresentada na Tabela 30 . As produtividades marginais das variáveis $\mathrm{CC}$, VI, DA, DM e OD foram obtidas também através de procedimentos semelhantes.

No cálculo das produtividades marginais de AL e EH é necessário considerar o preço do fator (preço por hectare de terra para lavouras e o salário anual de um trabalhador). Para isso utilizaram-se valores médios para o Brasil e para as regiões publicados pela Fundação Getúlio Vargas $(1985)^{37}$.

O preço médio da terra para lavouras nos dois semestres de 1985 é Cr\$ 6.445.648,00/ha e o valor médio da diária do trabalhador eventual é $\operatorname{Cr} \$ 16.730,50$, o que corresponde, considerando 300 dias de trabalho no ano, ao salário médio anual de Cr\$5.019.150,00 por equivalente-homem. Assim, tendo em vista que o valor médio de VP (Tabela 5) está em $10^{8} \mathrm{Cr} \$$, as produtividades por cruzeiro investido em terra para

\footnotetext{
${ }^{37}$ A Tabela 7 do Apêndice contém o preço médio por hectare de terras para lavouras e o salário anual de um trabalhador eventual para o Brasil e as quatro regiões.
} 
lavouras (AL) e por cruzeiro investido em mão-de-obra (EH), adotando-se as elasticidades da equação 5 para 1985, são dadas por:

$$
0,1589 \times\left(3.307 \times 10^{8} / 97.742 \times 6.445 .648\right)=0,083
$$

$\mathrm{e}$

$$
0,3354 \times\left(3.307 \times 10^{8} / 46.092 \times 5.019 .150\right)=0,479, \quad \text { respectivamente }
$$

As produtividades marginais nos demais anos foram obtidas de forma análoga.

No caso da terra de lavouras (AL), considerando-se que não há amortização, tendo em vista tratar-se de um bem de capital que normalmente sofre valorização até mesmo em uso, desde que se empreguem técnicas de exploração adequadas, espera-se uma produtividade marginal por cruzeiro investido que corresponda aos juros sobre o capital empatado.

Para os fatores de produção que correspondem a fluxos anuais de despesas, tais como DA, DM, OD e EH, é esperada uma produtividade marginal por cruzeiro investido igual ou um pouco superior a 1 .

No caso dos fatores de produção que correspondem a capital fixo CC, CA e VI, espera-se uma produtividade marginal por cruzeiro investido inferior a 1 . Neste caso a produtividade marginal deve corresponder ao valor da amortização e aos juros sobre o capital empatado.

A Tabela 30 apresenta as produtividades marginais dos principais fatores de produção empregados para estimar as equações de regressão, adotando-se os modelos 5 e 6, para 1975,1980 e 1985 . Nota-se que a produtividade marginal da terra de lavouras 
pode ser considerada boa, principalmente quando se emprega a equação 6 , chegando a atingir $10 \%$ em 1985. Isto significa que, mantendo-se as quantidades dos demais fatores de produção constantes, ao se empregar uma unidade monetária a mais do fator 'terra de lavouras" teríamos um aumento de 0,10 no valor da produção.

A produtividade marginal de VI é em geral muito baixa, enquanto que a de CA é bastante elevada em 1975 e $1980^{38}$. O fator de produção CC, cujo coeficiente de elasticidade é estatisticamente significativo apenas em 1985, apresenta produtividade marginal baixa.

Os fatores de produção que correspondem a fluxos anuais de despesas (DA, DM e OD) apresentam, em 1985, produtividades marginais superiores a 1, conforme o esperado. Por outro lado, as produtividades marginais de DA e DM são, em 1975, menores que 1 . Com base nestes resultados pode-se concluir que houve uma mudança expressiva na função de produção da agricultura brasileira, entre 1975 e 1985, no que se refere à eficiência de componentes do capital variável. Observa-se, através da equação 6 , que as produtividades marginais de DA e DM aumentaram 191 e $246 \%$, respectivamente, entre 1975 e 1985. Por outro lado, a produtividade marginal de OD sofreu uma redução, neste mesmo período, de aproximadamente $28 \%$, atingindo $2,676 \mathrm{em} 1985$, que é ainda uma produtividade marginal bastante elevada.

A baixa produtividade marginal de VI e a elevada produtividade marginal de OD, à primeira vista, é contraditório, já que a maioria dos fatores de produção que compõem

\footnotetext{
${ }^{38} \mathrm{O}$ coeficiente de elasticidade de VI é estatisticamente diferente de zero somente na equação 6 para 1985 (ver Tabelas 12,18 e 25 )
} 
Tabela 30 - Produtividades marginais, em 1975, 1980 e 1985, por cruzeiro gasto ou investido nos fatores de produção, no ponto das médias geométricas das variáveis, adotando-se os coeficientes de elasticidade das equações 5 e 6 dos respectivos anos.

\begin{tabular}{lccc|ccc}
\hline & \multicolumn{3}{c|}{ Equação 5 } & \multicolumn{3}{c}{ Equação 6 } \\
\cline { 2 - 7 } Variável & 1975 & 1980 & 1985 & 1975 & 1980 & 1985 \\
\hline AL & 0,097 & 0,063 & 0,083 & 0,088 & 0,075 & 0,101 \\
CC & 0,057 & 0,021 & 0,089 & 0,019 & 0,006 & 0,079 \\
CA & 0,186 & 0,142 & 0,018 & 0,153 & 0,133 & 0,012 \\
VI & 0,051 & 0,004 & 0,031 & 0,067 & 0,006 & 0,028 \\
DA & 0,597 & 1,506 & 1,598 & 0,568 & 1,566 & 1,656 \\
DM & 0,928 & 0,912 & 2,590 & 0,800 & 0,933 & 2,768 \\
OD & 3,761 & 2,424 & 2,657 & 3,729 & 2,528 & 2,676 \\
EH & 0,195 & 0,504 & 0,479 & $-\cdots$ & $\cdots--$ & $\cdots$ \\
EHF & $-\cdots$ & $-\cdots---$ & $-\cdots$ & 0,184 & 0,495 & 0,424 \\
EHA & $\cdots--$ & $\cdots--$ & $\cdots$ & 0,495 & 0,560 & 0,534 \\
\hline
\end{tabular}

estas variáveis são complementares ${ }^{39}$. Porém isto indica apenas que os agricultores estão utilizando estes fatores de produção em proporções inadequadas, com excesso de VI e/ou escassez de OD.

Observa-se na equação 6 da Tabela 18 que o valor do coeficiente de elasticidade de VI é extremamente baixo e absolutamente não-significativo. Isto, certamente, deve estar associado à subutilização desses bens de capital no meio rural.

Em 1975, o nível de utilização de tratores no Brasil foi de 594 horas-máquina por $\mathrm{ano}^{40}$, o que corresponde a 74 dias de uso anual, aproximadamente 2,5 meses. Este índice

\footnotetext{
${ }^{39}$ Vale lembrar que OD inclui as despesas com combustiveis. lubrificantes e energia elétrica. insumos necessários para movimentar máquinas, instrumentos agrários e veículos, cujo valor é componente da variável VI.
} 
caiu para 72 horas em 1985 (Nojimoto, 1987, p.221). Ainda segundo este Autor, "este baixo nível (de uso) ... estaria ocorrendo muito em função do crédito subsidiado que distorcia os custos reais do trator, principalmente nos periodos de elevada inflação e taxa de juro fixa" (p.280).

Observando-se a variável mão-de-obra (EH) na equação 5 , nota-se que houve um aumento significativo (146\%) na produtividade marginal deste fator entre 1975 e 1985. Isto deve-se, principalmente, aos investimentos em máquinas, equipamentos agrários e insumos modernos, ocorridos na década de 70 , oriundos do crédito rural subsidiado.

As produtividades marginais de EHF e EHA cresceram 130 e 7,9\%, respectivamente, entre 1975 e 1985 (equação 6). Observa-se, também, que a produtividade marginal da mão-de-obra assalariada (EHA) é sensivelmente superior à da mão-de-obra familiar $(\mathrm{EHF})^{41}$, confirmando a idéia da existência de um relativo excesso de mão-de-obra nas propriedades familiares. Finalmente, a produtividade marginal da área de lavouras sofreu um acréscimo de $14,7 \%$. Todas estas constatações nos levam a supor que houve mudança tecnológica na agricultura brasileira neste periodo. O que será verificado na seção 4.5 .

A Tabela 31 mostra as produtividades marginais por cruzeiro gasto ou investido nos principais fatores de produção, para as quatro regiões, em 1975, 1980 e 1985, adotando-se a equação 5 . Sempre que o coeficiente de elasticidade estimado foi negativo,

\footnotetext{
${ }^{40}$ Isto representa $59,4 \%$ do nível de utilização estimado pela indústria de tratores, que é de 1.000 horas/ano.

${ }^{41}$ Esta superioridade é de $169 \%$ em 1975, 13\% em 1980 e $26 \%$ em 1985.
} 
a correspondente produtividade marginal foi considerada nula, não sendo apresentada na tabela.

No cálculo das produtividades marginais por cruzeiro gasto ou investido foram utilizadas as médias geométricas das variáveis em cada região (ver Tabela 2 do Apêndice). No caso dos fatores de produção área de lavouras (AL), mão-de-obra (EH) e suas formas desagregadas EHF e EHA, onde é necessário considerar o preço destes fatores, utilizou-se o preço médio do hectare de terra para lavouras e o salário médio anual do trabalhador eventual, em cada região, publicados pela Fundação Getúlio Vargas $(1985)^{42}$

Observa-se na Tabela 31 que, nas quatro regiões, os fatores de produção que correspondem a capital fixo (CC, CA e VI) apresentam produtividades marginais bastante baixas, não correspondendo, portanto, ao valor da amortização e aos juros sobre o capital investido. As produtividades marginais dos fatores referentes a capital circulante (DA, DM e OD) são na grande maioria superiores a 1. Por outro lado, a produtividade marginal da mão-de-obra (EH) é inferior a 1, em todos os anos, nas quatro regiões, com excessão de São Paulo que no ano de 1980 é 1,361.

\footnotetext{
${ }^{42}$ Ver Tabela 7 do Apêndice.
} 


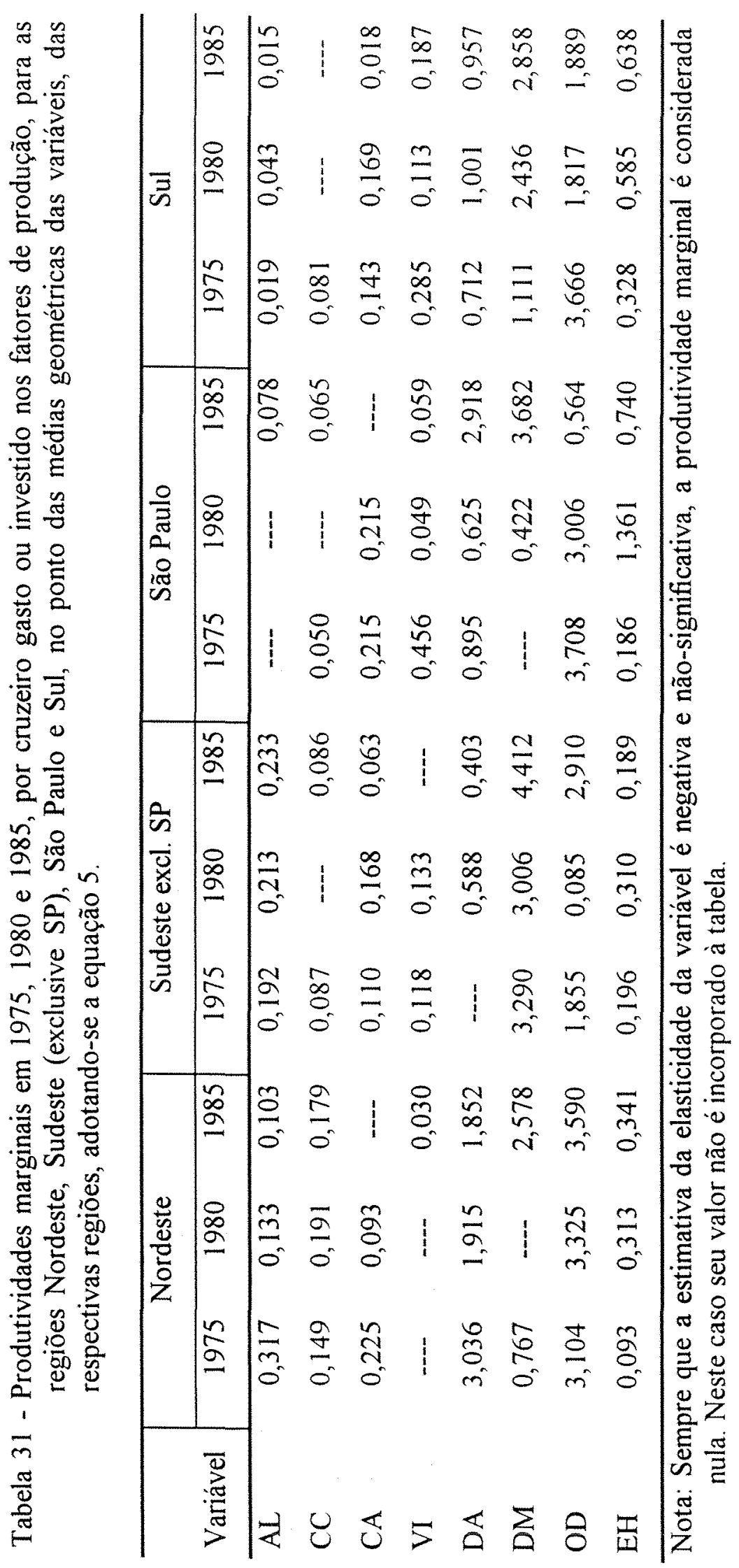


Em 1985, a produtividade marginal da mão-de-obra em São Paulo corresponde a aproximadamente 2,2 vezes a do Nordeste, 3,9 vezes a do Sudeste, e apenas 1,2 vezes a da região Sul. Esta diferença pode ser explicada principalmente pelo elevado nível de mecanização da agricultura paulista, relativamente às demais regiões. Sabe-se que o uso de tratores, máquinas e instrumentos agrários aumenta quase que exclusivamente a produtividade da mão-de-obra. Isto foi claramente constatado por David Ricardo, já em 1817, em sua obra clássica "Princípios de Economia Política e Tributação", ao afirmar que

"Os melhoramentos na agricultura ... são de dois tipos: os que aumentam a capacidade produtiva da terra, e os que nos permitem pelo aperfeiçoamento da maquinaria, obter o produto com menos trabalho ... As melhorias que aumentam a capacidade produtiva da terra são, por exemplo, a rotação mais eficiente das culturas ou a escolha mais cuidadosa dos fertilizantes" (p.71).

Considerando-se que a produtividade marginal de terras de lavouras por cruzeiro investido deve corresponder pelo menos aos juros sobre o capital empatado, tendo em vista não se considerar amortização sobre o valor da terra, observa-se que a produtividade marginal deste fator é elevada no Nordeste e no Sudeste, e extremamente baixa na região Sul.

A desagregação da variável EH em EHF e EHA (Tabela 32) alterou substancialmente os valores das produtividades marginais de quase todos os fatores incluídos na função de produção.

$\mathrm{Na}$ região Nordeste, as produtividades marginais dos fatores $\mathrm{AL}, \mathrm{CC}$ e $\mathrm{OD}$ sofreram uma redução, em 1985 , de $40,8 \%, 13,0 \%$ e 3,6\%, respectivamente. Os fatores 


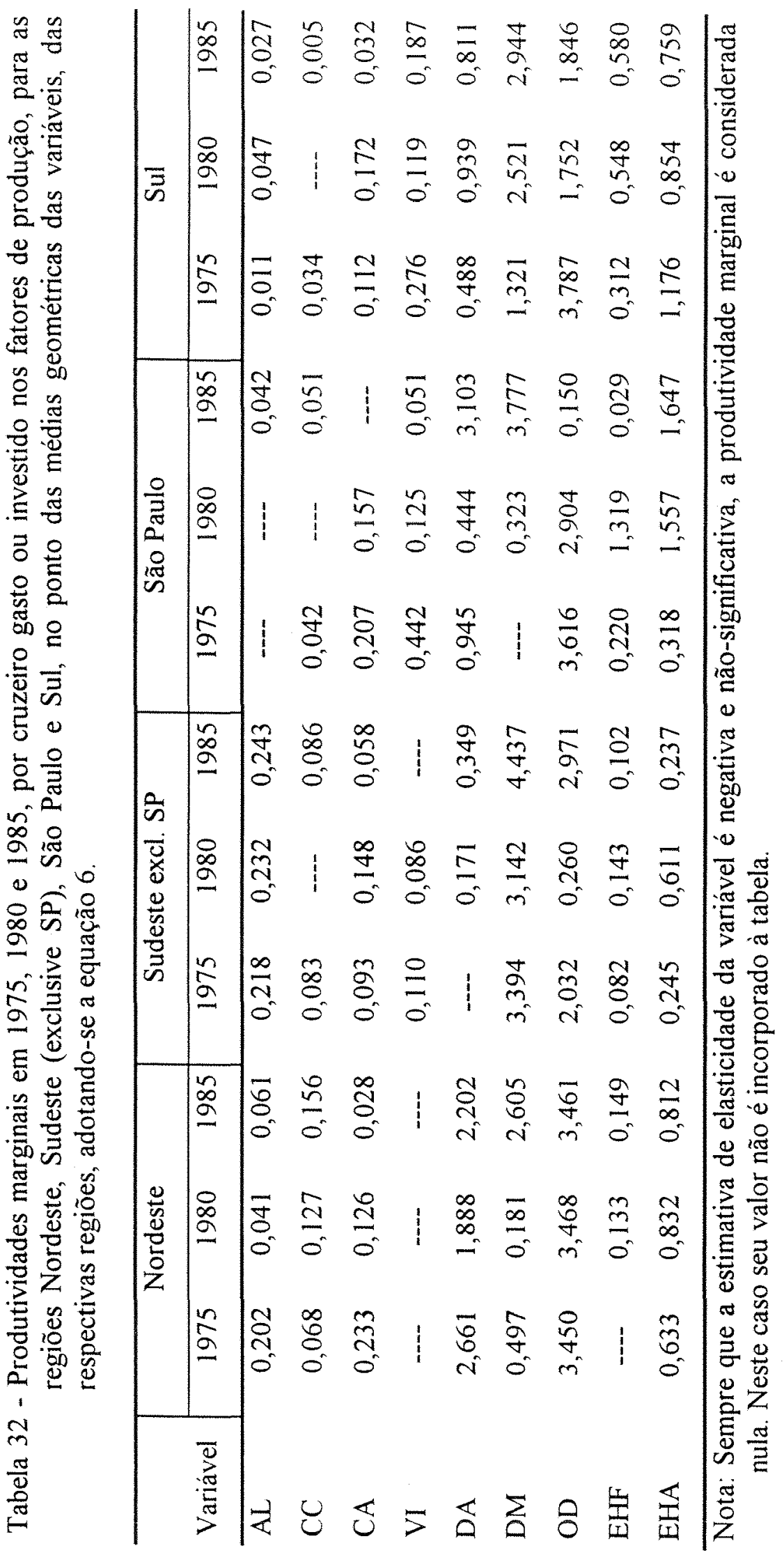


correspondentes a capital circulante apresentam, nas quatro regiões e em quase todos os anos, produtividades marginais elevadas, destacando-se DM (despesas com medicamentos para animais, sal e rações), cuja produtividade marginal é 4,437, em 1985, na região Sudeste.

Comparando-se as quatro regiões entre si, pode-se observar que, em 1985, a maior produtividade marginal da mão-de-obra assalariada ocorre no estado de São Paulo $(1,647)$, que corresponde a 2,0 vezes a do Nordeste, 6,9 vezes a do Sudeste, e 2,2 vezes a do Sul. Por outro lado, é em São Paulo onde se observa a menor produtividade para a mão-de-obra familiar $(0,029)$. Em relação a este fator destaca-se a região Sul, onde a produtividade marginal da mão-de-obra familiar é 0,580 , em 1985 .

Em geral, os fatores de produção que correspondem a capital fixo apresentam baixa produtividade marginal por cruzeiro investido. No caso da terra de lavouras, em que normalmente não se considera amortização sobre o capital investido, uma produtividade acima de $5 \%$ pode ser considerada boa. Portanto, a produtividade marginal da área de lavouras é muito boa no Sudeste, boa no Nordeste, e baixa no Sul e em São Paulo.

\subsection{Comparação Intertemporal das Funções de Produção}

Para verificar se há diferenças estatisticamente significativas entre as funções de produção das 300 microrregiões homogêneas em 1975, 1980 e 1985, ajustou-se o modelo estatístico apresentado a partir da página 47 a 900 observações. As variáveis 
empregadas no ajustamento são as mesmas contidas na equação 6 , o que implica em uma equação de regressão com 36 parâmetros. Os valores de "F" calculados para testar a hipótese de que não há diferenças entre parâmetros em dois anos estão associados a $12 \mathrm{e}$ 864 graus de liberdade.

Procedimento análogo foi empregado para verificar se há modificação significativa da função de produção de cada região entre aqueles anos, adotando-se também o modelo da equação 6 . Os valores de "F" calculados estão associados a $12 \mathrm{e}$ 339 graus de liberdade para o Nordeste, 12 e 168 para o Sudeste, 12 e 93 para São Paulo, e 12 e 156 para a região Sul.

Os resultados dos testes das diferenças intertemporais das funções de produção do Brasil e das regiões estão na Tabela 33. Nota-se que as funções de produção para o Brasil (300 MRH) são estatisticamente diferentes nos três anos. Observa-se na Tabela 4 do Apêndice que a diferença das funções de produção do Brasil relativas aos anos de 1975 e 1980, deve-se, principalmente, às alterações ocorridas nos coeficientes dos fatores de produção despesas com adubos, corretivos, etc. (DA), outras despesas (OD), mão-deobra familiar (EHF), e preço da terra (PRT). Portanto, os fatores de produção relativos a capital fixo não contribuíram, do ponto de vista estatístico, para a diferença entre as funções de produção de 1975 e 1980.

A diferença constatada, estatisticamente, entre as funções de produção de 1975 e 1985 deve-se, basicamente, às mudanças ocorridas nos coeficientes dos fatores capital em culturas (CC), capital em animais (CA), despesas com adubos, corretivos, etc. (DA), 
Tabela 33 - Testes das diferenças na função de produção entre 1975, 1980 e 1985, para as 300 MRH e as quatro Regiões, adotando-se o modelo da equação 6 .

\begin{tabular}{ll}
\hline Anos comparados & F \\
\hline 300 MRH & $3,18^{*}$ \\
1975 com 1980 & $5,32^{*}$ \\
1975 com 1985 & $3,28^{*}$ \\
1980 com 1985 & \\
Nordeste & $1,86^{*}$ \\
1975 com 1980 & $1,88^{*}$ \\
1975 com 1985 & 0,98 \\
1980 com 1985 & \\
Sudeste exclusive SP & 1,06 \\
1975 com 1980 & $2,20^{*}$ \\
1975 com 1985 & $3,78^{*}$ \\
1980 com 1985 & \\
São Paulo & 1,57 \\
1975 com 1980 & $3,01^{*}$ \\
1975 com 1985 & $3,07^{*}$ \\
1980 com 1985 & \\
Sul 1975 com 1980 & $1,92^{*}$ \\
1975 com 1985 & 1,29 \\
1980 com 1985 & 0,81 \\
\hline
\end{tabular}

$(*)$ - significativo ao nível de $5 \%$ de significância.

despesas com medicamentos (DM), outras despesas (OD), preço da terra (PRT) e escolaridade (ESCl).

Para verificar a natureza da mudança tecnológica da função de produção empregou-se, no cálculo da estimativa do valor da produção, em cada ano, as médias 
geométricas das variáveis em 1985. Assim, empregando-se essas médias na equação 6 dos respectivos anos chegou-se aos valores estimados de $\operatorname{Cr} \$ 3.414 \times 10^{8}$ para $1975 ; \mathrm{Cr} \$$ $3.602 \times 10^{8}$ para $1980 ;$ e $\operatorname{Cr} \$ 3.307 \times 10^{8}$ para 1985 . Esta queda no valor da produção entre 1975 e 1985 não era esperado.

Fixadas as quantidades de insumos, se esperaria uma produção crescente, devido ao progresso tecnológico. Mas a variável dependente não é produção fisica, mas valor da produção. Como a agricultura é um setor para o qual os preços são formados em mercados com competição entre grande número de produtores, espera-se que o progresso técnico se reflita na redução dos preços. Sob esse ponto de vista os resultados deixam de ser inesperados.

Considerando-se os testes contidos na Tabela 33 pode-se concluir que, entre as regiões analisadas, o Nordeste não apresenta diferença significativa nas funções de produção de 1980 e 1985, enquanto que, na região Sul essa diferença ocorre somente entre as funções de produção de 1975 e 1980. Tanto em São Paulo como no Sudeste não ocorre mudança estatisticamente significativa na função de produção entre 1975 e 1980.

A Tabela 34 apresenta o crescimento da produtividade bruta do trabalho entre 1975, 1980 e 1985 para o conjunto das 300 MRH, utilizando a equação 6 dos respectivos anos e as médias geométricas apresentadas na Tabela 6.

Verifica-se que, em 1975, o valor da produção por equivalente-homem (em $10^{5} \mathrm{Cr} \$$ de 85 ) é 60,18 , em 1980 é 73,25 , - representando um acréscimo de $21,7 \%$-, e em 1985 cai para 71,74. Isto corresponde a uma redução de $2,1 \%$. Considerando o período $1975 / 1985$, observa-se um aumento de $19,2 \%$ na produtividade bruta do 
Tabela 34 - Decomposição da produtividade bruta do trabalho e de sua variação nos anos de 1975,1980 e 1985 , nas $300 \mathrm{MRH}$, alterando inicialmente os insumos.

\begin{tabular}{ccccc}
\hline $\begin{array}{c}\text { Função } \\
\text { de }\end{array}$ & $\begin{array}{c}\text { Com insumos } \\
\text { convencionais } \\
\text { de }\end{array}$ & $\begin{array}{c}\text { Com insumos } \\
\text { não-convenc. } \\
\text { de }\end{array}$ & $\begin{array}{c}\text { VP/EH } \\
10^{5} \mathrm{Cr} \$ \text { de } \\
85 / \mathrm{EH}\end{array}$ & $\begin{array}{c}\text { Variação } \\
(\%)\end{array}$ \\
\hline 75 & 75 & 75 & 60,18 & $\cdots$ \\
75 & 80 & 75 & 68,18 & 13,3 \\
75 & 80 & 80 & 70,96 & 4,1 \\
80 & 80 & 80 & 73,25 & 3,2 \\
75 & 75 & 75 & 60,18 & $-\cdots$ \\
75 & 85 & 75 & 66,07 & 9,8 \\
75 & 85 & 85 & 74,07 & 12,1 \\
85 & 85 & 85 & 71,74 & $-3,1$ \\
80 & 80 & 80 & 73,25 &.-- \\
80 & 85 & 80 & 69,88 & $-4,6$ \\
80 & 85 & 85 & 78,14 & 11,8 \\
85 & 85 & 85 & 71,74 & $-8,2$ \\
\hline
\end{tabular}

trabalho. Esse acréscimo pode ser decomposto, conforme observa-se na referida Tabela. Para isso, altera-se inicialmente os insumos convencionais, mantendo a função de produção e os insumos PRT e ESC1 de 1975. Em seguida mantém-se a função de 1975 e emprega-se todos os insumos dos anos subsequentes. Procedimento análogo é utilizado para 1980.

Empregando-se a função de 1975 e os insumos convencionais de 1980, o valor da produtividade bruta do trabalho cresce $13,3 \%$. O efeito devido as variáveis PRT e ESC1 (maior nivel de escolaridade, melhor rede de transporte, mais pesquisa agropecuária, etc.) 
é igual a 4,1\%. O efeito correspondente à mudança da função de produçao entre 1975 e 1980 é positivo $(3,2 \%)$, o que indica uma mudança tecnológica nesse período.

Considerando-se a função de 1975 e os insumos convencionais de 1985, o valor da produção por equivalente-homem é 66,07 , correspondendo a um aumento de $9,8 \%$. Isto representa o acréscimo na produtividade do trabalho que os produtores obteriam se tivessem a oportunidade de empregar esses insumos. Verifica-se, ainda, que o efeito dos insumos não-convencionais (PRT e ESC1) de 1985 na produtividade do trabalho, empregando-se a função de 1975 ou a de 1980 é positivo, em torno de $12,0 \%$.

Finalmente, pode-se observar na Tabela 34 que, ao se empregar os insumos convencionais de 1985 na função de 1980, a produtividade do trabalho decresce $4,6 \%$, e que os efeitos devidos às mudanças da função de 75 para 85 , e de 80 para 85 são negativos e iguais a $3,1 \%$ e $8,2 \%$, respectivamente. Este dado, a princípio, é dificil de ser aceito, uma vez que não se pode admitir que tenha havido uma reversão no processo de modernização da agricultura brasileira entre estes anos. A redução do valor da produção por equivalente-homem é decorrente, provavelmente, de problemas de preços, uma vez que a produção agrícola cresceu principalmente na década de 80 . Segundo Resende (1987, p.157), os preços da safra agrícola de 1985 (ano de referência do Censo) revelaram-se muito inferiores aos recebidos em 1984.

Em resumo, pode-se concluir que, entre 1975 e 1985, houve mudanças significativas nas funções de produção da agropecuária do Brasil como um todo, e das regiões Nordeste, Sudeste (exclusive SP) e São Paulo. Estas alterações ocorreram, 
certamente, devido a mudanças nas origens das diferenças na produção e produtividade ${ }^{43}$, quais sejam: disponibilidades de recursos naturais; tecnologias incorporadas através de novas máquinas e equipamentos; fertilizantes, rações e outros materiais biológicos e químicos mais eficientes; e capital humano, incluindo educação, habilidade e grau de conhecimento. Estas mudanças foram, provavelmente, conseqüências, também, do crédito agrícola subsidiado, ocorrido principalmente na década de 70 , que não só intensificou o uso de insumos modernos, mudando a eficiência técnica, mas também incorporou nova tecnologia, o que certamente contribuiu para a mudança tecnológica observada na agricultura brasileira neste período.

${ }^{43}$ Citadas por Hayami e Ruttan (1988, p.164-83) ao estudarem as diferenças de produção e produtividade entre vários países. 


\subsection{A Função de Produção Ulveling-Fletcher para as 300 MRH, em 1985, 1980 e 1975.}

Nas seções anteriores foram apresentados e discutidos os melhores ajustamentos obtidos empregando-se o modelo Cobb-Douglas. Este modelo tem como uma das suas principais características apresentar elasticidades parciais constantes e, consequentemente, elasticidade de escala constante.

Porém, do conjunto de variáveis utilizadas nestes ajustamentos, as variáveis escolaridade (ESCl), urbanização (URB) e preço da terra (PRT), consideradas como fatores de produção não-convencionais, apesar de serem importantes no processo de produção, não podem ser consideradas propriamente como insumos que entrem de forma direta no processo produtivo. Por isso, pode-se acreditar que a participação destes fatores na determinação do valor da produção ocorra indiretamente, através de outras variáveis incluídas no modelo, e que esta influência se dê através das elasticidades destas variáveis. Esta influência, torna as elasticidades parciais de produção variáveis e, consequentemente, a elasticidade de escala variável.

Para verificar estes efeitos utilizou-se o modelo Ulveling-Fletcher, o qual permite este tipo de análise.

O efeito de uma variável sobre a elasticidade de uma outra é representado, nas próximas tabelas, através do produto entre a primeira e o logaritmo da segunda. Assim, sempre que a variável escolaridade (ESC1) foi empregada no ajustamento afetando o 
coeficiente de elasticidade da variável mão-de-obra $(\mathrm{EH})$, esta interação é representada nas tabelas por ESC1.LEH.

Nas várias tentativas de ajustamento considerou-se que a influência das variáveis não-convencionais (ESC1, URB e PRT) sobre outras variáveis ocorria obedecendo uma relação linear, quadrática ou cúbica. Porém, das várias tentativas realizadas observou-se, segundo critérios econométricos, que os melhores ajustamentos ocorreram quando se empregou o modelo linear.

A Tabela 35 contém duas equações estimadas empregando-se o modelo UlvelingFletcher para as $300 \mathrm{MRH}$, em 1985. O modelo representado pela equação 1 tem as mesmas variáveis da equação 1 da Tabela 10 , onde se utilizou o modelo Cobb-Douglas. A diferença metodológica entre estas duas equações é que no modelo Ulveling-Fletcher as variáveis escolaridade (ESC1) e preço da terra (PRT) relacionam-se com a variável dependente VP (valor da produção) de forma indireta através dos coeficientes de elasticidade das variáveis área de lavouras (AL) e mão-de-obra (EH). Assim, na equação 1 da Tabela 35 temos a variável ESC1 afetando a elasticidade da variável mão-de-obra (EH) - esta relação está indicada por ESC1.LEH - e PRT afetando a variável área de lavouras, cuja indicação é LPRT.LAL. O ajustamento aqui obtido foi um pouco melhor do que o do modelo Cobb-Douglas da Tabela 10.

O coeficiente de determinação é superior a $96 \%$, e o teste "F" para qualidade do ajustamento é altamente significativo. O coeficiente de ESC1.LEH não é estatisticamente significativo, indicando que, neste modelo, a variável escolaridade não influencia a elasticidade da mão-de-obra e, consequentemente, o valor da produção. 
Tabela 35 - Equações de regressão tipo Ulveling-Fletcher para as $300 \mathrm{MRH}$, com 12 ou 13 variáveis explanatórias, em 1985.

\begin{tabular}{|c|c|c|c|c|}
\hline & \multicolumn{2}{|c|}{ Equação 1} & \multicolumn{2}{|c|}{ Equação 2} \\
\hline Variável & Coeficiente & Teste $t$ & Coeficiente & Teste $\mathrm{t}$ \\
\hline Intercepto & 1,6816 & $7,79^{*}$ & 2,0222 & $9,43^{*}$ \\
\hline LAL & $-0,1059$ & $-2,25^{*}$ & 0,0229 & $-0,55$ \\
\hline LPRT.LAL & 0,0166 & $5,98^{*}$ & 0,0127 & $5,44^{*}$ \\
\hline LAP & $-0,0706$ & $-2,53^{*}$ & $-0,0806$ & $-2,63^{*}$ \\
\hline LAM & 0,0331 & 1,65 & $-\cdots$ & $-\cdots$ \\
\hline LCC & 0,0465 & $4,06^{*}$ & 0,0450 & $3,93 *$ \\
\hline LCA & 0,1064 & $2,39^{*}$ & 0,1297 & $2,78^{*}$ \\
\hline LVI & 0,0400 & 1,25 & 0,0345 & 1,04 \\
\hline LDA & 0,0919 & $3,92 *$ & 0,0980 & $3,88^{*}$ \\
\hline LDM & 0,1187 & $5,88^{*}$ & 0,1256 & $6,13^{*}$ \\
\hline LOD & 0,1933 & $6,21 *$ & 0,2031 & $5,71^{*}$ \\
\hline LEH & 0,3036 & $9,39^{*}$ & --- & $-\cdots$ \\
\hline ESC1.LEH & 0,0132 & 1,16 & $\cdots-$. & $-\cdots$ \\
\hline LEHF & $-\cdots$ & $-\cdots$ & $-0,0152$ & $-0,25$ \\
\hline ESC1.LEHF & --- & $-\cdots$ & 0,2255 & $2,77^{*}$ \\
\hline LEHA & --- & $-\cdots$ & 0,2941 & $4,65^{*}$ \\
\hline ESC1.LEHA & $-\cdots$ & --- & $-0,2197$ & $-2,54^{*}$ \\
\hline$\overline{R^{2}}$ & \multicolumn{2}{|c|}{0,9610} & \multicolumn{2}{|c|}{0,9597} \\
\hline $\mathrm{F}$ & \multicolumn{2}{|c|}{$589,46 *$} & \multicolumn{2}{|c|}{$523,49^{*}$} \\
\hline
\end{tabular}

$\left({ }^{*}\right)$ - significativo ao nível de $5 \%$ de significância.

A estimativa do coeficiente da variável preço da terra (LPRT.LAL) é positiva e estatisticamente significativa, indicando que esta variável afeta a elasticidade da área de lavouras.

O coeficiente da variável AP, a exemplo do que se observou nos modelos CobbDouglas, continua negativo e significativo. Das demais variáveis incluídas neste modelo, apenas VI e AM não apresentam significância estatística para seus coeficientes. 
Este modelo pode ser apresentado, alternativamente, pela seguinte forma algébrica:

$$
\begin{aligned}
V P= & 1,6816 \cdot A L^{-0,1059+0,0166 . L P R T} \cdot A P^{-0,0706} \cdot A M^{0,0331} \cdot C C^{0,0465} \cdot C A^{0,1064} \cdot V I^{0,0400} . \\
& D A^{0,0919} \cdot D M^{0,1187} \cdot O D^{0,1933} \cdot E H^{(0,3036+0,0132 \cdot E S C 1)}
\end{aligned}
$$

Observa-se nesta equação que o coeficiente de elasticidade da área de lavouras (AL) é variável e está relacionado linearmente com o logaritmo do preço da terra (LPRT). Portanto, para cada valor de LPRT temos distintos valores para a elasticidade da área de lavouras e, consequentemente, estimativas do valor da produção diferentes. O mesmo não ocorre com a elasticidade de EH, uma vez que o coeficiente de ESC1.LEH não foi estatisticamente significativo.

A equação 2 foi obtida após a exclusão de AM e a decomposição de EH em EHF e EHA. É importante mencionar que ao se empregar a mão-de-obra na forma mais agregada (EH), o grau de escolaridade das pessoas das MRH, representado por ESCl, não influencia o valor da elasticidade de $\mathrm{EH}$. No entanto, afeta significativamente as elasticidades de EHF e EHA, sendo que o efeito de ESC1 sobre a elasticidade de EHA é negativo. Isto, porém, não implica necessariamente em elasticidade parcial de EHA negativa. Empregando os valores da Tabela 6, no ponto médio, os coeficientes de elasticidade de VP em relação a EHF e EHA são positivos $(0,1234$ e 0,1590, respectivamente), indicando que o valor da produção agropecuária das microrregiões está diretamente associado ao uso destes fatores. Utilizando o valor máximo de ESC1 
$(0,0864)$, o que comprova a forte relação existente entre a quantidade de mão-de-obra assalariada utilizada e o valor da produção agropecuária.

As estimativas dos coeficientes de elasticidade das demais variáveis praticamente não mudaram, como também seus respectivos testes de significância.

Comparando-se estas equações com as ajustadas através do modelo CobbDouglas para 1985 (Tabelas 10 e 11), constata-se que a qualidade dos ajustamentos é bastante semelhante, tanto no que se refere aos valores dos coeficientes de determinação quanto à significância e sinais dos coeficientes de regressão.

As estimativas das equações de regressão para 1980 se encontram nas Tabelas 36 e 37. O modelo representado pela equação 1 é semelhante ao da Tabela 16 , onde se empregou o modelo Cobb-Douglas. Os resultados obtidos são muito semelhantes, tanto no que se refere à qualidade dos ajustamentos quanto ao valor e significância dos parâmetros. Os valores de $\mathrm{R}^{2}$ e de "F" são praticamente os mesmos, e os coeficientes de regressão da equação 1 (Tabela 16) cujos valores são estatisticamente significativos também o são na equação 1 da Tabela 36.

Nota-se no modelo da equação 2 que a elasticidade de AL é influenciada positivamente pelo preço da terra (PRT), e que ESC1 afeta as elasticidades de EHF e EHA, sendo que essa influência é negativa no caso de EHA, fato também constatado em 1985. Os ajustamentos são bons, com $R^{2}$ superiores a 0,95 nos dois modelos. 
Tabela 36 - Equações de regressão tipo Ulveling-Fletcher para as $300 \mathrm{MRH}$, com $12 \mathrm{ou}$ 13 variáveis explanatórias, em 1980.

\begin{tabular}{|c|c|c|c|c|}
\hline & \multicolumn{2}{|c|}{ Equação I } & \multicolumn{2}{|c|}{ Equação 2} \\
\hline Variável & Coeficiente & Teste $t$ & Coeficiente & Teste $t$ \\
\hline Intercepto & 1,6237 & $7,27^{*}$ & 2,0414 & $9,94^{*}$ \\
\hline LAL & $-0,1226$ & $-2,46^{*}$ & $-0,0990$ & $-2,42^{*}$ \\
\hline LPRT.LAL & 0,0143 & $4,75^{*}$ & 0,0128 & $5,30^{*}$ \\
\hline LAP & $-0,1180$ & $-3,33^{*}$ & $-0,0948$ & $-2,62^{*}$ \\
\hline LAM & 0,0354 & 1,63 & $-\cdots$ & --- \\
\hline LCC & 0,0112 & 0,97 & $-0,0012$ & $-0,11$ \\
\hline LCA & 0,2897 & $5,69 *$ & 0,2780 & $5,57^{*}$ \\
\hline LVI & 0,0038 & 0,10 & $-0,0190$ & $-0,52$ \\
\hline LDA & 0,1081 & $4,62^{*}$ & 0,1034 & $4,57^{*}$ \\
\hline LDM & 0,0481 & $2,52^{*}$ & 0,0515 & $2,80^{*}$ \\
\hline LOD & 0,1958 & $5,65^{*}$ & 0,2446 & $6,96^{*}$ \\
\hline LEH & 0,3132 & $8,65^{*}$ & $\cdots$ & $\cdots$ \\
\hline ESC1.LEH & 0,0523 & $4,03 *$ & --- & ---- \\
\hline LEHF & ---- & ---- & $-0,1672$ & $-3,00 *$ \\
\hline ESC1.LEHF & --- & $\cdots$ & 0,5566 & $6,79^{*}$ \\
\hline LEHA & ---- & ---- & 0,4998 & $8,07^{*}$ \\
\hline ESC1.LEHA & --- & $-\cdots$ & $-0,5267$ & $-6,03 *$ \\
\hline $\mathrm{R}^{2}$ & \multicolumn{2}{|c|}{0,9515} & \multicolumn{2}{|c|}{0,9555} \\
\hline $\mathrm{F}$ & \multicolumn{2}{|c|}{$469.28 *$} & \multicolumn{2}{|c|}{$472,38^{*}$} \\
\hline
\end{tabular}

$\left({ }^{*}\right)$ - significativo ao nivel de $5 \%$ de significância.

Os modelos apresentados na Tabela 37 mostram que os coeficientes de elasticidade da mão-de-obra familiar e da mão-de-obra assalariada são afetadas pela variável escolaridade, e que o preço da terra modifica a elasticidade da área de lavouras. Nota-se também que a urbanização não tem influência direta nem indireta sobre o valor da produção, pois seus coeficientes de regressão são estatisticamente nulos. ESCl e a elasticidade de EHA continuam inversamente relacionados, mas pode-se mostrar que isto 
Tabela 37 - Equações de regressão tipo Ulveling-Fletcher para as $300 \mathrm{MRH}$, com 13 variáveis explanatórias, em 1980.

\begin{tabular}{|c|c|c|c|c|}
\hline \multirow[b]{2}{*}{ Variável } & \multicolumn{2}{|c|}{ Equação 3} & \multicolumn{2}{|c|}{ Equação 4} \\
\hline & Coeficiente & Teste $\mathrm{t}$ & Coeficiente & Teste $t$ \\
\hline Intercepto & 2,1081 & $10,15^{*}$ & 2,1569 & $9,90^{*}$ \\
\hline LAL & $-0,1670$ & $-4,53 *$ & $-0,1707$ & $-4,47^{*}$ \\
\hline LPRT.LAL & 0,0175 & $9,98^{*}$ & 0,0174 & $9,98^{*}$ \\
\hline URB.LAL & $-\cdots$ & $\cdots$ & 0,0101 & 1,00 \\
\hline LCC & $-0,0059$ & $-0,53$ & $-0,0059$ & $-0,53$ \\
\hline LCA & 0,1641 & $5,83^{*}$ & 0,1647 & $5,87^{*}$ \\
\hline LVI & $-0,0405$ & $-1,13$ & $-0,0403$ & $-1,12$ \\
\hline LDA & 0,0846 & $3,64^{*}$ & 0,0852 & $3,69^{*}$ \\
\hline LDM & 0,0656 & $3,45^{*}$ & 0,0654 & $3,45^{*}$ \\
\hline LOD & 0,2686 & $7,30^{*}$ & 0,2681 & $7,31^{*}$ \\
\hline LEHF & $-0,1732$ & $-3,08^{*}$ & $-0,1727$ & $-3,07^{*}$ \\
\hline ESC1.LEHF & 0,6089 & $7,59 *$ & 0,6071 & $7,56^{*}$ \\
\hline LEHA & 0,5294 & $8,63^{*}$ & 0,5281 & $8,60^{*}$ \\
\hline ESC1.LEHA & $-0,5703$ & $-6,60^{*}$ & $-0,5685$ & $-6,56^{*}$ \\
\hline URB & 0,1140 & 1,01 & $\cdots$ & $-\cdots$ \\
\hline $\mathrm{R}^{2}$ & \multicolumn{2}{|c|}{0,9546} & \multicolumn{2}{|c|}{0,9546} \\
\hline$F$ & \multicolumn{2}{|c|}{$462,50 *$} & \multicolumn{2}{|c|}{$462,47^{*}$} \\
\hline
\end{tabular}

(*) - significativo ao nivel de $5 \%$ de significância.

não chega a afetar a relação direta existente entre EHA e VP.

A Tabela 38 mostra os resultados do ajustamento das equações 1 e 2 para 1975.

O ajustamento é bom, com $\mathrm{R}^{2}$ superior a $95,8 \%$. As variáveis preço da terra e escolaridade afetam positivamente as elasticidades de $\mathrm{AL}$ e $\mathrm{EH}$, respectivamente. Ao se decompor a variável EH em EHF e EHA, o coeficiente de CC torna-se não-significativo e a elasticidade da variável EHA é negativamente influenciada por ESC1. Esta relação é "estranha", pois espera-se que aumento no grau de escolaridade do trabalhador melhore 
Tabela 38 - Equações de regressão tipo Ulveling-Fletcher para as $300 \mathrm{MRH}$, com $12 \mathrm{ou}$ 13 variáveis explanatórias, em 1975.

\begin{tabular}{|c|c|c|c|c|}
\hline \multirow[b]{2}{*}{ Variável } & \multicolumn{2}{|c|}{ Equação 1} & \multicolumn{2}{|c|}{ Equação 2} \\
\hline & Coeficiente & Teste $t$ & Coeficiente & Teste t \\
\hline Intercepto & 1,3342 & $6,11^{*}$ & 1,5339 & $7,97^{*}$ \\
\hline LAL & 0,0550 & 1,30 & 0,0244 & 0,68 \\
\hline LPRT.LAL & 0,0073 & $2,99^{*}$ & 0,0067 & $3,27^{*}$ \\
\hline LAP & $-0,0738$ & $-2,61^{*}$ & $-0,0774$ & $-2,79^{*}$ \\
\hline LAM & 0,0030 & 0,17 & --- & --- \\
\hline LCC & 0,0241 & $2,12^{*}$ & 0,0093 & 0,87 \\
\hline LCA & 0,2596 & $5,60^{*}$ & 0,2473 & $5,77^{*}$ \\
\hline LVI & 0,0498 & 1,77 & 0,0486 & 1,83 \\
\hline LDA & 0,0262 & 1,43 & 0,0253 & 1,48 \\
\hline LDM & 0,0290 & 1,40 & 0,0139 & 0,71 \\
\hline LOD & 0,3956 & $9,68^{*}$ & 0,4209 & $11,11^{*}$ \\
\hline LEH & 0,1264 & $3,36^{*}$ & $\cdots$ & --- \\
\hline ESC1.LEH & 0,0308 & $2,57^{*}$ & --- & --- \\
\hline LEHF & --- & $-\cdots$ & $-0,1610$ & $-3,43 *$ \\
\hline ESC1.LEHF & $-\cdots$ & $-\cdots$ & 0,3928 & $5,74 *$ \\
\hline LEHA & ---- & $-\cdots$ & 0,3665 & $7,24 *$ \\
\hline ESC1.LEHA & $-\cdots$ & --- & $-0,3720$ & $-4,92 *$ \\
\hline $\mathrm{R}^{2}$ & \multicolumn{2}{|c|}{0,9587} & \multicolumn{2}{|c|}{0,9647} \\
\hline $\mathrm{F}$ & \multicolumn{2}{|c|}{$554,49^{*}$} & \multicolumn{2}{|c|}{$601,90^{*}$} \\
\hline
\end{tabular}

$(*)$ - significativo ao nível de $5 \%$ de significância.

a eficiência da mão-de-obra, e, consequentemente, eleve o valor da produção agropecuária. Nota-se, porém, que empregando-se os valores contidos na Tabela 6, no ponto médio, o coeficiente de elasticidade de VP em relação a EHA é positivo $(0,1718)$.

A Tabela 39 contém as equações 3 e 4 estimadas para as $300 \mathrm{MRH}$, em 1975. Nota-se que a variável urbanização (URB) representa um condicionante de grande 
importância na determinação do valor da produção. Na equação 3 esta variável é incluída afetando diretamente VP. Seu coeficiente é positivo e estatisticamente significativo.

Das várias tentativas de ajustamento chegou-se ao modelo representado pela equação 4 da Tabela 39. A princípio considerou-se que as variáveis preço da terra (PRT) e urbanização (URB) afetariam a área de lavouras. Espera-se que quanto mais elevado o preço da terra maior tende a ser a área dedicada a culturas, em detrimento das áreas dedicadas a pastagens, havendo assim uma substituição de pastagens por culturas.

As estimativas dos coeficientes de LPRT.LAL e URB.LAL são positivas e estatisticamente diferentes de zero, confirmando que estas variáveis afetam diretamente a elasticidade da área de lavouras, que por sua vez encontra-se diretamente relacionada com o valor da produção. Nota-se ainda que todas as interações (produtos de variáveis) incluídas nestes modelos apresentam coeficientes estatisticamente significativos. A qualidade do ajustamento de ambas as equações é muito boa. Os valores de $\mathrm{R}^{2}$ indicam que mais de $96 \%$ da soma de quadrados total de LVP é "explicada" pelas variáveis explanatórias incluidas nestes modelos.

Em resumo, observa-se que os ajustamentos através do modelo Ulveling-Fletcher são, sob o ponto de vista estatístico, muito bons. Comparando-se estas equações com as ajustadas através do modelo Cobb-Douglas, pode-se notar que a qualidade dos ajustamentos é muito semelhante, tanto no que se refere ao valor dos coeficientes de determinação quanto à significância e sinais dos parâmetros estimados. 
Tabela 39 - Equações de regressão tipo Ulveling-Fletcher para as $300 \mathrm{MRH}$, com 13 variáveis explanatórias, em 1975.

\begin{tabular}{|c|c|c|c|c|}
\hline \multirow[b]{2}{*}{ Variável } & \multicolumn{2}{|c|}{ Equação 3} & \multicolumn{2}{|c|}{ Equação 4} \\
\hline & Coeficiente & Teste $\mathrm{t}$ & Coeficiente & Teste $\mathrm{t}$ \\
\hline Intercepto & 1,5774 & $8,12^{*}$ & 1,6997 & $8,28^{*}$ \\
\hline LAL & $-0,0403$ & $-1,19$ & $-0,0503$ & $-1,43$ \\
\hline LPRT.LAL & 0,0104 & $6,39^{*}$ & 0,0103 & $6,37^{*}$ \\
\hline URB.LAL & --- & --- & 0,0303 & $2,38^{*}$ \\
\hline $\mathrm{LCC}$ & 0,0099 & 0,92 & 0,0098 & 0,91 \\
\hline LCA & 0,1399 & $4,99 *$ & 0,1412 & $5,08^{*}$ \\
\hline LVI & 0,0312 & 1,21 & 0,0305 & 1,18 \\
\hline LDA & 0,0083 & 0,49 & 0,0089 & 0,53 \\
\hline LDM & 0,0416 & $2,09 *$ & 0,0416 & $2,10^{*}$ \\
\hline LOD & 0,4463 & $11,74^{*}$ & 0,4456 & $11,76^{*}$ \\
\hline LEHF & $-0,1645$ & $-3,49^{*}$ & $-0,1645$ & $-3,49^{*}$ \\
\hline ESC1.LEHF & 0,4296 & $6,43^{*}$ & 0,4260 & $6,38^{*}$ \\
\hline LEHA & 0,3829 & $7,62 *$ & 0,3805 & $7,58^{*}$ \\
\hline ESC1.LEHA & $-0,3989$ & $-5,35^{*}$ & $-0,3939$ & $-5,28 *$ \\
\hline URB & 0,3143 & $2,22 *$ & $\cdots$ & $\cdots$ \\
\hline $\mathrm{R}^{2}$ & \multicolumn{2}{|c|}{0,9644} & \multicolumn{2}{|c|}{0,9645} \\
\hline
\end{tabular}

(*) - significativo ao nível de $5 \%$ de significância. 


\section{CONCLUSÕES}

Neste capítulo são apresentadas, de forma resumida, as principais conclusões a que se chegou do estudo da agropecuária brasileira, através do ajustamento de funções de produção a 300 microrregiões homogêneas (MRH).

Em 1985, do total da área ocupada na agropecuária brasileira, aqui representada pelas $300 \mathrm{MRH}$ que compõem as regiões Nordeste, Sudeste (exclusive SP), São Paulo e Sul, $21 \%$ correspondiam a área de matas (AM) e $55 \%$ a área de pastagens (AP). Desta, $65 \%$ correspondiam a área de pastagens naturais. No período compreendido entre $1975 \mathrm{e}$ 1985 a variação da área de pastagens foi praticamente nula, enquanto que a área ocupada com lavouras cresceu $23 \%$, reduzindo, consequentemente, a relação entre AP e AL. Paralelamente, o valor da produção agropecuária cresceu 45,3\%, em termos reais. Constatou-se, também, que houve acréscimos nos valores dos componentes do capital fixo (CC, CA e VI), e do capital variável (DA, DM e OD), sendo que o aumento do valor do capital fixo foi quase sempre superior a $100 \%$. O preço da terra cresceu em termos reais, neste mesmo período, aproximadamente $45 \%$.

Em relação à mão-de-obra (EH), observou-se que houve, em média, um acréscimo de $21 \%$ no total de equivalentes-homem empregados na agropecuária 
brasileira entre 1975 e 1985, sendo que a mão-de-obra familiar (EHF) e a mão-de-obra assalariada (EHA) cresceram 7 e $52 \%$, respectivamente. No entanto o emprego da mãode-obra familiar na agricultura brasileira ainda é predominante, correspondendo a $61 \%$ do total de equivalentes-homem empregados em 1985.

Os ajustamentos das funções de produção tipo Cobb-Douglas aos dados das 300 MRH foram muito bons, com coeficientes de determinação superiores a 0,95 , indicando que mais de $95 \%$ da soma de quadrados total do logaritmo do valor da produção é “explicada" pelas variáveis explanatórias incluídas nos modelos em 1975, 1980 e 1985. Constatou-se que a agropecuária brasileira apresenta retornos constantes à escala, pois a elasticidade de escala " $\varepsilon$ " foi diferente da unidade em apenas um caso.

Com base nos coeficientes de elasticidade dos fatores de produção, observou-se que os fatores que mais contribuíram para a determinação do valor da produção agropecuária brasileira, em 1985, foram mão-de-obra (EH), outras despesas (OD), preço da terra (PRT) e área de lavouras (AL); em 1980 foram EH, capital em animais (CA), OD e PRT; e em 1975 foram os fatores OD, EH, CA e AL. Quando área com matas (AM) foi incluída no modelo, seu coeficiente não apresentou significância estatística em nenhuma equação, e sua exclusão não afetou de forma expressiva a significância nem a qualidade dos ajustamentos. Isto mostra a pouca influência que este fator exerce na determinação do valor da produção.

O coeficiente de regressão do fator escolaridade (ESC1) foi significativo em todos modelos ajustados aos dados de 1980, não o sendo nos modelos de 1975 e 1985. Porém, nestes dois anos, sempre que se excluiu esta variável dos modelos, a qualidade estatística 
da maioria das estimativas dos coeficientes das demais variáveis foi reduzida. Isto mostra, de certa forma, que esta variável direta e/ou indiretamente é importante para a determinação do valor da produção .

A mão-de-obra (EH) se constitui em um dos fatores que mais contribuiram para a formação do valor da produção, pois o coeficiente de elasticidade foi sempre positivo e altamente significativo em todos os modelos ajustados para os três anos. Sempre que a mão-de-obra foi empregada nos ajustamentos de forma desagregada (EHF e EHA) os coeficientes de elasticidade destas variáveis foram também significativos ao nível de $5 \%$ de significância, reafirmando, portanto, a importância deste fator no processo produtivo.

Ao se ajustar as funções de produção regionais observou-se que o fator de produção mão-de-obra é, na maioria das regiões, o que mais contribui para a determinação dos respectivos valores da produção. A mão-de-obra assalariada apresenta coeficiente de elasticidade superior à da mão-de-obra familiar no Nordeste, Sudeste (exclusive SP) e São Paulo. Relação inversa ocorre na região Sul, onde as unidades de exploração agrícolas são predominantemente familiares.

Os ajustamentos dos modelos Ulveling-Fletcher aos dados das $300 \mathrm{MRH}$ foram, sob o ponto de vista estatístico, muitos bons. A qualidade dos ajustamentos, no entanto, é muito semelhante à das regressões obtidas através do modelo Cobb-Douglas, tanto no que se refere ao valor dos coeficientes quanto à significância e sinais dos parâmetros estimados. Verificou-se, também, através do modelo Ulveling-Fletcher, que o coeficiente de elasticidade da área de lavouras é afetado positivamente pelos fatores de produção preço da terra e urbanização (URB), e que o fator de produção mão-de-obra é afetado 
pelo grau de escolaridade através de sua elasticidade. Desta forma, os fatores de produção "grau de escolaridade" e "urbanização e preço da terra" influenciaram o valor da produção agropecuária ao modificarem os coeficientes de elasticidade das variáveis mão-de-obra e área de lavouras, respectivamente.

Do estudo das produtividades marginais pode-se observar que os fatores de produção que correspondem a capital fixo (capital em culturas - CC, capital em animais - CA e valor das instalações e outras benfeitorias - VI) apresentaram baixa produtividade marginal por cruzeiro investido, não correspondendo ao valor da amortização e aos juros sobre o capital empatado. No caso da terra de lavouras, em que normalmente não se considera amortização sobre o capital empatado, a produtividade marginal foi superior a $5 \%$, podendo ser considerada boa. A produtividade marginal deste fator sofreu um acréscimo de $146 \%$ entre 1975 e 1985, decorrente, certamente, dos investimentos em máquinas, equipamentos agrícolas e insumos modernos. Observou-se, também, que as produtividades marginais dos fatores correspondentes a capital circulante (despesas com adubos, corretivos, etc, -DA, despesas com medicamentos para animais, sal e rações - DM, e outras despesas - OD) foram, na grande maioria, maiores que 1. As produtividades marginais de DA, e DM, cujos componentes são essencialmente insumos modernos, tiveram um aumento de 191 e 246\%, respectivamente, entre 1975 e 1985.

Existem diferenças marcantes das produtividades marginais dos fatores entre regiões. A produtividade marginal da mão-de-obra no estado de São Paulo, por exemplo, correspondeu, em 1985, a aproximadamente 2,2 vezes a do Nordeste, 3,9 vezes a do Sudeste e a 1,2 vez a da região Sul. Essa diferença pode ser explicada pelo elevado grau 
de mecanização e uso de insumos modernos da agricultura paulista, relativamente às demais regiões.

Os testes mostram que há diferença estatisticamente significativa entre as funções de produção de 1975, 1980 e 1985, para o Brasil como um todo. A estimativa do logaritmo do valor da produção para 1985, empregando-se a média geométrica das variáveis deste ano é $3,1 \%$ inferior à estimativa para 1975 . Este resultado, à primeira vista, parece estranho, pois, é provável que entre 1975 e 1985 a mudança tecnológica fez com que a função de produção tenha se deslocado para cima. Porém, como a variável dependente é o valor da produção, é provável que esta queda do valor da produção seja decorrente da redução dos preços e/ou da produção provocada por variações climáticas mais ou menos favoráveis.

Da análise regional constatou-se que houve mudança significativa da função de produção das regiões Nordeste, Sudeste e São Paulo entre 1975 e 1985. Na região Sul essa diferença ocorreu somente entre as funções de produção de 1975 e 1980. 


\section{Referências Bibliográficas}

ALLEN, R. G. D. Mathematical analysis for economists. 3. ed. London: Macmillian and Co., limited, 1947. 548p.

AHMAD, M.; B. E. BRAVO-URETA. An econometric decomposition of dairy output growth. American Journal of Agricultural Economics, v.77, p.914-21, Nov. 1995.

BARBOSA, F. H. Microeconomia: teoria, modelos econométricos e aplicações à economia brasileira. Rio de Janeiro: IPEA/INPES, 1985. 534p. (Série PNPE, 10).

BEATTLE, B. R.; TAYLOR, R. C. The economics of production. New York: John Wiley \& Sons, Inc., 1985. 257p.

BINSWANGER, H. P. Induced technical changer: evolution of thought. In: HAYAMI \& RUTTAN, V. W. coord. Induced innovation: technology, institutions and development. Baltimore, Fohn Hopkins University, 1978. p.13-43.

CAMARGO, J. R. V. Análise da produtividade nas culturas de algodão e soja com a aplicação do modelo Ulveling-Fletcher. Piracicaba, 1974. 131p. Dissertação (Mestrado ) - Escola Superior de Agricultura "Luiz de Queiroz", Universidade de São Paulo. 
CHAMBERS, R. G. Applied production analysis: a dual approach. 1.ed. New York: Cambridge University Press, 1988. 331p.

CHIANG, A. C. Matemática para economistas. 2 ed. São Paulo: MAKRON Books do Brasil Editora Ltda, 1982. 684p.

COBB, C. W.; P. H. DOUGLAS. A theory of production. The American Economic Review, v.18, n.1, p.139-65, 1928.

De JANVRY, A. The generalized power production function. American Journal of Agricultural Economics, v.54, n.2, p. 234-237, May. 1972.

ENGLER, J. J. C. Análise da produtividade de recursos na agricultura. Piracicaba, 1968. 102p. Tese ( Doutorado ) - Escola Superior de Agricultura "Luiz de Queiroz", Universidade de São Paulo.

ENGLER, J. J. C. Análise da produtividade agrícola entre regiões do estado de São Paulo. Piracicaba, 1978. 132p. Tese ( Livre-Docência ) - Escola Superior de Agricultura "Luiz de Queiroz", Universidade de São Paulo.

ENGLER, J. J. C. O capital humano numa função de produção da agricultura de São Paulo. Pesquisa e Planejamento Econômico, v.9, n.3, p.845-884, jan. 1979.

FERGUSON, C. E. Microeconomia. 15 ed. Rio de Janeiro: Editora ForenseUniversitária LTDA, 1991. 610p.

FIBGE: Fundação Instituto Brasileiro de Geografia e Estatística - Censos Agropecuáros de 1975,1980 e 1985.

FIBGE: Fundação Instituto Brasileiro de Geografia e Estatística - Censos Demográficos de 1970 e 1980. 
FIBGE: Fundação Instituto Brasileiro de Geografia e Estatística - Anuário Estatístico do Brasil, 1994.

FIGUEIREDO, N. M. S. Modernização, distribuição de renda, pobreza e emprego na agricultura brasileira, 1975, 1980 e 1985. Piracicaba, 1996. 246p. Tese (Doutorado)

- Escola Superior de Agricultura "Luiz de Queiroz", Universidade de São Paulo.

FISHER, F. M. Aggregate production functions and the explanation of wages: a simulation experiment. The Review of Economics and Statistics, v.53, n.4, p.305325, Nov., 1971.

FULGINITI, L. E.; R. K. PERRI. Prices and productivity in agriculture. The Review of Economics and Statistics, v.75, n.3, p.471-82, Aug. 1993.

FUNDAÇÃO GETÚLIO VARGAS, IBRE, Centro de contas nacionais: contas nacionais do Brasil - metodologia e tabelas estatísticas. Rio de Janeiro. 1984. 48p.

FUNDAÇÃO GETÚLIO VARGAS. IBRE, Centro de estudos agrícolas - Preços médios de: arrendamentos, vendas de terras, salários, empreitadas, transportes. Revisão e atualização da série 1966-1984. 1985.

GRAZIANO DA SILVA, F. Coord. Emprego e relações de trabalho na agricultura paulista, 1960-1975. DEPE/IFCH/UNICAMP, Texto para Discussão n.15. 1982. $74 \mathrm{p}$.

GRAZIANO DA SILVA, J.; A. KAGEYAMA. Emprego e relações de trabalho na agricultura brasileira: uma análise dos dados censitários de 1960, 1970 e 1975 . Pesquisa e Planejamento Econômico, v.13, n.1, p.235-266. abr. 1983. 
GIRÃO, J. A. A função de produção Cobb-Douglas e a análise inter-regional de produção agrícola. Lisboa: Fundação Calouste Gulbenkian, Centro de Estudos de Economias Agrícola. 1965. 117p.

GRILICHES, Z. Estimates of the aggregate agricultural production function from crosssectional data. Journal of Farm Economics, v.45, n.1, p.419-428. Feb. 1963.

GRILICHES, Z. Research expenditures, education and the aggregate agricultural production function. American Economic Review, v.54, n.6, p.961-974. Traduzido in: ARAUJO, P. F. C.; G.E. SCHUH (coord.), Desenvolvimento da Agricultura. São Paulo: Livraria Pioneira Editora, v.2, p.101-116. 1975.

HAYAMI, Y. ; C. W. RUTTAN. Agricultural productivity differences among countries. The American Economic Review. v.60, n.5, p.895-911. Dec. 1970.

HAYAMI, Y. ; C. W. RUTTAN. Desenvolvimento Agrícola: teoria e experiências internacionais. Brasilia. EMBRAPA-SEP, Documentos, n.40. 1988. 583p.

HEADLEY, J. C. Estimating the productivity of agricultural pesticides. American Journal of Agricultural Economics, v.50, n.1, p.13-23, Feb. 1968.

HEADY, E. O. ; J. L. DILLON. Agricultural production functions. Iowa: Ames, The Iowa State University Press, 1961. 667p.

HEATHFIELD, D. F.; S. WIBE. An introduction to cost and production functions. Massachusetts: Humanities Press International, Inc., 1987. 193p.

HOFFMANN, R. A pobreza no Brasil: análise dos dados dos Censos Demográficos de 1970 e 1980. ENCONTRO BRASILEIRO DE ECONOMETRIA, 6, São Paulo, 1984. Sociedade Brasileira de Econometria (SBE). 1984. p. 177-213. 
HOFFMANN, R. Distribuição da renda e pobreza na agricultura brasileira. In. Delgado, G. C.; Garques, J. G. e Villa Verde, C. M. (Org.). Agricultura e políticas públicas. Rio de Janeiro: Instituto de Pesquisa Econômica Aplicada, 1990, p.3-111. (Série IPEA, 127).

HOFFMANN, R. Sensibilidade das medidas de pobreza à redução da renda de um pobre. ENCONTRO BRASILEIRO DE ECONOMETRIA, 17, Salvador, 1995. p.623-32.

HOFFMANN, R., et al. Administração da empresa agrícola. São Paulo. 2 ed. (revisada). Livraria Pioneira Editora. 1978. 325p.

HOFFMANN, R., et al. Inovações tecnológicas e transformações recentes na agricultura brasileira.. Convênio FINEP/USP/FEALQ. Piracicaba/SP, 1985. p.520778. (Relatório de Pesquisa-v.3).

HOFFMANN, R. ; A. L. JAMAS ; A. L. KASSOUF. Modernização e produtividade da agropecuária em 332 microrregiões homogêneas do Brasil em 1975 e 1980. ESAL/USP, 1990. 146p. (Relatório de pesquisa).

HOFFMANN, R. ; S. VIEIRA. Análise de regressão: uma introdução à econometria. 2. ed. São Paulo: Editora Hucitec, 1993. 379p.

JAMES, D. E. ; C. D. THROSBY. Métodos quantitativos aplicados à economia: uma introdução à econometria. 1. ed. São Paulo: Atlas S. A., 1977. 410p.

JATILEKSONO, T.; K. OTSUKA. Impact of modern rice technology on land prices: the case of Lampug in Indonesia. American Journal of Agricultural Economics, n.75, p.652-65, Aug. 1993. 
JOHNSTON, J. Métodos econométricos. 1. ed. Rio de Janeiro: Atlas S. A., 1977. $318 \mathrm{p}$.

KAGEYAMA, A. A. O emprego temporário na agricultura brasileira: seus determinantes e sua evolução recente. Reforma Agrária. Campinas, v.12, n.5, p.312, set/out. 1982 .

KAGEYAMA, A. A. Modernização, produtividade e emprego na agricultura - uma análise regional. Campinas, 1985. 463p. Tese (Doutorado) - Instituto de Economia, Universidade Estadual de Campinas.

KAGEYAMA, A. A. O emprego agrícola em 1985 - análise preliminar. Campinas, Instituto de Economia/UNICAMP. Texto para Discussão, n.8. 1992, 19p.

KLEIN, L. R. Introdução à econometria. 1. ed. São Paulo: Atlas S. A., 1978. 307p.

LIMA, J. E. Relações econômicas em uma fase de crescimento de novilhos em três graus de sangue. Viçosa, 1972. 62p. Dissertação (Mestrado) - Universidade Federal de Viçosa.

LOPES, J. R. B. Empresas e pequenos produtores no desenvolvimento do capitalismo agrário em São Paulo (1940-1970). Estudos CEBRAP n.22. São Paulo. 1978. p. 41-110.

NADIRI, M. I. Some approaches to the theory and measurement of total factor productivity: a survey. Journal of Economic Literature, v. 8, n.4, p. 1137-1177, 1970. 
NOJMOTO, T. Obstáculos à modernização da agricultura brasileira. São Paulo, 1987. 345p. Tese (Doutorado) - Faculdade de Economia e Administração, Universidade de São Paulo.

RESENDE, G. C. A política agrícola e a estabilização macroeconômica. In. Perspectivas da economia brasileira - 1987. Rio de Janeiro: Instituto de planejamento econômico e social (IPEA), 1987. p.143-66.

RICARDO, D. Princípios de economia política e tributação. Coleção "Os Economistas". São Paulo: Abril Cultural, 1982. 286p.

ROCHA, J. Análise econômica da engorda de bovinos em confinamento através da superficie de resposta Ulveling-Fletcher. Viçosa, 1972. 130p. Dissertação (Mestrado) - Universidade Federal de Viçosa.

SCHNEIDER, E. Teoria econômica: capítulos selecionados da história da teoria econômica. 1. ed. Rio de Janeiro: Fundo de Cultura S.A., v.4, 1968. 396p.

SHAIKH, A. Laws of production and laws of algebra: the humbug production function. The Review of Economics and Statistics, v.16, n.1, p.115-120, Feb. 1974.

SILBERBERG, E. The structure of economics: a mathematical analysis. 2. ed. USA: McGraw-Hill Publishing Co., 1990. 686p.

SILVA, Z. P. Uso e eficiência do crédito rural e dos fatores de produção, Jardinópolis e Guaíra, estado de São Paulo, ano agrícola 1971/72. Piracicaba, 1973. 140p. Dissertação ( Mestrado ) - Escola Superior de Agricultura "Luiz de Queiroz", Universidade de São Paulo. 
SIMONSEN, M. H. Teoria microeconômica. 11. ed. Rio de Janeiro: Editora da Fundação Getúlio Vargas, v.1, 1993. 426p.

SOLOW, R. M. Law of production and laws of algebra: the humbug production function: a comment. The Review of Economics and Statistics, v.16, n.1, p.121, Feb. 1974.

THOMPSON, R. L. Economia da produção. Viçosa-MG: Departamento de Economia Rural - 1973. 222p. (Mimeo.).

THOMPSON, R. L. The metaproduction function for Brazilian agriculture: an analysis of productivity and other aspects of agricultural growth. Indiana, 1974. 175p. Tese $(\mathrm{PhD})$ - - Purdue University.

ULVELING, E. F. ; FLETCHER, L. B. A Cobb-Douglas production function with variable returns to scale. American Journal of Agricultural Economics, v.52, n.2, 1970. p.322-329. 
A P E N D I C E 


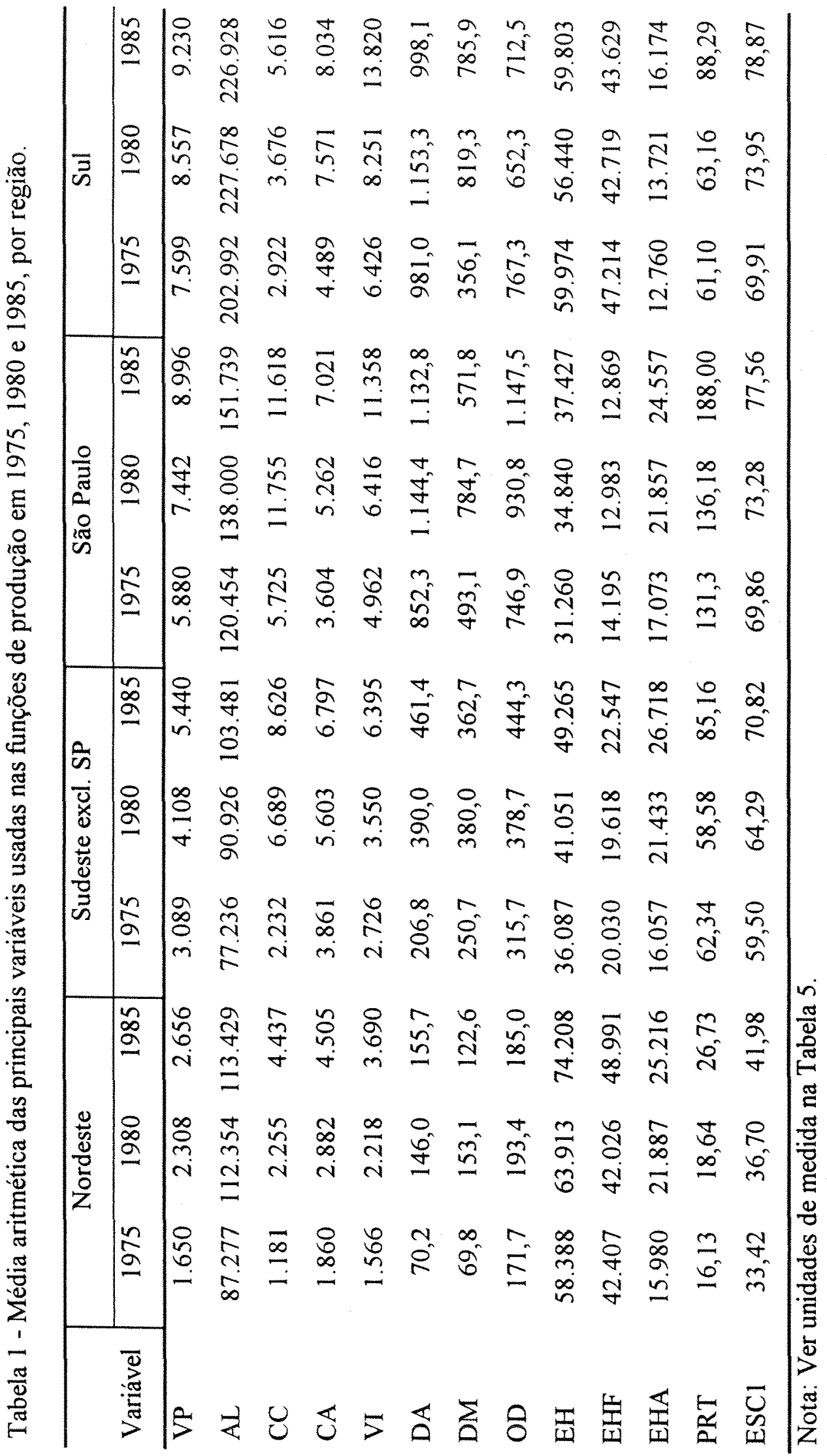




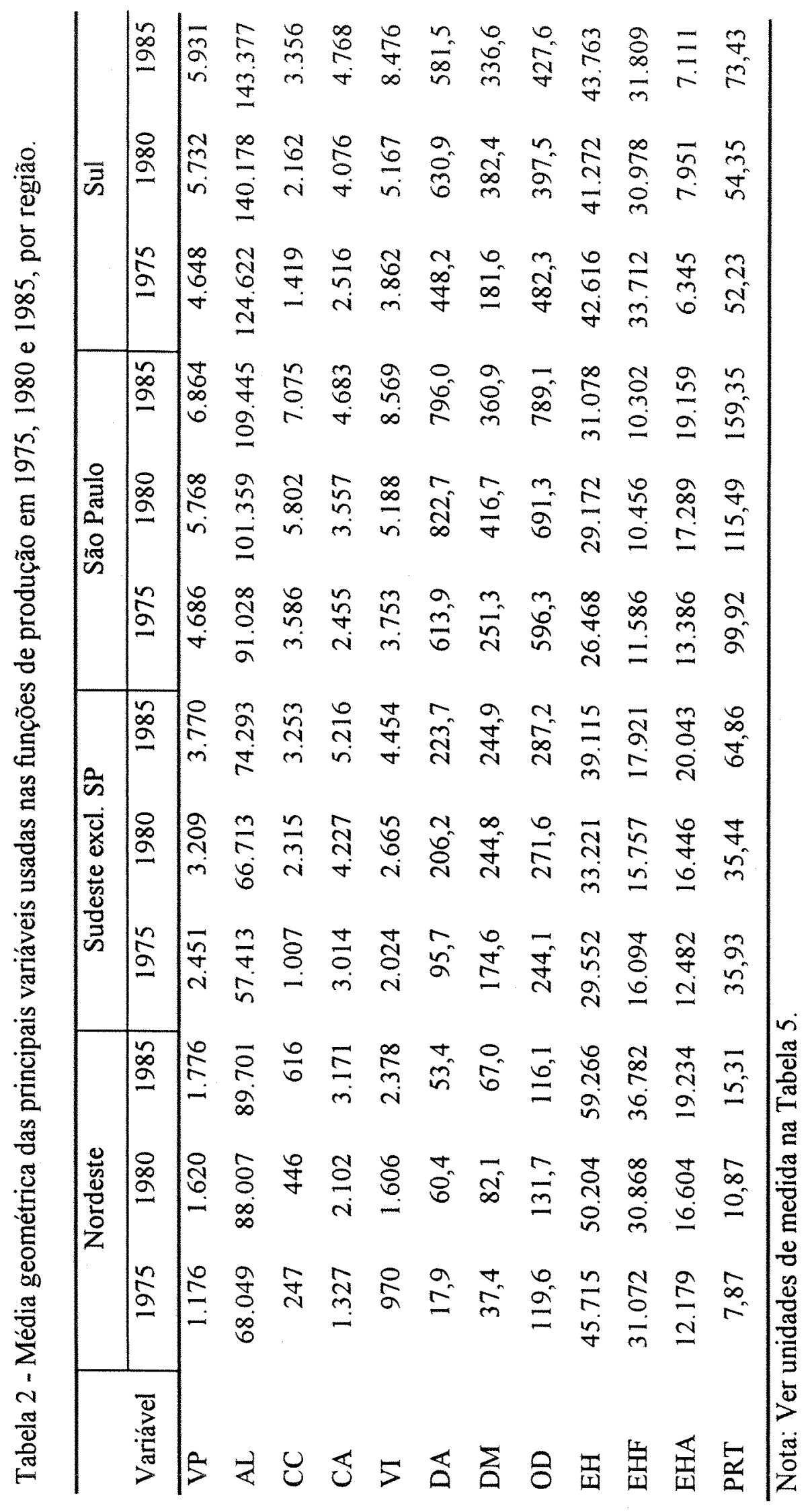


Tabela 3 - Equações ajustadas para comparar as funções de produção das regiões em 1975, 1980 e 1985, adotando-se o modelo da equação 6.

\begin{tabular}{|c|c|c|c|c|c|c|}
\hline \multirow[b]{2}{*}{ Variável } & \multicolumn{2}{|c|}{1975} & \multicolumn{2}{|c|}{1980} & \multicolumn{2}{|c|}{1985} \\
\hline & coeficiente & teste $t$ & coeficiente & teste $t$ & coeficiente & teste $\mathrm{t}$ \\
\hline Intercepto & $-0,2118$ & $-0,43$ & $-1,2445$ & $-2,19^{*}$ & $-0,7544$ & $-1,21$ \\
\hline $\mathrm{LAL}$ & 0,1566 & $2,76^{*}$ & 0,0386 & 0,76 & 0,0551 & 1,08 \\
\hline $\mathrm{LCC}$ & 0,0143 & 0,89 & 0,0351 & $2,35^{*}$ & 0,0542 & $3,72^{*}$ \\
\hline LCA & 0,2635 & $4,55^{*}$ & 0,1634 & $3,16^{*}$ & 0,0495 & 1,11 \\
\hline LVI & $-0,0692$ & $-1,86$ & $-0,0925$ & $-2,18 *$ & $-0,0154$ & $-0,38$ \\
\hline LDA & 0,0420 & 1,90 & 0,0704 & $2,50^{*}$ & 0,0661 & $2,05^{*}$ \\
\hline LDM & 0,0158 & 0,55 & 0,0092 & 0,34 & 0,0981 & $3,27^{*}$ \\
\hline LOD & 0,3509 & $7,04^{*}$ & 0,2819 & $5,81^{*}$ & 0,2259 & $4,49 *$ \\
\hline LEHF & $-0,0313$ & $-0,72$ & 0,1217 & $3,29 *$ & 0,1286 & $3,38^{*}$ \\
\hline LEHA & 0,2845 & $7,15^{*}$ & 0,4097 & $9,66^{*}$ & 0,3675 & $8,63^{*}$ \\
\hline LPRT & 0,1064 & $4,49^{*}$ & 0,2035 & $7,57^{*}$ & 0,1884 & $6,64^{*}$ \\
\hline ESC1 & 0,4493 & 1,84 & 0,2517 & 1,09 & $-0,0686$ & $-0,34$ \\
\hline $\mathrm{R}_{1}$ & $-0,1555$ & $-0,18$ & 0,2079 & 0,21 & $-1,0417$ & $-0,97$ \\
\hline $\mathrm{R}_{1} . \mathrm{LAL}$ & 0,0717 & 0,77 & 0,2040 & $2,22^{*}$ & 0,2638 & $2,78^{*}$ \\
\hline $\mathrm{R}_{1} \cdot \mathrm{LCC}$ & 0,0200 & 0,69 & $-0,0367$ & $-1,17$ & 0,0197 & 0,57 \\
\hline $\mathrm{R}_{1} \cdot \mathrm{LCA}$ & $-0,1488$ & $-1,40$ & 0,0319 & 0,30 & 0,0309 & 0,34 \\
\hline $\mathrm{R}_{1 .} \mathrm{LVI}$ & 0,1603 & $2,31^{*}$ & 0,1638 & 1,32 & $-0,0570$ & $-0,59$ \\
\hline $\mathrm{R}_{1} . \mathrm{LDA}$ & $-0,0499$ & $-1,12$ & $-0,0594$ & $-1,03$ & $-0,0454$ & $-0,72$ \\
\hline $\mathrm{R}_{1} . \mathrm{LDM}$ & 0,2260 & $3,76^{*}$ & 0,2305 & $4,01^{*}$ & 0,1902 & $3,36^{*}$ \\
\hline $\mathrm{R}_{1} \cdot \mathrm{LOD}$ & $-0,1485$ & $-1,35$ & $-0,2599$ & $-3,17^{*}$ & $-0,0004$ & $-0,01$ \\
\hline $\mathrm{R}_{1} . \mathrm{LEHF}$ & 0,0597 & 0,75 & $-0,0810$ & $-1,01$ & $-0,1040$ & $-1,30$ \\
\hline $\mathrm{R}_{1} \cdot \mathrm{LEHA}$ & $-0,2185$ & $-2,12^{*}$ & $-0,2282$ & $-2,04^{*}$ & $-0,3036$ & $-2,49^{*}$ \\
\hline $\mathrm{R}_{1} . \mathrm{LPRT}$ & 0,0471 & 1,05 & $-0,0122$ & $-0,25$ & 0,0785 & 1,52 \\
\hline $\mathrm{R}_{1} \cdot \mathrm{ESC} 1$ & $-0,8326$ & $-1,77$ & $-0,5292$ & $-1,10$ & $-0,6388$ & $-1,34$ \\
\hline $\mathrm{R}_{2}$ & 1,9848 & 1,43 & 0,8942 & 0,67 & 3,7364 & $2,11^{*}$ \\
\hline $\mathrm{R}_{2} \cdot \mathrm{LAL}$ & $-0,2816$ & $-1,88$ & $-0,0752$ & $-0,50$ & 0,0138 & 0,10 \\
\hline $\mathrm{R}_{2} \cdot \mathrm{LCC}$ & 0,0178 & 0,36 & $-0,0740$ & $-1,66$ & 0,0012 & 0,03 \\
\hline $\mathrm{R}_{2} \cdot \mathrm{LCA}$ & $-0,1549$ & $-1,36$ & $-0,0666$ & $-0,77$ & $-0,1427$ & $-1,52$ \\
\hline $\mathrm{R}_{2} \cdot \mathrm{LVI}$ & 0,4234 & $2,89^{*}$ & 0,2049 & 1,40 & 0,0794 & 0,46 \\
\hline $\mathrm{R}_{2}$.LDA & 0,0818 & 0,64 & 0,0071 & 0,06 & 0,2937 & $2,43^{*}$ \\
\hline $\mathrm{R}_{2} \cdot \mathrm{LDM}$ & $-0,0772$ & $-1,01$ & 0,0141 & 0,23 & 0,1005 & 1,22 \\
\hline $\mathrm{R}_{2} \cdot \mathrm{LOD}$ & 0,1095 & 0,56 & 0,0661 & 0,47 & $-0,2086$ & $-1,68$ \\
\hline $\mathrm{R}_{2} \cdot \mathrm{LEHF}$ & 0,0677 & 0,65 & 0,0401 & 0,40 & $-0,1260$ & $-1,20$ \\
\hline $\mathrm{R}_{2} . \mathrm{LEHA}$ & $-0,2237$ & $-1,27$ & $-0,0939$ & $-0,50$ & $-0,0883$ & $-0,50$ \\
\hline $\mathrm{R}_{2} . \mathrm{LPRT}$ & $-0,0882$ & $-1,06$ & $-0,0251$ & $-0,32$ & $-0,1615$ & $-1,58$ \\
\hline $\mathrm{R}_{2} . \mathrm{ESC} 1$ & $-1,3223$ & $-1,29$ & $-0,9157$ & $-0,83$ & $-0,2898$ & $-0,28$ \\
\hline
\end{tabular}


Tabela 3 (continuação).

\begin{tabular}{|c|c|c|c|c|c|c|}
\hline \multirow[b]{2}{*}{ Variável } & \multicolumn{2}{|c|}{1975} & \multicolumn{2}{|c|}{1980} & \multicolumn{2}{|c|}{1985} \\
\hline & coeficiente & teste $t$ & coeficiente & teste $t$ & coeficiente & teste $t$ \\
\hline $\mathrm{R}_{3}$ & 1,3535 & 1,08 & 2,4135 & $2,27^{*}$ & 0,8993 & 0,66 \\
\hline $\mathrm{R}_{3} \cdot \mathrm{LAL}$ & $-0,1365$ & $-1,34$ & 0,0435 & 0,41 & 0,0098 & 0,09 \\
\hline $\mathrm{R}_{3} \cdot \mathrm{LCC}$ & $-0,0038$ & $-0,11$ & $-0,0492$ & $-1,17$ & $-0,0516$ & $-1,12$ \\
\hline $\mathrm{R}_{3} \cdot \mathrm{LCA}$ & $-0,2027$ & $-2,33^{*}$ & $-0,0409$ & $-0,52$ & $-0,0236$ & $-0,27$ \\
\hline $\mathrm{R}_{3} . \mathrm{LVI}$ & 0,2988 & $2,26^{*}$ & 0,1994 & 1,28 & 0,2832 & 1,97 \\
\hline $\mathrm{R}_{3}$.LDA & 0,0051 & 0,07 & 0,0328 & 0,37 & 0,0133 & 0,13 \\
\hline $\mathrm{R}_{3} . \mathrm{LDM}$ & 0,0358 & 0,60 & 0,1589 & $3,05^{*}$ & 0,0690 & 1,35 \\
\hline $\mathrm{R}_{3}$.LOD & 0,0421 & 0,35 & $-0,1604$ & $-1,24$ & $-0,0928$ & $-0,75$ \\
\hline $\mathrm{R}_{3}$.LEHF & 0,1906 & $2,42^{*}$ & 0,0878 & 1,12 & 0,0669 & 0,82 \\
\hline $\mathrm{R}_{3}$.LEHA & $-0,1717$ & $-2,07^{*}$ & $-0,3259$ & $-3,46^{*}$ & $-0,3104$ & $-3,34^{*}$ \\
\hline $\mathrm{R}_{3}$.LPRT & $-0,1076$ & $-1,53$ & $-0,1466$ & $-2,38^{*}$ & $-0,0428$ & $-0,59$ \\
\hline $\mathrm{R}_{3} \cdot \mathrm{ESCl}$ & $-0,5046$ & $-0,96$ & 0,1481 & 0,23 & $-0,6080$ & $-1,03$ \\
\hline & $\mathrm{R}^{2}=0,9727$ & $\mathrm{~F}=191,06^{*}$ & $\mathrm{R}^{2}=0,9694$ & $\mathrm{~F}=169,90^{*}$ & $\mathrm{R}^{2}=0,9695$ & $\mathrm{~F}=170,24^{*}$ \\
\hline
\end{tabular}

(*) - significativo ao nível de $5 \%$ de significância. 
Tabela 4 - Equação ajustada para comparar as funções de produção das $300 \mathrm{MRH}$ entre 1975, 1980 e 1985, adotando-se o modelo da equação 6.

\begin{tabular}{|c|c|c|}
\hline Variável & Coeficiente & Teste $\mathrm{t}$ \\
\hline Intercepto & $-0,4144$ & $-1,15$ \\
\hline LAL & 0,1542 & $4,63 *$ \\
\hline LCC & 0,0062 & 0,52 \\
\hline LCA & 0,1348 & $4,47^{*}$ \\
\hline LVI & 0,0550 & 1,93 \\
\hline LDA & 0,0216 & 1,17 \\
\hline LDM & 0,0344 & 1,63 \\
\hline LOD & 0,3915 & $9,34^{*}$ \\
\hline LEHF & 0,1040 & $4,15^{*}$ \\
\hline LEHA & 0,1277 & $4,80^{*}$ \\
\hline LPRT & 0,1112 & $5,63^{*}$ \\
\hline ESCl & 0,5804 & $4,06^{*}$ \\
\hline$T_{1}$ & $-0,7656$ & $-1,48$ \\
\hline$T_{1}$ LAL & $-0,0278$ & $-0,62$ \\
\hline $\mathrm{T}_{1} \mathrm{LCC}$ & $-0,0037$ & $-0,22$ \\
\hline$T_{1} \cdot \mathrm{LCA}$ & 0,0017 & 0,04 \\
\hline $\mathrm{T}_{1} . \mathrm{LVI}$ & $-0,0498$ & $-1,08$ \\
\hline $\mathrm{T}_{1} \cdot \mathrm{LDA}$ & 0,0793 & $2,71^{*}$ \\
\hline $\mathrm{T}_{1} . \mathrm{LDM}$ & 0,0235 & 0,83 \\
\hline$T_{1} . L O D$ & $-0,1794$ & $-3,26^{*}$ \\
\hline $\mathrm{T}_{1}$.LEHF & 0,1120 & $3,30 *$ \\
\hline$T_{1} . \mathrm{LEHA}$ & 0,0255 & 0,67 \\
\hline $\mathrm{T}_{1} . \mathrm{LPRT}$ & 0,0746 & $2,67^{*}$ \\
\hline $\mathrm{T}_{1} . \mathrm{ESC} 1$ & 0,1581 & 0,79 \\
\hline $\mathrm{T}_{2}$ & 0,4353 & $-0,80$ \\
\hline $\mathrm{T}_{2} . \mathrm{LAL}$ & 0,0387 & 0,83 \\
\hline $\mathrm{T}_{2} \cdot \mathrm{LCC}$ & 0,0373 & $2,21^{*}$ \\
\hline $\mathrm{T}_{2} \mathrm{LCA}$ & $-0,1200$ & $-2,87^{*}$ \\
\hline $\mathrm{T}_{2} . \mathrm{LVI}$ & $-0,0180$ & $-0,41$ \\
\hline $\mathrm{T}_{2} . \mathrm{LDA}$ & 0,0691 & $2,21^{*}$ \\
\hline $\mathrm{T}_{2} . \mathrm{LDM}$ & 0,1008 & $3,39 *$ \\
\hline $\mathrm{T}_{2} . \mathrm{LOD}$ & $-0,1910$ & $-3,46^{*}$ \\
\hline $\mathrm{T}_{2} . \mathrm{LEHF}$ & 0,0584 & 1,70 \\
\hline $\mathrm{T}_{2}$.LEHA & 0,0064 & 0,17 \\
\hline $\mathrm{T}_{2} . \mathrm{LPRT}$ & 0,0757 & $2,60^{*}$ \\
\hline \multirow[t]{2}{*}{$\mathrm{T}_{2} \cdot \mathrm{ESC} 1$} & $-0,3893$ & $-1,98^{*}$ \\
\hline & & \\
\hline
\end{tabular}

(*) - significativo ao nível de 5\% de significância. 
Tabela 5 - Equações ajustadas para comparar as funções de produção do Nordeste e do Sudeste (exclusive SP) entre 1975, 1980 e 1985, adotando-se a equação 6.

\begin{tabular}{|c|c|c|c|c|}
\hline \multirow[b]{2}{*}{ Variável } & \multicolumn{2}{|c|}{ Nordeste } & \multicolumn{2}{|c|}{ Sudeste excl. SP } \\
\hline & Coeficiente & Teste $t$ & Coeficiente & Teste $t$ \\
\hline Intercepto & $-0,2118$ & $-0,36$ & $-0,3673$ & $-0,62$ \\
\hline LAL & 0,1566 & $2,28 *$ & 0,2283 & $3,79 *$ \\
\hline LCC & 0,0143 & 0,73 & 0,0343 & 1,75 \\
\hline LCA & 0,2635 & $3,77^{*}$ & 0,1146 & 1,58 \\
\hline LVI & $-0,0692$ & $-1,54$ & 0,0911 & 1,89 \\
\hline LDA & 0,0420 & 1,57 & $-0,0079$ & $-0,25$ \\
\hline LDM & 0,0158 & 0,45 & 0,2418 & $5,60 *$ \\
\hline LOD & 0,3509 & $5,83 *$ & 0,2024 & $2,51^{*}$ \\
\hline LEHF & $-0,0313$ & $-0,59$ & 0,0283 & 0,52 \\
\hline LEHA & 0,2845 & $5,91^{*}$ & 0,0659 & 0,85 \\
\hline LPRT & 0,1064 & $3,72^{*}$ & 0,1536 & $4,93^{*}$ \\
\hline ESC1 & 0,4493 & 1,52 & $-0,3833$ & $-1,16$ \\
\hline$T_{1}$ & $-1,0327$ & $-1,15$ & $-0,6693$ & $-0,75$ \\
\hline $\mathrm{T}_{1} . \mathrm{LAL}$ & $-0,1180$ & $-1,29$ & 0,0144 & 0,17 \\
\hline $\mathrm{T}_{1} . \mathrm{LCC}$ & 0,0208 & 0,79 & $-0,0359$ & $-1,21$ \\
\hline $\mathrm{T}_{1} . \mathrm{LCA}$ & $-0,1001$ & $-1,08$ & 0,0807 & 0,78 \\
\hline $\mathrm{T}_{1} . \mathrm{LVI}$ & $-0,0233$ & $-0,35$ & $-0,0198$ & $-0,19$ \\
\hline $\mathrm{T}_{1} . \mathrm{LDA}$ & 0,0284 & 0,67 & 0,0189 & 0,37 \\
\hline $\mathrm{T}_{1} . \mathrm{LDM}$ & $-0,0066$ & $-0,14$ & $-0,0021$ & $-0,03$ \\
\hline$T_{1}$. LOD & $-0,0690$ & $-0,83$ & $-0,1804$ & $-1,87$ \\
\hline$T_{1}$. LEHF & 0,1531 & $2,23^{*}$ & 0,0124 & 0,16 \\
\hline $\mathrm{T}_{1}$.LEHA & 0,1252 & 1,80 & 0,1155 & 1,02 \\
\hline $\mathrm{T}_{1}$.LPRT & 0,0971 & $2,27^{*}$ & 0,0377 & 0,84 \\
\hline $\mathrm{T}_{1} \cdot \mathrm{ESC} 1$ & $-0,1975$ & $-0,49$ & 0,1059 & 0,22 \\
\hline $\mathrm{T}_{2}$ & 0,5426 & 0,59 & 0,4149 & 0,51 \\
\hline $\mathrm{T}_{2} . \mathrm{LAL}$ & $-0,1014$ & $-1,13$ & 0,0907 & 1,05 \\
\hline $\mathrm{T}_{2} . \mathrm{LCC}$ & 0,0400 & 1,57 & 0,0397 & 1,27 \\
\hline $\mathrm{T}_{2} . \mathrm{LCA}$ & $-0,2140$ & $-2,48^{*}$ & $-0,0343$ & $-0,36$ \\
\hline $\mathrm{T}_{2 .} \mathrm{LVI}$ & 0,0538 & 0,84 & $-0,1634$ & $-1,98^{*}$ \\
\hline $\mathrm{T}_{2} . \mathrm{LDA}$ & 0,0242 & 0,53 & 0,0286 & 0,55 \\
\hline $\mathrm{T}_{2} . \mathrm{LDM}$ & 0,0822 & 1,69 & 0,0464 & 0,82 \\
\hline $\mathrm{T}_{2} . \mathrm{LOD}$ & $-0,1250$ & $-1,51$ & 0,0239 & 0,24 \\
\hline $\mathrm{T}_{2} . \mathrm{LEHF}$ & 0,1600 & $2,35^{*}$ & $-0,0037$ & $-0,05$ \\
\hline $\mathrm{T}_{2}$.LEHA & 0,0831 & 1,22 & $-0,0020$ & $-0,02$ \\
\hline $\mathrm{T}_{2} . \mathrm{LPRT}$ & 0,0819 & 1,90 & 0,1133 & $2,48^{*}$ \\
\hline \multirow[t]{2}{*}{$\mathrm{T}_{2} . \mathrm{ESC} 1$} & $-0,5179$ & $-1,38$ & $-0,3240$ & $-0,69$ \\
\hline & $\mathrm{R}^{2}=0,9344$ & $\mathrm{~F}=138,01^{*}$ & $\mathrm{R}^{2}=0,9698$ & $\mathrm{~F}=154,04^{*}$ \\
\hline
\end{tabular}

(*) - significativo ao nível de $5 \%$ de significância. 
Tabela 6 - Equações ajustadas para comparar as funções de produção de São Paulo e do Sul entre 1975, 1980 e 1985, adotando-se a equação 6.

\begin{tabular}{|c|c|c|c|c|}
\hline \multirow[b]{2}{*}{ Variável } & \multicolumn{2}{|c|}{ São Paulo } & \multicolumn{2}{|c|}{ Sul } \\
\hline & Coeficiente & Teste $t$ & Coeficiente & Teste $\mathrm{t}$ \\
\hline Intercepto & 1,7730 & 1,75 & 1,1417 & 1,06 \\
\hline LAL & $-0,1251$ & $-1,15$ & 0,0200 & 0,25 \\
\hline LCC & 0,0321 & 0,87 & 0,0104 & 0,36 \\
\hline LCA & 0,1086 & 1,41 & 0,0608 & 1,00 \\
\hline LVI & 0,3542 & $3,20^{*}$ & 0,2296 & 1,93 \\
\hline LDA & 0,1238 & 1,25 & 0,0471 & 0,73 \\
\hline LDM & $-0,0613$ & $-1,23$ & 0,0516 & 1,06 \\
\hline LOD & 0,4603 & $3,13^{*}$ & 0,3930 & $3,84^{*}$ \\
\hline LEHF & 0,0364 & 0,49 & 0,1593 & $2,59^{*}$ \\
\hline LEHA & 0,0608 & 0,45 & 0,1128 & 1,66 \\
\hline LPRT & 0,0183 & 0,29 & $-0,0012$ & $-0,02$ \\
\hline ESC1 & $-0,8730$ & $-1,12$ & $-0,0553$ & $-0,13$ \\
\hline$T_{1}$ & $-2,1233$ & $-1,55$ & 0,0273 & 0,02 \\
\hline$T_{1} . \mathrm{LAL}$ & 0,0885 & 0,58 & 0,0621 & 0,54 \\
\hline$T_{1} \cdot L C C$ & $-0,0709$ & $-1,45$ & $-0,0244$ & $-0,53$ \\
\hline $\mathrm{T}_{1}$ LCA & $-0,0118$ & $-0,13$ & 0,0618 & 0,76 \\
\hline $\mathrm{T}_{1} . \mathrm{LVI}$ & $-0,2419$ & $-1,57$ & $-0,1227$ & $-0,67$ \\
\hline $\mathrm{T}_{1}$.LDA & $-0,0605$ & $-0,45$ & 0,0561 & 0,55 \\
\hline $\mathrm{T}_{1} . \mathrm{LDM}$ & 0,0847 & 1,31 & 0,1165 & 1,84 \\
\hline $\mathrm{T}_{1} . \mathrm{LOD}$ & $-0,1124$ & $-0,63$ & $-0,2715$ & $-1,81$ \\
\hline $\mathrm{T}_{1} . \mathrm{LEHF}$ & 0,1254 & 1,21 & 0,0502 & 0,57 \\
\hline $\mathrm{T}_{1}$.LEHA & 0,2550 & 1,32 & $-0,0290$ & $-0,28$ \\
\hline $\mathrm{T}_{1} . \mathrm{LPRT}$ & 0,1601 & 1,91 & 0,0581 & 0,72 \\
\hline $\mathrm{T}_{1} . \mathrm{ESC} 1$ & 0,2090 & 0,18 & 0,4552 & 0,65 \\
\hline $\mathrm{T}_{2}$ & 1,3951 & 1,02 & 0,0089 & 0,01 \\
\hline $\mathrm{T}_{2} \cdot \mathrm{LAL}$ & 0,1940 & 1,39 & 0,0449 & 0,39 \\
\hline $\mathrm{T}_{2} \mathrm{LCC}$ & 0,0209 & 0,44 & $-0,0078$ & $-0,16$ \\
\hline $\mathrm{T}_{2} \cdot \mathrm{LCA}$ & $-0,2018$ & $-2,06^{*}$ & $-0,0349$ & $-0,38$ \\
\hline $\mathrm{T}_{2} . \mathrm{LVI}$ & $-0,2902$ & $-1,75$ & 0,0383 & 0,22 \\
\hline $\mathrm{T}_{2} \cdot \mathrm{LDA}$ & 0,2360 & 1,80 & 0,0324 & 0,31 \\
\hline $\mathrm{T}_{2} . \mathrm{LDM}$ & 0,2599 & $3,47^{*}$ & 0,1155 & 1,90 \\
\hline $\mathrm{T}_{2} . \mathrm{LOD}$ & $-0,4431$ & $-2,62^{*}$ & $-0,2598$ & $-1,82$ \\
\hline $\mathrm{T}_{2} . \mathrm{LEHF}$ & $-0,0337$ & $-0,32$ & 0,0362 & 0,41 \\
\hline $\mathrm{T}_{2}$.LEHA & 0,2184 & 1,19 & $-0,0556$ & $-0,56$ \\
\hline $\mathrm{T}_{2}$.LPRT & 0,0086 & 0,09 & 0,1468 & 1,72 \\
\hline \multirow[t]{2}{*}{$\mathrm{T}_{2}$. ESCl } & 0,5146 & 0,47 & $-0,6213$ & $-0,95$ \\
\hline & $\mathbf{R}^{2}=0,9785$ & $\mathrm{~F}=121,00^{*}$ & $\mathrm{R}^{2}=0,9757$ & $\mathrm{~F}=179,14^{*}$ \\
\hline
\end{tabular}

$\left({ }^{*}\right)$ - significativo ao nível de $5 \%$ de significância. 
Tabela 7 - Preço por hectare de terra para lavouras e salário médio anual do trabalhador eventual, considerando 300 dias de trabalho no ano, para o Brasil e quatro regiões, em 1975, 1980 e 1985.

\begin{tabular}{l|l|l|l}
\hline Brasil e Regiões & 1975 & 1980 & 1985 \\
\hline
\end{tabular}

Preço da Terra de Lavouras (Cr $\$ / \mathrm{ha})^{*}$

$\begin{array}{lrrr}\text { Brasil } & 5.127 .628,83 & 5.397 .502,43 & 6.445 .648,00 \\ \text { Nordeste } & 1.338 .581,07 & 1.724 .227,77 & 1.793 .012,50 \\ \text { Sudeste (excl. SP) } & 4.462 .722,26 & 5.040 .295,25 & 6.669 .461,33 \\ \text { São Paulo } & 11.283 .130,73 & 11.512 .996,37 & 10.197 .536,00 \\ \text { Sul } & 6.752 .981,90 & 7.219 .154,87 & 10.007 .395,50\end{array}$

Salário do Trabalhador Eventual (Cr\$/ano)*

\begin{tabular}{llll} 
Brasil & $5.425 .195,57$ & $5.704 .925,44$ & $5.019 .150,00$ \\
Nordeste & $4.336 .777,37$ & $4.805 .868,06$ & $4.177 .200,00$ \\
Sudeste (excl. SP) & $5.275 .943,12$ & $5.792 .106,29$ & $5.074 .950,00$ \\
São Paulo & $6.688 .211,85$ & $6.767 .446,86$ & $6.073 .500,00$ \\
Sul & $7.028 .958,64$ & $7.078 .030,17$ & $6.288 .000,00$ \\
\hline
\end{tabular}

Fonte: Fundação Getúlio Vargas, IBRE (1985).

(*) - Valores em cruzeiros de 1985. 